\title{
Two-Phase Boost Converter
}

\author{
A Master Thesis \\ Presented to \\ The Faculty of California Polytechnic State University \\ San Luis Obispo
}

\author{
In Partial Fulfillment \\ Of the Requirements for the Degree \\ Master of Science in Electrical Engineering \\ By
}

Tadeus Gunawan

December 2009 
(C) 2009

Tadeus Gunawan

ALL RIGHTS RESERVED 


\section{COMMITTEE MEMBERSHIP}

TITLE:

AUTHOR:

DATE SUBMITTED:

COMMITTEE CHAIR:

COMMITTEE MEMBER:

COMMITTEE MEMBER:
Two-Phase Boost Converter

Tadeus Gunawan

December 2009

Taufik, Professor

Bill L. Ahlgren, Associate Professor

Dale Dolan, Assistant Professor 


\title{
ABSTRACT \\ Two-Phase Converter \\ Tadeus Gunawan
}

\begin{abstract}
A boost converter is one of the most efficient techniques to step up DC input voltage to a higher needed DC output voltage. The boost converter has many possible applications, such as in a photovoltaic system, hybrid car and battery charger. The proposed prototype in this report is a proof of concept that a Two-Phase Boost Converter is a possible improvement topology to offer higher efficiency without compromising any advantages readily offered by a basic boost. The prototype is designed to be able to handle up to 200 watts of output power with an input of 36 volts and an output of 48 volts. This paper goes through step-by-step the calculation, design, build and test of a Two-Phase Boost Converter. Calculations found in this paper were done on Mathcad and the simulations were done on LTSpice and Pspice. These include converter's efficiency and other measures of converter's performance. Advantages, disadvantages as well as possible improvements of the proposed topology will be presented. Data collected and analyzed from the prototype were done on a bench test, not through an actual application.
\end{abstract}

Keywords: Two phase boost converter. 


\section{ACKNOWLEDGEMENT}

It is a pleasure for me to thank those who made this thesis possible. First I would like to give my thanks to Dr. Taufik for all his help and guidance throughout my college career especially during this thesis project. It has been a fun and challenging journey and thank you for being my advisor and teacher. I also want to extend my thanks to my friends and/or fellow students. Arief Hernadi, Kyaw Kyaw Htin, and Jonathan Paolucci thank you for all the help and support during my design processes and late night consultations. Also, I thank Rithy Chhean and Mike McCarty for helping me with the troubleshooting and data gathering. Lastly, I want to thank my family for all their support that helped me through college. I do not know where I would be without them. 


\section{TABLE OF CONTENTS}

Page

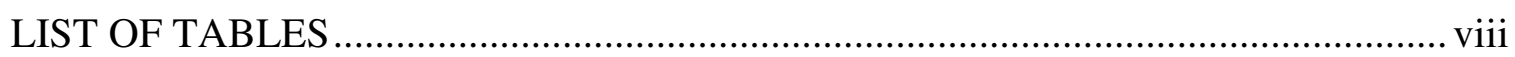

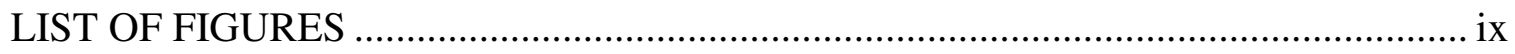

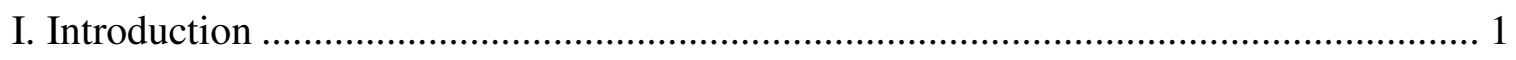

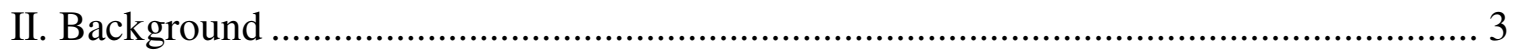

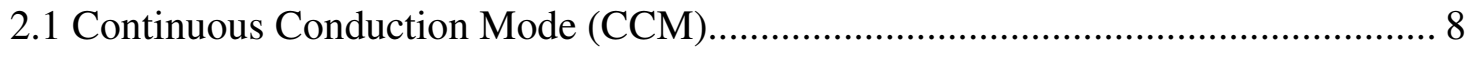

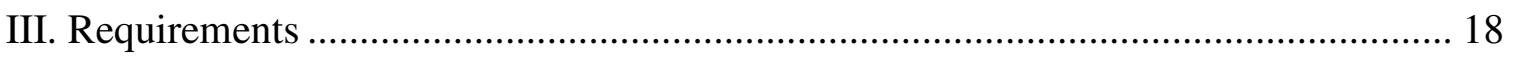

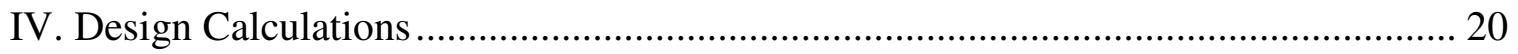

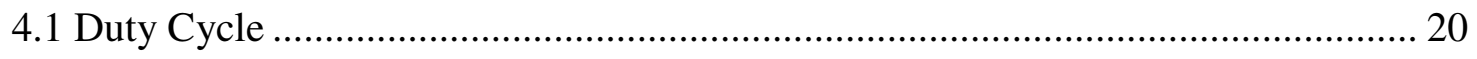

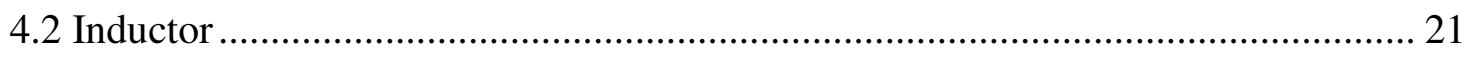

4.3 Input Capacitor

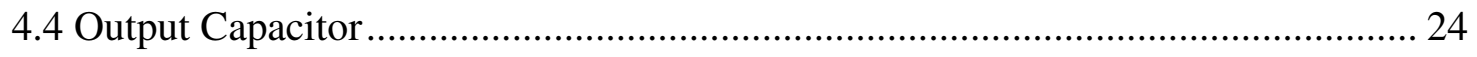

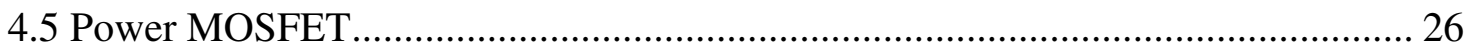

4.6 Voltage and Current Sense Resistors .............................................................. 29

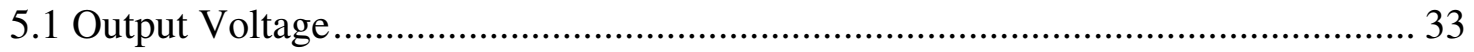

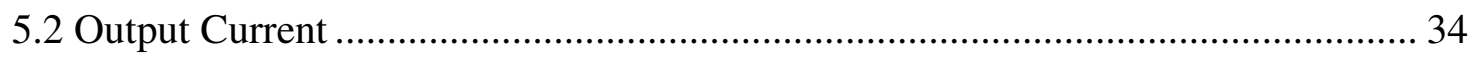

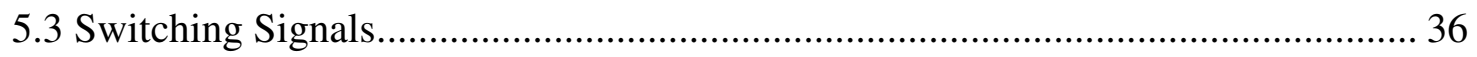

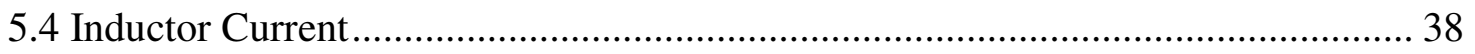

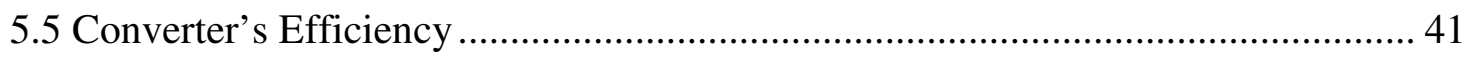

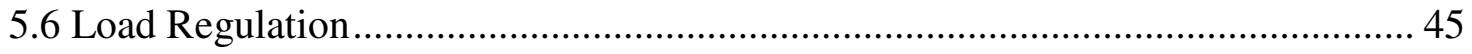

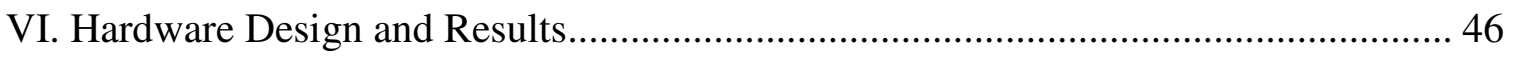

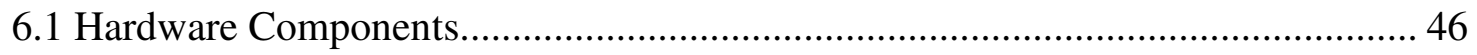


6.1.1 Pulse Width Modulator ........................................................................... 48

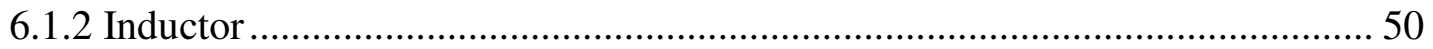

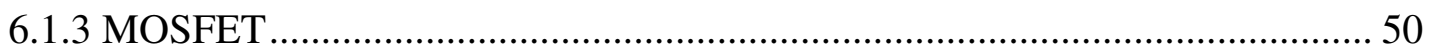

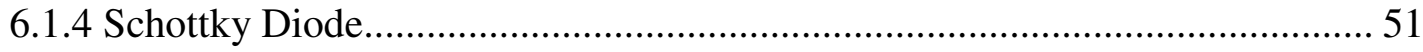

6.1.5 Input and Output Capacitors .............................................................. 51

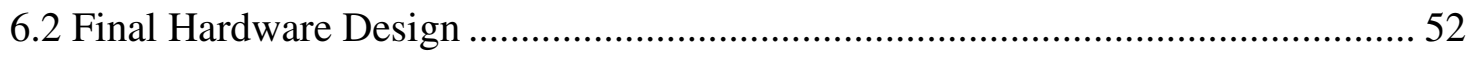

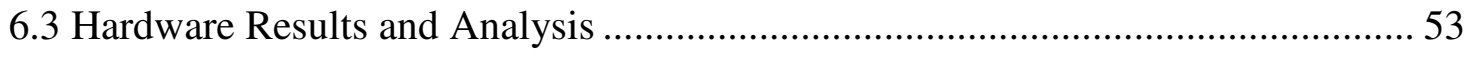

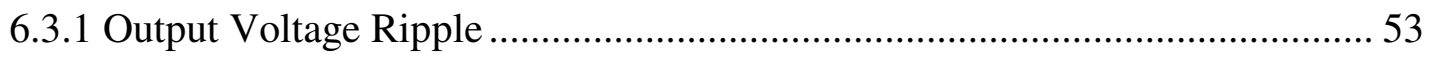

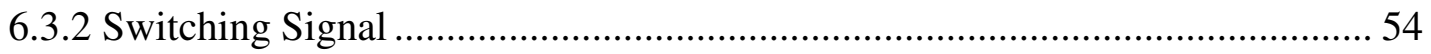

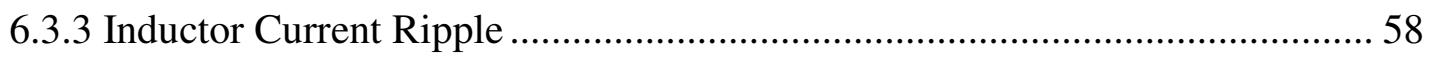

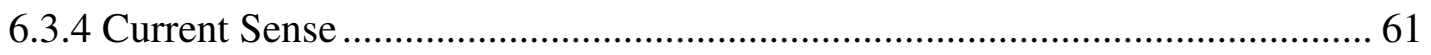

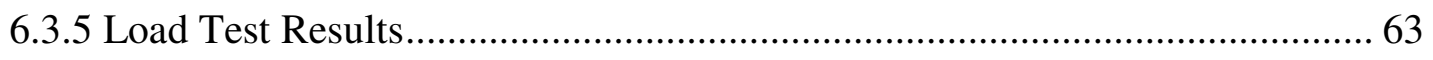

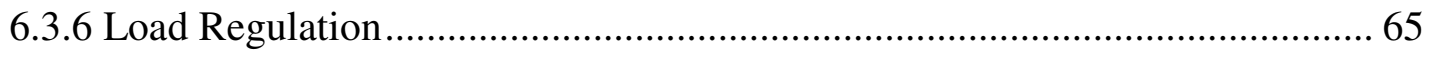

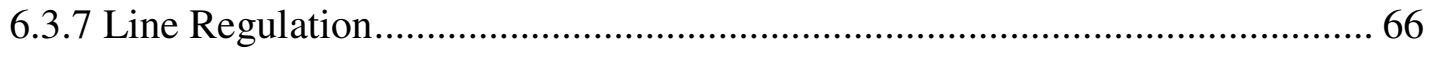

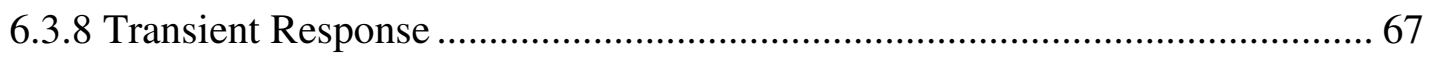

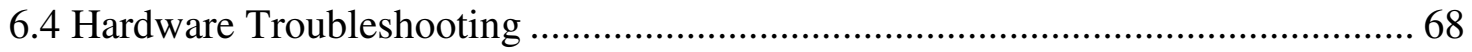

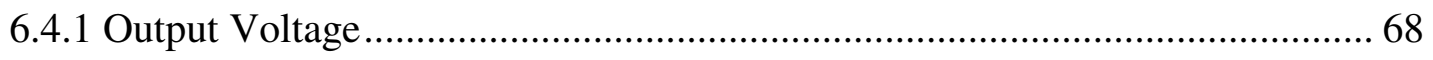

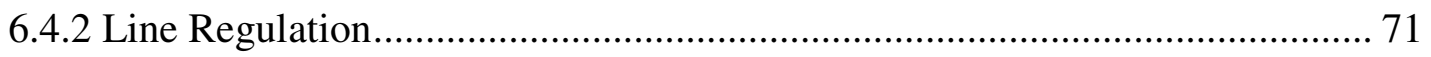

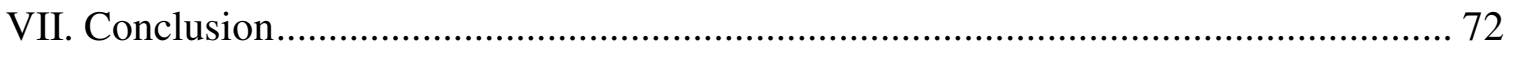

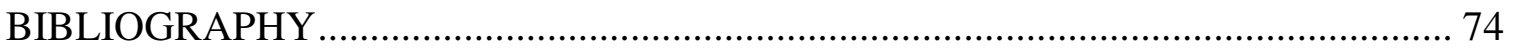




\section{LIST OF TABLES}

Table Page

3-1. Design requirements for Proposed Two-Phase Boost ........................19

5-1. Simulated Efficiency from 10\% - 100\% Load.........................44

5-2. Simulated Load Regulation..........................................45

5-3. Simulated Line Regulation.......................................45

6-1. Hardware Efficiency from 10\% - 100\% Load...............................64

6-2. Hardware Load Regulation...........................................66

6-3. Hardware Line Regulation........................................66 


\section{LIST OF FIGURES}

Figure $\quad$ Page

2-1. Boost Convert.....................................................

2-2. Two-Phase Boost Converter..........................................

2-3. Switching Signals of Two-Phase Boost...............................

2-4. Ideal Boost Converter with Conducting Switch.............................8

2-5. $\quad \mathrm{I}_{\mathrm{L}}$ vs. Time and $\mathrm{V}_{\mathrm{L}}$ vs. Time in CCM with Conducting Switch................10

2-6. Ideal Boost Converter with Open Switch.................................11

2-7. $\mathrm{I}_{\mathrm{L}}$ vs. Time and $\mathrm{V}_{\mathrm{L}}$ vs. Time in CCM with Open Switch in Each Phase...........12

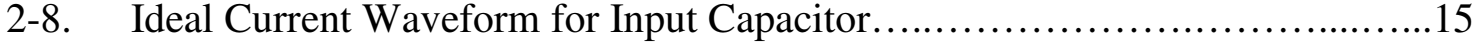

2-9. Ideal Current Waveform for Output Capacitor............................ 15

2-10. Frequency Multiplication in Two-Phase Boost ........................... 16

4-1. $\quad$ RMS Ripple Input Current Rating.......................................23

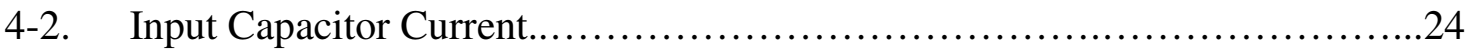

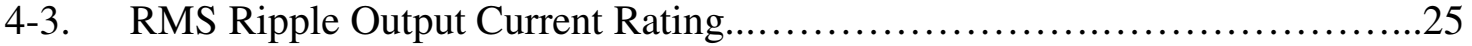

4-4. Output Capacitor Current.............................................26

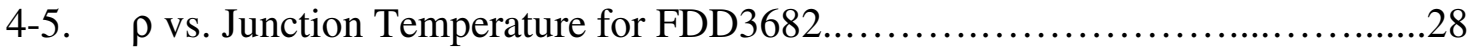

4-6. Voltage Divider................................................... 30

5-1. Two-Phase Boost Schematic Using LTSpice............................32

5-2. Output Voltage Ripple...........................................33

5-3. Overlaid unfiltered Output Current of Phase 1 and Phase 2....................34

5-4. $\quad$ Filtered Output Current Ripple........................................ 35

5-5 Phase 1 Switching Signals........................................... 36 


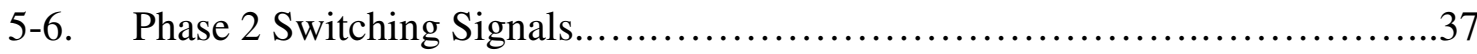

5-7. Superimposed Duty Cycles..............................................

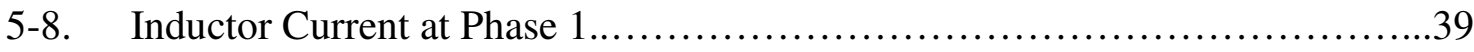

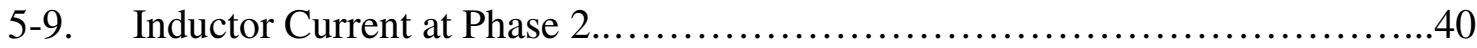

5-10. Overlay of Phase 1 and Phase 2 Inductor Current..........................40

5-11. Low Load Inductor Currents.......................................... 41

5-12. Input Power Ripple..............................................42

5-13. Output Power Ripple..............................................43

5-14. Efficiency vs. Load from Simulation....................................44

6-1. Top Layer of the Final PCB Design.................................. 47

6-2. Bottom Layer of the Final PCB Design.....................................47

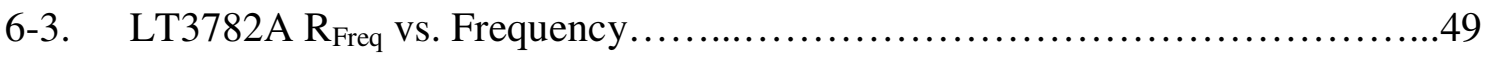

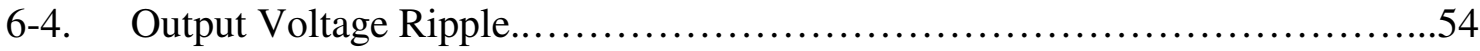

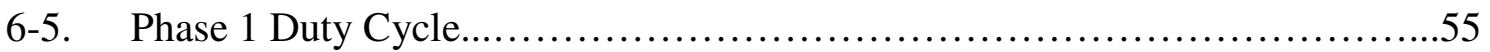

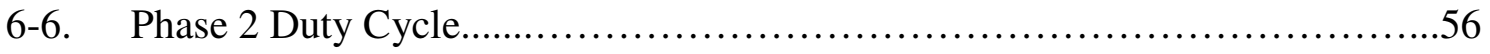

6-7. Overlaid Duty Cycle.......................................................

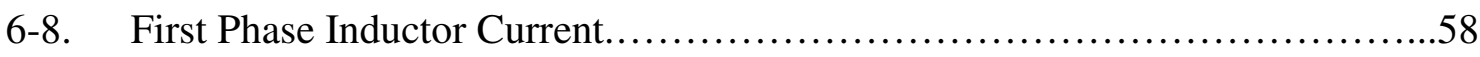

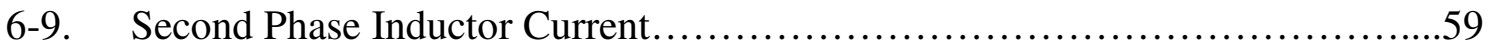

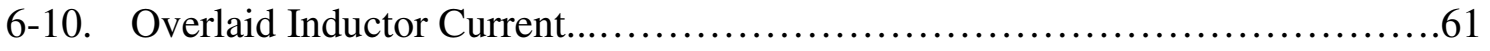

6-11. Phase 1 Current Sense Waveform.......................................

6-12. Phase 2 Current Sense Waveform....................................62

6-13. Load vs. Efficiency for Hardware Test................................65

6-14. Output Voltage Overshoot from Full Load to Low Load.....................67 
6-15. Output Voltage Overshoot from Low Load to Full Load ......................68

6-16. Phase 1 Inductor Current during Low Load............................... 70

6-17. Phase 2 Inductor Current during Low Load..............................70 


\section{Introduction}

DC - DC converters are widely used in today's industrial or commercial electronic devices to manipulate a dc voltage source. As the name implies, DC - DC converters work exclusively to take a dc voltage input and convert it to output a different level of dc voltage. They can either step-up or step-down the input dc voltage while maintaining minimal power loss during the process. There are many different topologies available for use such as Buck (step down), Boost (Step up), Flyback, Push-Pull, etc. This versatility is the reason that $\mathrm{DC}-\mathrm{DC}$ converters are popular among many current electronic devices.

Many portable devices and even industrial grade machines today depend on a reliable and efficient DC - DC converters. Examples such as hybrid or electric cars, mp3 players, cell phones, laptops, photovoltaic systems to name a few contain sub-systems that require different and constant level of voltage to operate properly. From power electronics' point of view the main issue revolves around the batteries. The charge in the batteries will start to decline as time passes, therefore to provide constant and different level of voltages it will have to use multiple batteries for a single device. However, with DC - DC converters we are able to provide a more efficient solution than extra batteries because of the following two reasons. First, DC - DC converters are designed to have a certain load and line regulations which provides "cushion" in the case of unstable or changing input level and/or load. Secondly, these converters are able to split a single constant source to several different voltage levels by using a multi-winding transformer. Other benefits of using DC - DC converters include the ability to operate the system in 
high switching frequency operation. This would further result in a relatively small system crucial especially in portable and vehicle applications. 


\section{Background}

There are two categories of DC - DC converters: Isolated and Non-Isolated DC DC converters. Isolated DC - DC converters, as the name implies, electrically isolate the output from the input using a high frequency transformer. The transformer's turns ratio dictates the relationship between the input and output voltage. By having multiple secondary windings, isolated converters are able to provide multiple levels of output voltages. The size of the transformer usually dictates the size of isolated converter; hence they generally are large in size. On the other hand the Non-Isolated topologies can vary the dc output voltage and provide different level of output voltages without the use of transformer and require fewer components to implement.

Boost converter is also known as the step-up converter. It is one of the well known topology in the field of power electronics and like any other DC - DC converters it aims to achieve high efficiency conversion. The existence of boost converter relies on the discovery of semiconductor switches. These switches are much faster and reliable than other switches such as vacuum tubes and electromechanical relays. The semiconductor switches are able to operate at high frequency, from about $200 \mathrm{kHz}$ to as high as $2 \mathrm{MHz}$. The frequency of Boost converters has an inverse relationship with the size of the magnetic components; therefore having a high switching frequency is beneficial to decrease the size of the converter. 


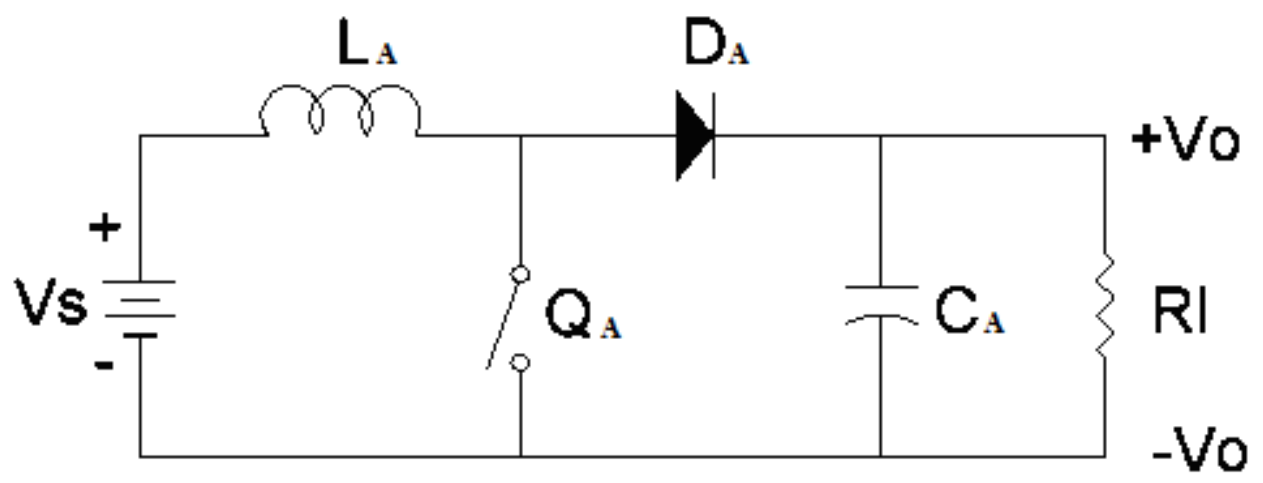

Figure 2-1: Boost Converter

The proposed Two-Phase Boost Converter is a way to create a more efficient step up converter while at the same time decreasing the strain seen on a basic boost converter. Just like the other topologies of DC - DC converters Two-Phase Boost Converter utilizes semiconductor switches as the foundation of its operation. Semiconductor switches have fast turn on and off times and low on resistances which help to decrease losses during switching and conduction. Two-Phase Boost converter is basically two boost converters placed in parallel, sharing the same input and output as shown in Figure 2-2. In essence it does the same thing as a Boost converter, which is stepping up the fixed dc voltage input. However, unlike paralleled boosts the two phases in the proposed two-phase boost will never draw input current at the same time, rather the path alternates between the first and second phase. Thus each path only carries half of the output power and hence half the strain compared to a single Boost converter with the same output power requirements. This further implies that the switching powered has to be equally split into he two phases. Consequently, the maximum duty cycle in each phase is limited to 50\%. Figure 2-4 shows the comparison of switching signal for a single boost vs. two-phase boost 
converter. Detailed analysis of the two-phase converter will be presented in the next chapter.

Just like the basic boost converter, there are three types of conduction modes for the Two-Phase Boost Converter: Continuous Conduction Mode (CCM), Discontinuous Conduction Mode (DCM) and Boundary Conduction Mode. During Continuous Conduction Mode the inductor current remains positive during switching while in Discontinuous Conduction Mode the inductor current is clipped at zero for a time during the switching. Lastly Boundary Conduction Mode happens when the lowest swing of the inductor current just barely reaches zero. In other words Boundary Conduction Mode happens when the inductor current is between CCM and DCM. In this thesis only continuous conduction mode will be considered in the design, calculation and hardware development of the proposed two-phase boost converter. A more detailed design equations and formula derivations would be covered in section 2.1.

Both Boost and Two-Phase Boost configuration share the same main components. As depicted in Figures 1 and 2, they both employ inductor, switch and diode. The inductor is being utilized as the main storage element that relies on its non instantaneous and linear current change following its Volt-Second Balance. The switch on the other hand depends on the converter's duty cycle. For efficiency purpose and in general, if the switch is conducting more than its idling time, a MOSFET with low $\mathrm{Rds}_{\text {on }}$ is preferred; otherwise a MOSFET with low gate capacitance to minimize switching loss is the preferred choice. As for the diode when quick turns off responses are needed as in DC DC converters, Schottky diode is commonly used. To increase the converter's efficiency further, a technique called synchronous rectification can be applied to the converter. With 
this technique, the diode is replaced with another switch. Depending on the duty cycle, this process would replace the diode with either low $\mathrm{Rds}_{\text {on }}$ or low switching loss MOSFET for a more efficient process. Nowadays the synchronous rectification technique is prevalent in the market to create more efficient and long lasting products $[1,8,10]$. Quite the contrary, the multiphase topologies including the proposed two-phase converter have only been recently studied. Most of the multiphase topologies have been centered on applications that require a very low step down with output voltage at relatively high current such as those found in microprocessors $[5,2,3,6]$. However, the potential of using multiphase topology in other topologies has not been extensively explored. One application that has recently gained an increased interest is the renewable energy. Many of the renewable energy sources provide dc output which needs to be stepped up in order to match the voltage level to that of the grid. Naturally, this is where boost converter plays an important role. Hence, this thesis is aimed to study the benefits of implementing a two-phase boost converter that may be used in conjunction with any renewable energy sources that require a step up function. The design and simulation of the proposed converter will be preformed as explained in later chapters, Moreover, to exhibit the potential of the proposed converter, a hardware prototype is built and tested. 


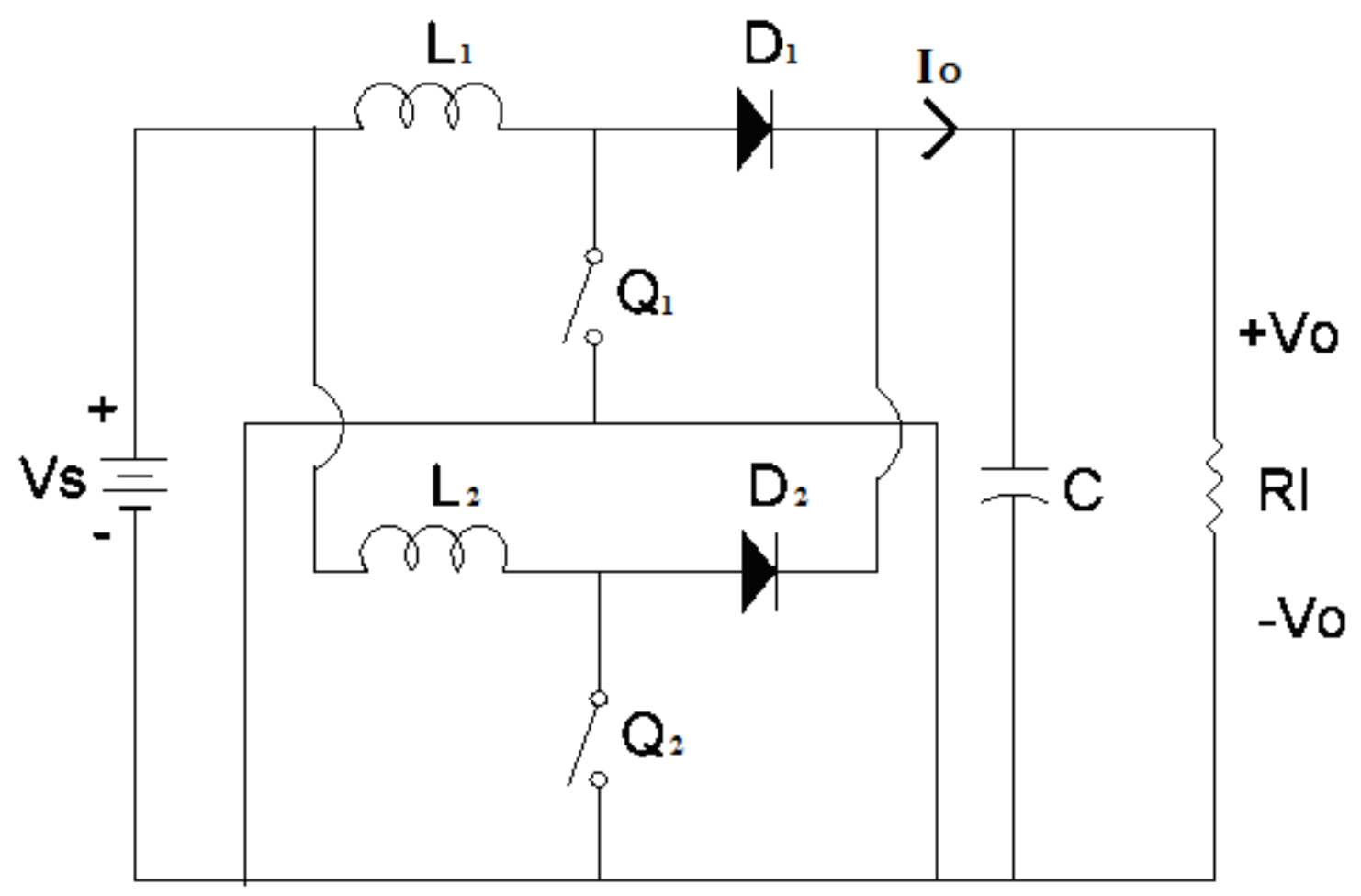

Figure 2-2: Two-Phase Boost Converter

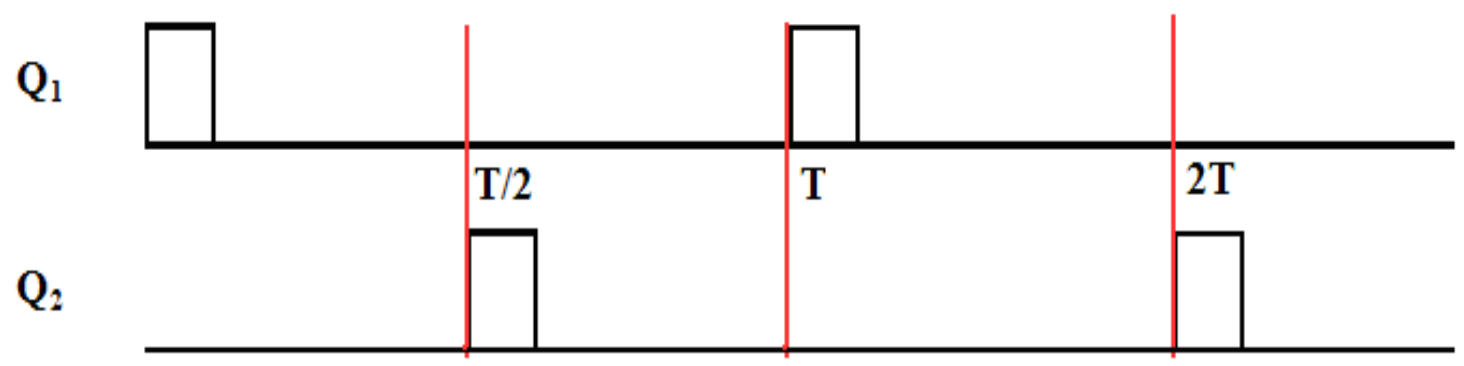

Figure 2-3: Switching Signals of Two-Phase Boost 


\section{$\underline{\text { 2.1 Continuous Conduction Mode (CCM) }}$}

Just like the basic boost converter, the two phase counterpart may operate in a Continuous Conduction Mode (CCM) or Discontinuous Conduction Mode (DCM). Taking into account that the two main switches in the two phases in this design would never turn on simultaneously, it is possible to analyze most of the CCM properties by only considering a single phase i.e. the basic boost. The analysis could be separated into two sections: analysis for closed switch and analysis for open switch.

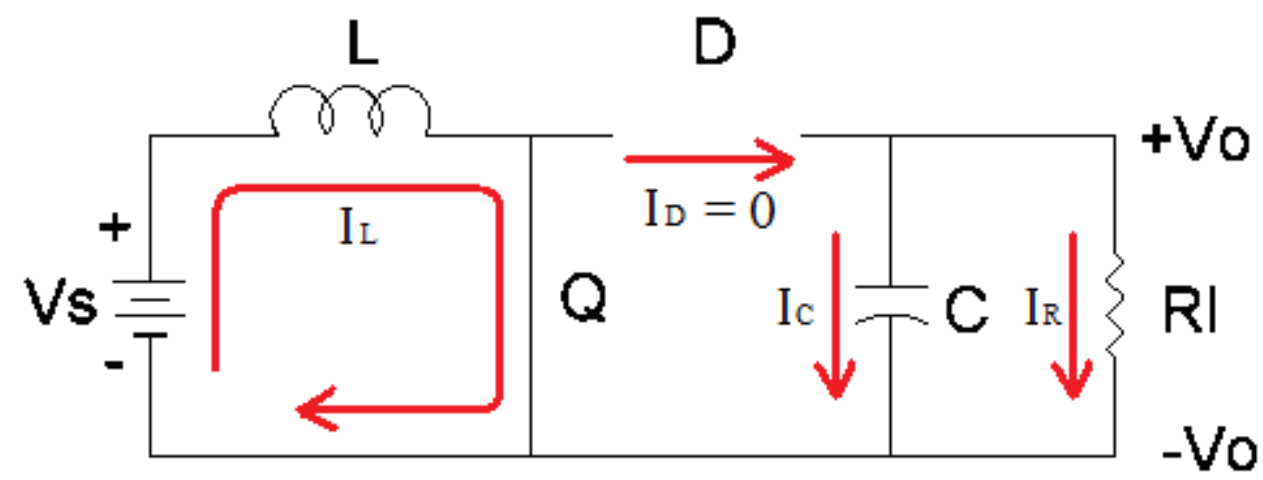

Figure 2-4: Ideal Boost Converter with Conducting Switch

When the switch or MOSFET conducts the diode will be reverse biased creating the scenario depicted by Figure 2-4. Assuming an ideal converter, the switch loss is negligible and no current is flowing through the diode, creating a singular path for the input current to flow, through the inductor and back to the negative end as represented in Figure $2-4$ by the $I_{L}$ current loop. The voltage across the inductor would then be equal to the voltage source, producing the expression below.

$$
\begin{aligned}
& \mathrm{V}_{\mathrm{S}}=\mathrm{V}_{\mathrm{L}-\mathrm{ON}} \\
& V_{S}=L \frac{d i_{L}}{d t}
\end{aligned}
$$




$$
\frac{V_{S}}{L}=\frac{d i_{L}}{d t}
$$

Ignoring heat and natural fluctuations, the value of $\mathrm{V}_{\mathrm{S}}$ and $\mathrm{L}$ can be assumed to remain constant. $\mathrm{V}_{\mathrm{S}}$ is a positive $\mathrm{DC}$ input and the inductance, $\mathrm{L}$, would also be a positive value. By using these assumptions, when the switch is closed the inductor current's rate of change or the slope of the current curve must therefore be linear and positive in value. By having a positive rate of change it can be hypothesized that the change in the inductor voltage would also be positive when the switch is conducting. Deriving the equation further, the change in the inductor current can be more accurately expressed by,

$$
\frac{V_{S}}{L}=\frac{d i_{L}}{d t}=\frac{\Delta i_{L}}{\Delta t}
$$

Where $\Delta t-o n=D^{*} T$,

$$
\begin{aligned}
& \frac{V_{S}}{L}=\frac{\Delta i_{L}}{D T} \\
& \Delta i_{L-O N}=\frac{V_{S}}{L} D T
\end{aligned}
$$

$\mathrm{D}$ here represents the percentage of the operating frequency when the switch is conducting or known as the duty cycle of the converter. The value of a duty cycle is always bound between 0 and 1 or $0 \%$ to $100 \%$. The higher the duty cycle, the more time the inductor has to store energy in the coils. $\mathrm{T}$ is the switching period, or the inverse of the operating frequency. For the proposed topology, since energy is split equally and alternately into two boost converters, the maximum duty cycle of each phase would therefore be $50 \%$. All four components: input voltage, duty cycle, switching period and inductance are positive in an ideal Boost converter; therefore the total change in the inductor's current when the switch is conducting would always be a positive. Figure 2-5 
depicts a graphical representation of the inductor current versus time during this specific time section. During toN the total change in the inductor's current is positive with a positive and linear rate of change throughout.

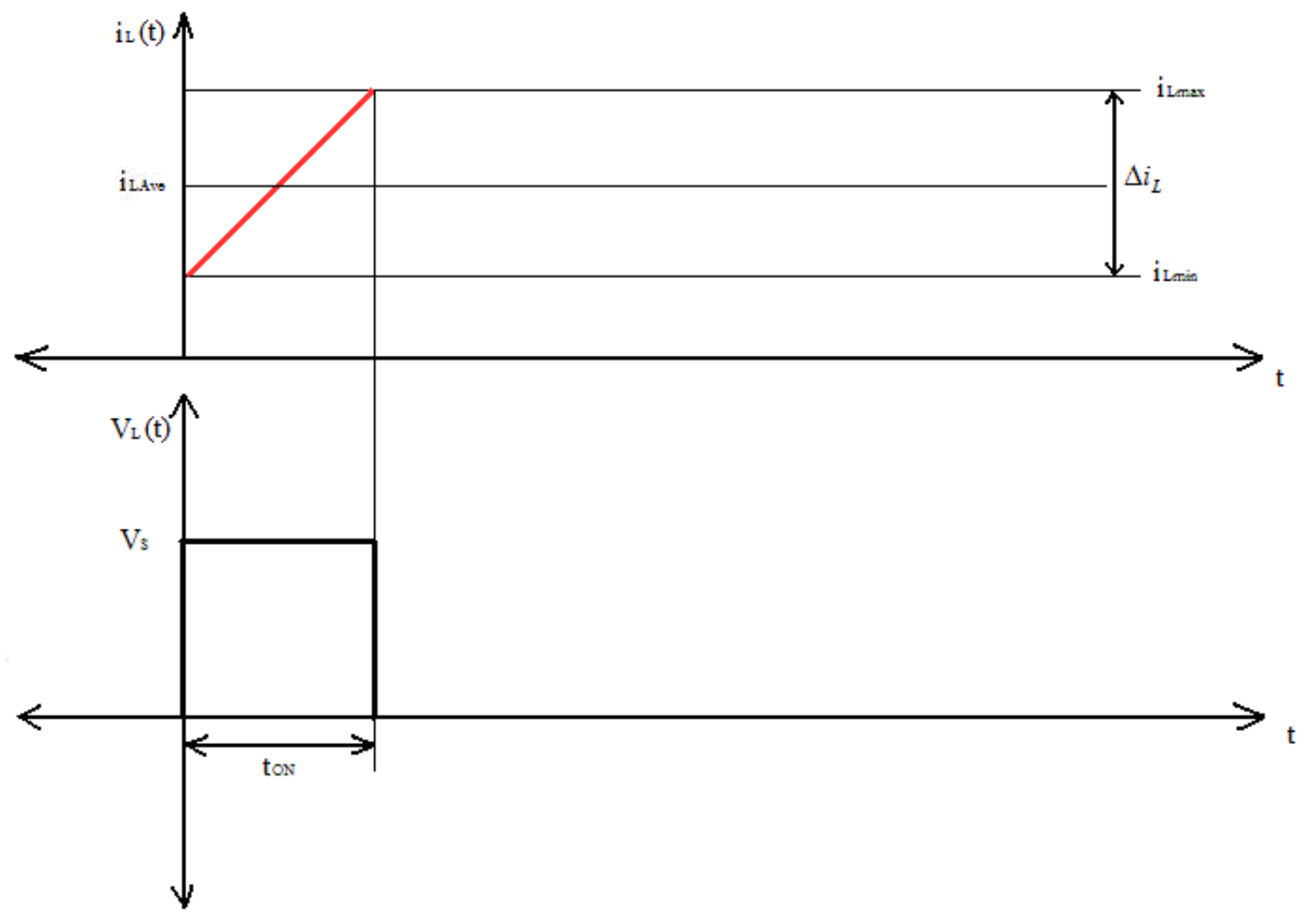

Figure 2-5: $\mathrm{I}_{\mathrm{L}}$ vs. Time and $\mathrm{V}_{\mathrm{L}}$ vs. Time in CCM with Conducting Switch

When the switch or MOSFET turns off, the diode would be forward biased, creating a current path between the input and output. This condition is shown below in Figure 2-6. 


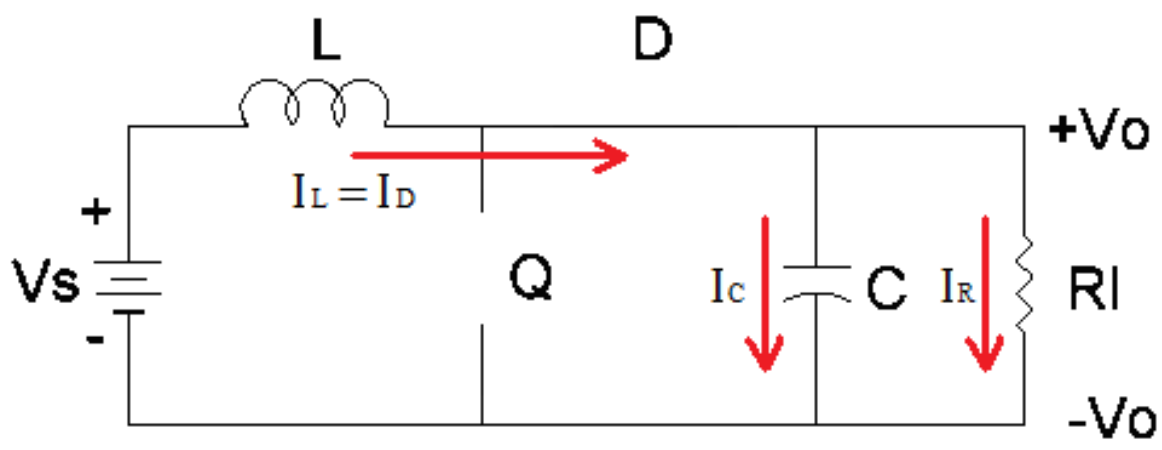

Figure 2-6: Ideal Boost Converter with Open Switch

$I_{D}$ is equivalent to $I_{L}$ assuming there is leakage across the open switch. The new voltage across the inductor:

$$
V_{L-O F F}=V_{S}-V_{O}=L \frac{d i_{L}}{d t}
$$

Next, knowing that $\Delta t-O f f=(1-D)^{*} T$ and applying the Volt-Second Balance, the transfer function may now be derived:

$$
\begin{aligned}
& \left(\Delta i_{L-O N}\right)+\left(\Delta i_{L-O F F}\right)=0 \\
& \left(V_{L-O N} * D T\right)+\left(V_{L-O F F} *(1-D) * T\right)=0 \\
& \frac{V_{S} * D T}{L}+\frac{\left(V_{S}-V_{O}\right) *(1-D) * T}{L}=0 \\
& \left(V_{S} * D T\right)+\left(V_{S}-V_{O}\right) *(1-D) * T=0 \\
& \left(V_{S} * D\right)+\left(V_{S}-V_{O}\right) *(1-D)=0 \\
& V_{S} D+V_{S}-V_{O}-V_{S} D+V_{O} D=0 \\
& V_{S}-V_{O}(1-D)=0 \\
& V_{O}=\frac{1}{(1-D)} V_{S}
\end{aligned}
$$


The transfer function shows that in boost the output voltage is greater than the input voltage. Returning to out $\mathrm{V}_{\mathrm{L}-\mathrm{OFF}}$ equation:

$$
\begin{aligned}
& L \frac{d i_{L}}{d t}=V_{S}-V_{O} \\
& \frac{d i_{L}}{d t}=\frac{V_{S}-V_{O}}{L}=\frac{\Delta i_{L}}{\Delta t} \\
& \frac{\Delta i_{L}}{(1-D) T}=\frac{V_{S}-V_{O}}{L} \\
& \Delta i_{L}=\frac{\left(V_{S}-V_{O}\right)}{L}(1-D) T
\end{aligned}
$$

Since in a boost converter $\mathrm{V}_{\mathrm{O}}$ is always greater than $\mathrm{V}_{\mathrm{S}}$, the rate of change and the total change in the inductor current would be negative during toFF. $_{\text {O }}$

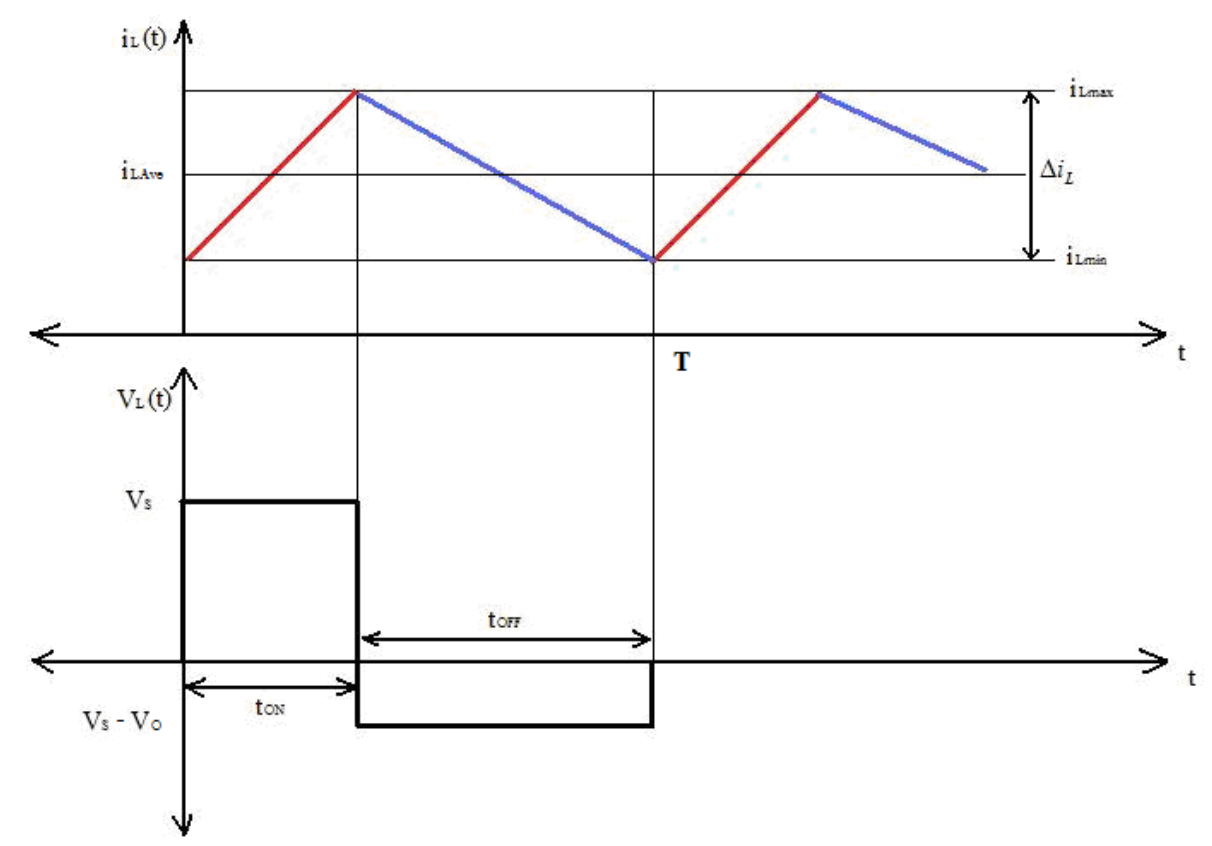

Figure 2-7: $\mathrm{I}_{\mathrm{L}}$ vs. Time and $\mathrm{V}_{\mathrm{L}}$ vs. Time in $\mathrm{CCM}$ with Open Switch in Each Phase Using this relation it is possible to find the duty cycle for a design given the required input and output voltage. Looking back to Figure 2-7, it can be seen that even though the current drops off in value, it never actually hits zero or below zero amps. This is because the Boost converter is being analyzed in CCM. The value of $\mathrm{I}_{\mathrm{Lmax}}$ and $\mathrm{I}_{\mathrm{Lmin}}$ can actually 
be calculated by deriving the formula for average inductor current and inductor current ripple.

$$
\begin{aligned}
& P_{I N}=P_{\text {Out }} \\
& V_{S} * I_{S}=\frac{{\overline{V_{O}}}^{2}}{R} \\
& I_{S}=\overline{I_{L}}=\frac{{\overline{V_{O}}}^{2}}{R^{*} V_{S}}
\end{aligned}
$$

Substituting $\mathrm{V}_{\mathrm{O}}$ by the transfer function gives,

$$
\begin{aligned}
& \overline{I_{L}}=\frac{\left[\frac{V_{S}}{(1-D)}\right]^{2}}{R * V_{S}} \\
& \overline{I_{L}}=\frac{V_{S}}{(1-D)^{2} * R}
\end{aligned}
$$

For the proposed topology, the above equation still holds although the average inductor current in each phase should now be half of the average of the source current:

$$
\overline{I_{L}}=\frac{I_{S}}{2}
$$

It was found previously that,

$$
\Delta i_{L-O N}=\frac{V_{S}}{L} D T=\frac{V_{S} D}{L f}
$$

Here $f$ denotes the operating frequency of the converter which is equal to the switching frequency in each phase. So, adding the half of the inductor's peak to peak current ripple to the average current gives the formula of $\mathrm{I}_{\mathrm{Lmax}}$,

$$
\begin{aligned}
I_{L \max } & =\overline{I_{L}}+\frac{\Delta i_{L}}{2} \\
I_{L \max } & =\frac{V_{S}}{(1-D)^{2} * R}+\frac{V_{S} D}{2 L f}
\end{aligned}
$$


The value of $\mathrm{R}$ in the equation above for the proposed converter must refer to the half of the maximum output current. Hence, if maximum output power is $\mathrm{P}_{\mathrm{O}-\mathrm{MAX}}$ and output voltage is $V_{O}$, then $R$ for each phase:

$$
\begin{aligned}
& R=\frac{V_{O}^{2}}{P_{O-M A X} / 2} \\
& R=2 * \frac{V_{O}^{2}}{P_{O-M A X}}
\end{aligned}
$$

Subtracting half of the current ripple, would instead give the formula to find $\mathrm{I}_{\mathrm{Lmin}}$,

$$
\begin{aligned}
I_{L \min } & =\overline{I_{L}}-\frac{\Delta i_{L}}{2} \\
I_{L \min } & =\frac{V_{S}}{(1-D)^{2} * R}-\frac{V_{S} D}{2 L f}
\end{aligned}
$$

Where $\mathrm{L}$ is known as the critical inductance of the converter whose value is derived from boundary conduction mode (BCM.) For boost, this value is:

$$
\begin{aligned}
& 0=I_{L-M I N} \\
& 0=I_{L-a v e}-\frac{\Delta i_{L}}{2} \\
& 0=\frac{V_{S}}{(1-D)^{2} R}-\frac{V_{S} D T}{2 L} \\
& L_{c r i t}=\frac{D(1-D)^{2} R}{2 f}
\end{aligned}
$$

In the actual design, we normally pick the inductance to be larger than the calculated $\mathrm{L}_{\text {crit }}$.

To find the new capacitance for the input and output capacitors it is important to remember one of the benefits from a two phase design, frequency multiplications.

Frequency multiplication increases the frequency of the noises, making them easier to filter out with smaller capacitance. With two phases the operating frequency of the input 
and output of the converter would be doubled to $1 \mathrm{MHz}$ and it will affect the charge needed for the capacitors. The equation to find the capacitance is:

$$
C=q^{*} \Delta V
$$

$\mathrm{C}$ is the required capacitance; $\mathrm{q}$ is the required charge of the capacitors and $\Delta \mathrm{V}$ is the change of voltage through the capacitor during normal operation. Figure 2-8 and Figure 2-9 depict ideal current waveform for the input and output capacitors, respectively.

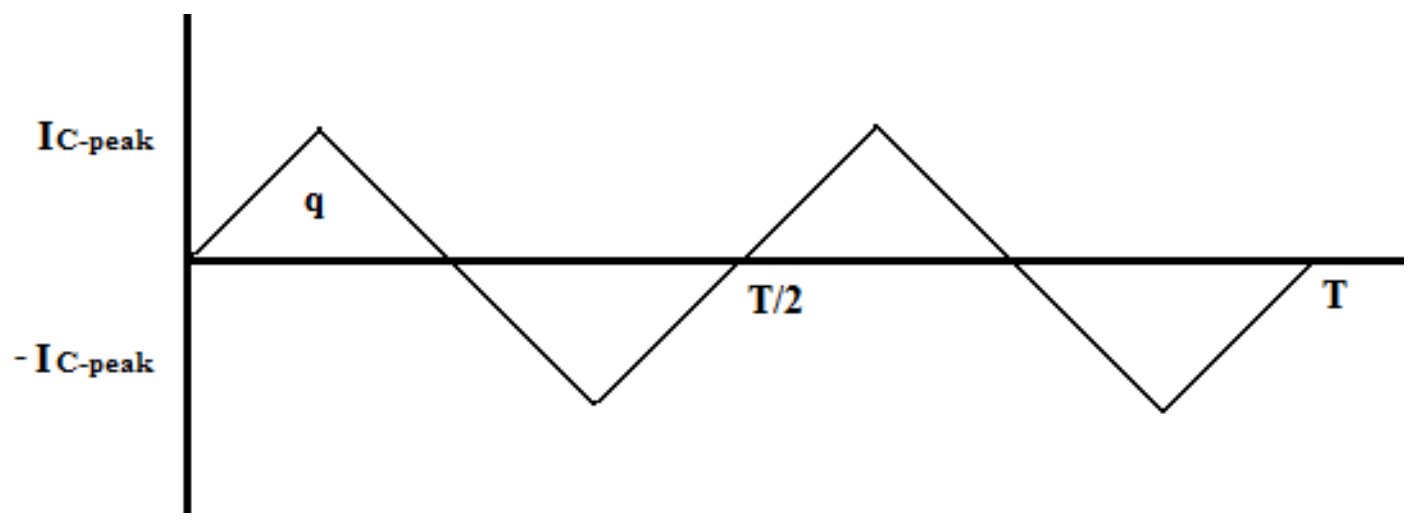

Figure 2-8: Ideal Current Waveform for Input Capacitor

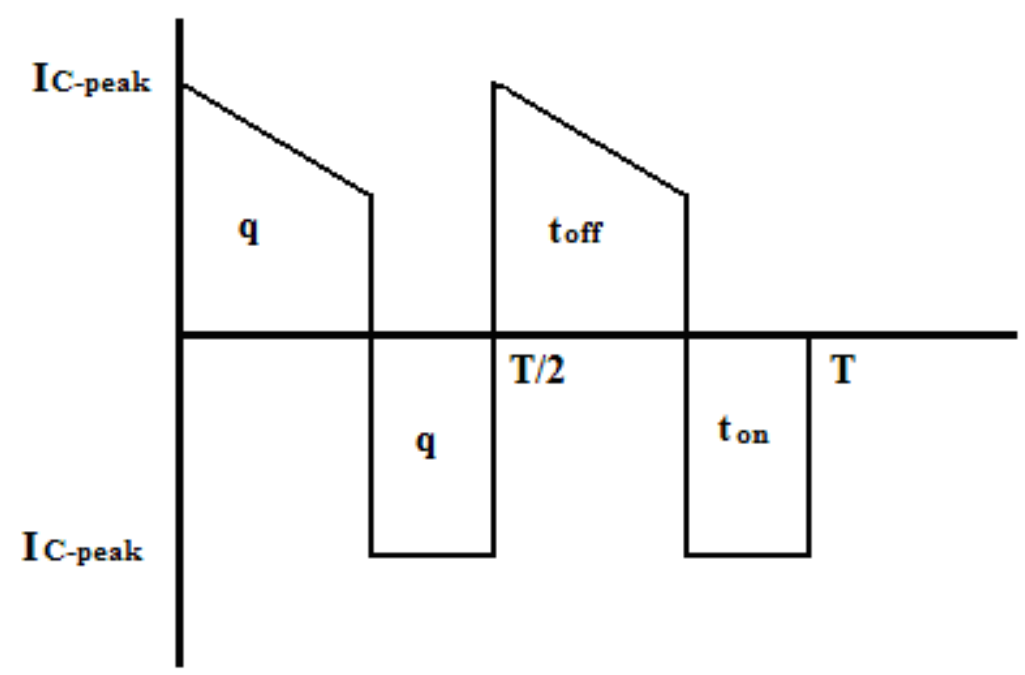

Figure 2-9: Ideal Current Waveform for Output Capacitor 
$\mathrm{T}$ represents the period found in each phase of the converter. With an operating frequency of $500 \mathrm{kHz}$ per phase the value of $\mathrm{T}$ comes out to be $2 \mu \mathrm{s}$. Notice that the current waveform in both figures has a period half of $\mathrm{T}$ due to the frequency multiplication, hence the value of q will decrease. This shows that frequency multiplication does help drop the capacitance needed to filter the converter.

To summarize, Figure 2-10 shows the critical waveforms in the proposed twophase boost converter of Figure 2-2.

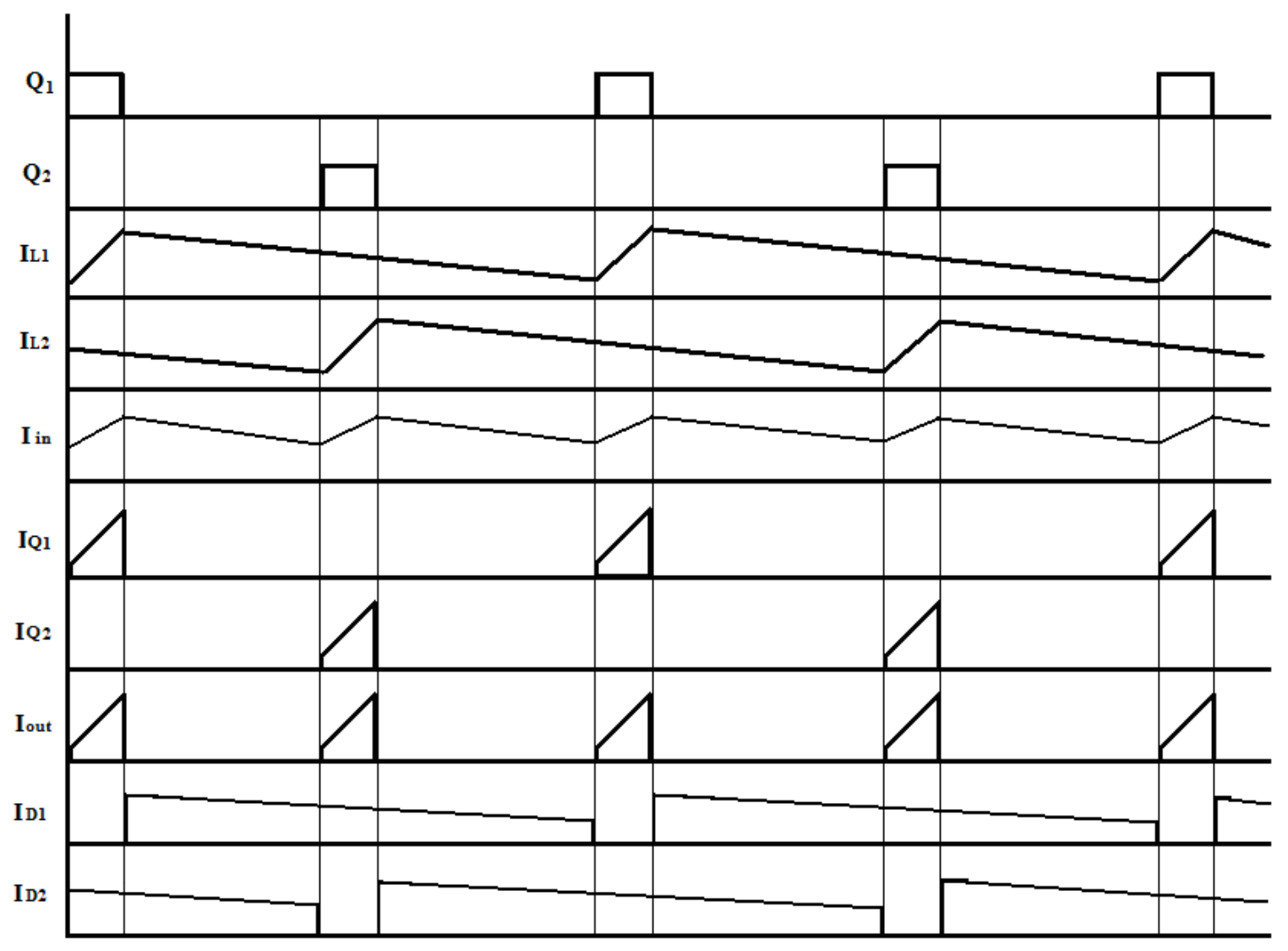

Figure 2-10: Frequency Multiplication in Two-Phase Boost 
Figure 2-10 exhibits the benefits of proposed two-phase topology. Firstly, as mentioned above, although each individual phase has an operating frequency of $500 \mathrm{kHz}$ the frequency multiplication effect causes the output current to have double the frequency. Secondly, the frequency multiplication also doubles the input current frequency. With less change in the current there would be less noise and less filtering required at both the input and output of the proposed two-phase topology. 


\section{Requirements}

The proposed Two-Phase Boost Converter was designed to fit within the given set of parameters in Table 3-1. The parameters were set to achieve the goal of creating a twophase converter that would have the potential to improve the efficiency of a regular Boost converter. Since many boost converters are being used in renewable energy applications to step up battery output voltage, hence the proposed converter will be designed to have input and output voltages at the level that would be achievable or usable by battery.

In terms of the output power level, since the objective of this thesis is to build the first prototype, then $200 \mathrm{~W}$ is chosen such that the prototype could be tested with the actual photovoltaic panels currently available in the power electronics lab. To achieve the efficiency at this power level while minimizing the physical size of the converter, switching frequency of $500 \mathrm{kHz}$ is selected. This frequency seems to be the value that is commonly used in multiphase dc-dc converters. For a two-phase converter, at this frequency the input and output stages of the converter will actually be seeing twice as much $(1 \mathrm{MHz})$ due to frequency multiplication property of multiphase converter. Careful considerations in the design and in selecting the components have to be taken since operating the converter at this frequency may worsen the efficiency. Therefore, efficiency of $90 \%$ at full load should be a good target for the converter.

To ensure reliable and good quality output, the proposed two-phase converter should have output voltage peak-to-peak ripple and load regulation of less than $1 \%$. In addition, to account for variation at the input voltage, the proposed converter should be able to maintain line regulation within $1 \%$. 
Table 3-1: Design Requirements for Proposed Two-Phase Boost.

\begin{tabular}{|c|c|}
\hline Parameters & Requirements \\
\hline Rated Power & 200 Watts \\
\hline Input Voltage & $36 \mathrm{VDC}$ \\
\hline Output Voltage & $48 \mathrm{VDC}$ \\
\hline Input Current Max & $5.56 \mathrm{Amps}$ \\
\hline Output Current Max & $4.167 \mathrm{Amps}$ \\
\hline Operating Frequency & $500 \mathrm{KHz}$ \\
\hline Line Regulation & $<1 \%$ \\
\hline Load Regulation & $<1 \%$ \\
\hline Output Voltage Ripple & $<1 \% \mathrm{VP}$ \\
\hline Efficiency & $>90 \%$ \\
\hline
\end{tabular}




\section{Design Calculations}

This chapter explains the design calculations for selecting the components used in the proposed two-phase boost converter.

\subsection{Duty Cycle}

Recall that duty cycle is the percentage of a switching period when the main switch of the converter in each phase is conducting. Previously it was derived that the duty cycle for both single and two phase Boost can be found by using the same formula given the input and output voltage. Looking at chapter III it can be seen that this converter needs to have input voltage of 36 volts and output voltage of 48 volts. So plugging in the values into the equation gives an ideal duty cycle of $25 \%$.

$$
\begin{aligned}
& V_{O}=\frac{1}{(1-D)} V_{S} \\
& 48=\frac{1}{(1-D)} * 36 \\
& \frac{4}{3} *(1-D)=1 \\
& 1-D=\frac{3}{4} \\
& D=\frac{1}{4}=25 \%
\end{aligned}
$$




\subsection{Inductor}

In boost topologies the inductor is a crucial energy storing element, thus it is very important that the inductor is sized correctly. To determine the minimum inductance needed for the given design requirements, we would first need to calculate the maximum load resistance. Using Ohm's law it can be seen that maximum load resistance would be achieved if the output current is at its minimum. For this design the minimum current has been specified as $5 \%$ of the maximum output current. Assuming maximum output power is during a perfect conversion, and then the three values can be calculated as follows.

$$
\begin{aligned}
& I_{O-\text { Max }}=\frac{P_{\text {Out }}}{V_{\text {Out }}}=\frac{200 \mathrm{~W}}{48 \mathrm{~V}}=4.167 \mathrm{~A} \\
& I_{O-\text { Min }}=I_{O-\text { Max }} * 5 \%=0.20835 \mathrm{~A} \\
& R_{\text {Load-Max }}=\frac{V_{\text {Out }}}{I_{O-\text { Min }}}=\frac{48 \mathrm{~V}}{0.20835 \mathrm{~A}}=230.38 \Omega
\end{aligned}
$$

However, in the proposed two-phase converter, the output power is divided equally into the two phases. Hence, $\mathrm{R}_{\text {load-max }}$ for each phase:

$$
\begin{aligned}
& R_{\text {Max }- \text { phase }}=\frac{R_{\text {Load }-\max }}{2} \\
& R_{\text {Max }- \text { phase }}=\frac{230.38 \Omega}{2}=115.19 \Omega
\end{aligned}
$$

The minimum inductance can then be found using:

$$
\begin{aligned}
L_{\text {Min }} & =\frac{\left[D *(1-D)^{2} * R_{\max -\text { phase }}\right]}{2 f} \\
L_{\text {Min }} & =\frac{\left[0.25 *(1-0.25)^{2} * 115.19\right]}{2 * 500000}=16.2 \mu \mathrm{H}
\end{aligned}
$$

Taking into account losses, how heat and high current lower inductance, the inductors being used in this design were chosen to have slightly higher inductance than $22 \mu H$. The maximum current limit of the inductor is also an important factor so as not to saturate it 
at maximum output power. The absolute maximum current that could go through the inductor in each phase is equal to half of the maximum input current:

$$
\begin{aligned}
& I_{\text {in-ave }-\max }=\frac{P \text { in }}{V_{S}}=\frac{200 \mathrm{~W}}{36 \mathrm{~V}}=5.56 \mathrm{~A} \\
& I_{L p k}=\frac{I_{\text {in-ave-max }}}{2}+\frac{\Delta I_{L}}{2}=\frac{I_{\text {in-ave-max }}}{2}+\frac{\left(\frac{V_{s}}{L} * D T\right)}{2} \\
& I_{L p k}=\frac{5.56}{2}+\frac{\left(\frac{36 \mathrm{~V}}{22 \mu \mathrm{H}} * 0.25 * \frac{1}{500000 \mathrm{~Hz}}\right)}{2}=3.19 \mathrm{~A}
\end{aligned}
$$

Copper loss of each inductor can be calculated from the equation below when an actual inductor has been acquired. This equation is taken from the LT3782A datasheet [4]:

$$
P_{\text {Winding }}=\left(\frac{\frac{I_{O(\operatorname{Max})}}{2}}{1-D_{\text {Max }}}\right)^{2} * R_{W}
$$

Another important aspect for selecting the inductor is the self-resonant frequency of the inductor. Each phase will operate with a frequency of $500 \mathrm{kHz}$, so the inductor needs to have a self-resonant frequency much larger than $500 \mathrm{kHz}$. This is because as the frequency increases, the parasitic capacitance of the inductor will increase and start to cancel out the inductance. If the inductor has a lower or nearly equal self-resonant frequency compared to the operating frequency, the inductor will act as a short and will no longer act as an energy storage element. 


\section{$\underline{4.3 \text { Input Capacitor }}$}

The input capacitor is placed to help filter out any possible noise from the DC input source. This component is not as crucial as the output capacitor because in Boost topologies, the inductor is placed in series with the source. The inductor would force the input current to be a continuous and triangle shaped waveform. However, it is still important to find the maximum possible rms current going through the input capacitor to ensure that the actual capacitors chosen will be able to handle loss due to ESR. For the two-phase converter each phase will operate at $500 \mathrm{kHz}$, but the capacitor will actually see twice the value. Figure 4-1 below is given in the LT3782A datasheet to find the rms ripple for the input capacitor current which comes out to be around $0.175 \mathrm{~A}$.

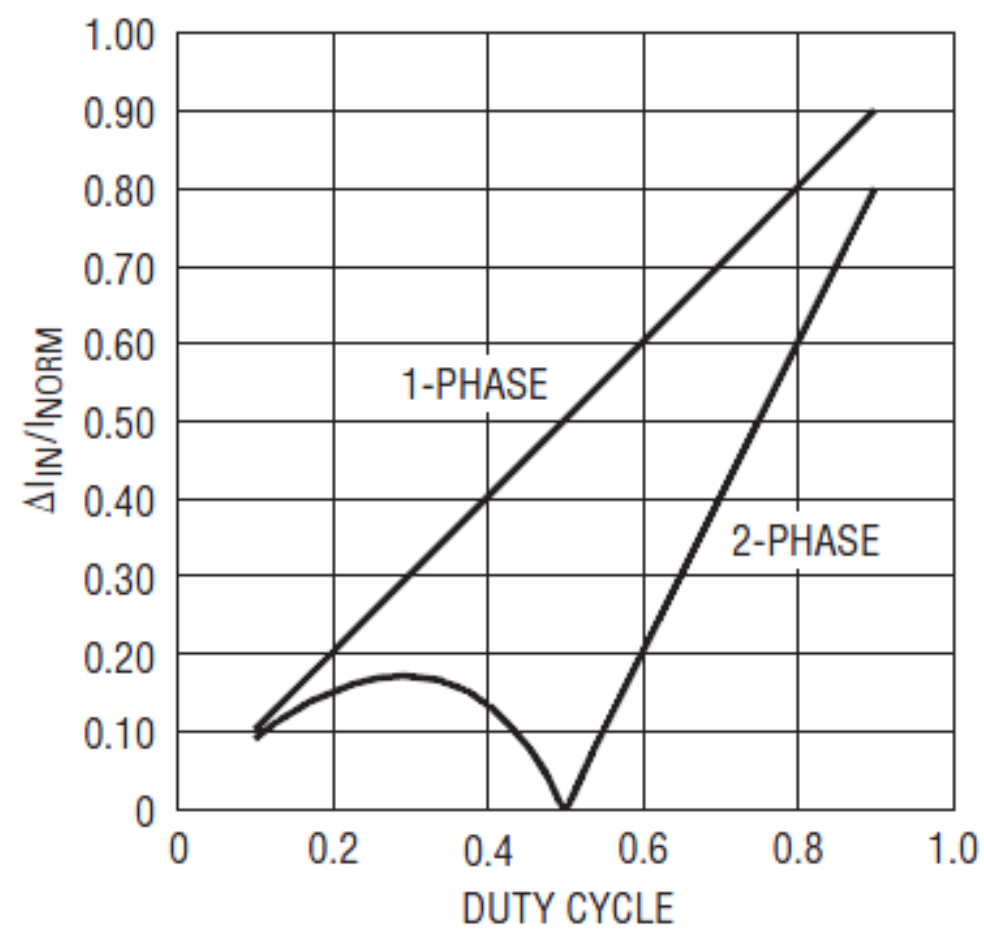

Figure 4-1: RMS Ripple Input Current Rating [7]

Figure 4-2 depicts the input capacitor current where the value of $\mathrm{I}_{\mathrm{C} \text {-peak }}$ is equal to $\mathrm{I}_{\mathrm{L}-\text { peak }}{ }^{-}$ $\mathrm{I}_{\mathrm{L}-\mathrm{ave}}$ and with frequency multiplication the period of the waveform is $\mathrm{T} / 2$ or $1 \mu \mathrm{s}$. With $\mathrm{q}$ 
being the area under the triangle and the input voltage ripple is $0.48 \mathrm{~V}$, the input capacitance can be calculated as:

$$
\begin{aligned}
& C_{I n}=q^{*} \Delta V \\
& C_{I n}=0.205 \mu C * 0.48 V=0.09 \mu F
\end{aligned}
$$

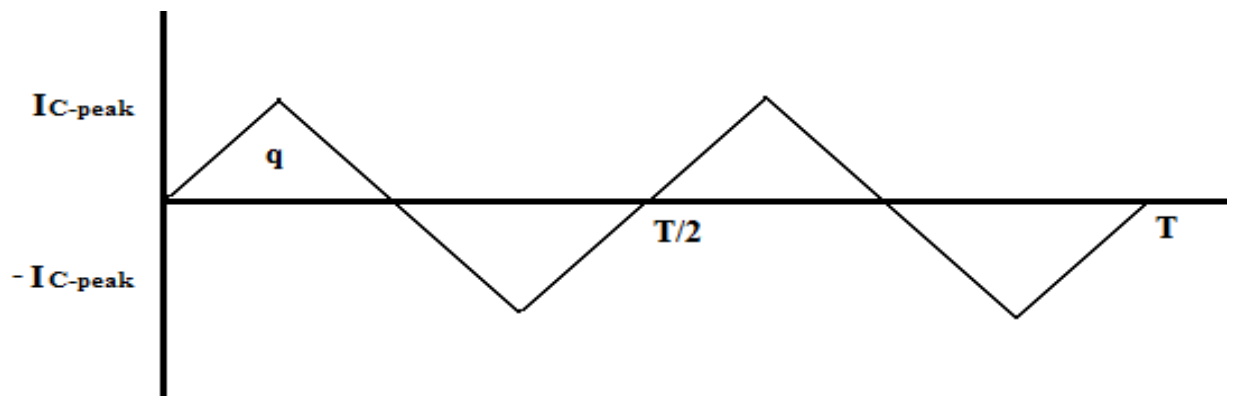

Figure 4-2: Input Capacitor Current

Two different capacitors were chosen as the input capacitors: $47 \mu \mathrm{F}$ capacitors and $0.22 \mu \mathrm{F}$ capacitors. The $47 \mu \mathrm{F}$ capacitors are electrolytic and are mainly being used as a storage element for the converter. Meanwhile, the $0.22 \mu \mathrm{F}$ capacitors are ceramic and have low ESR, therefore they are placed in parallel with the $47 \mu \mathrm{F}$ capacitors to reduce the equivalent series resistance of the input capacitors. These input capacitors see an average of $36 \mathrm{~V}$ input voltage, so capacitors with voltage rating higher than $36 \mathrm{~V}$ are needed for the hardware design.

\subsection{Output Capacitor}

To limit the peak to peak ripple of the output voltage, capacitor filter is needed at the output. Figure 4-4 is the unfiltered waveform of the output capacitor current waveform. The capacitance of the output filter is function of the duty cycle, frequency 
and minimum load resistance during maximum load. Plugging in the values into the output capacitance equation gives:

$$
\begin{aligned}
C_{\text {Out }} & =\frac{D}{\left(\frac{\Delta V}{V_{o}}\right) * R_{\text {min }} * 2 f} \\
C_{\text {Out }} & =\frac{0.25}{(1 \%) * 11.52 \Omega * 2 * 500 \mathrm{kHz}}=2.17 \mu \mathrm{F}
\end{aligned}
$$

Similar to the input current, it is important to find the rms current for the output capacitor. According to Figure 4-3 its rms current should be rated around 0.3A.

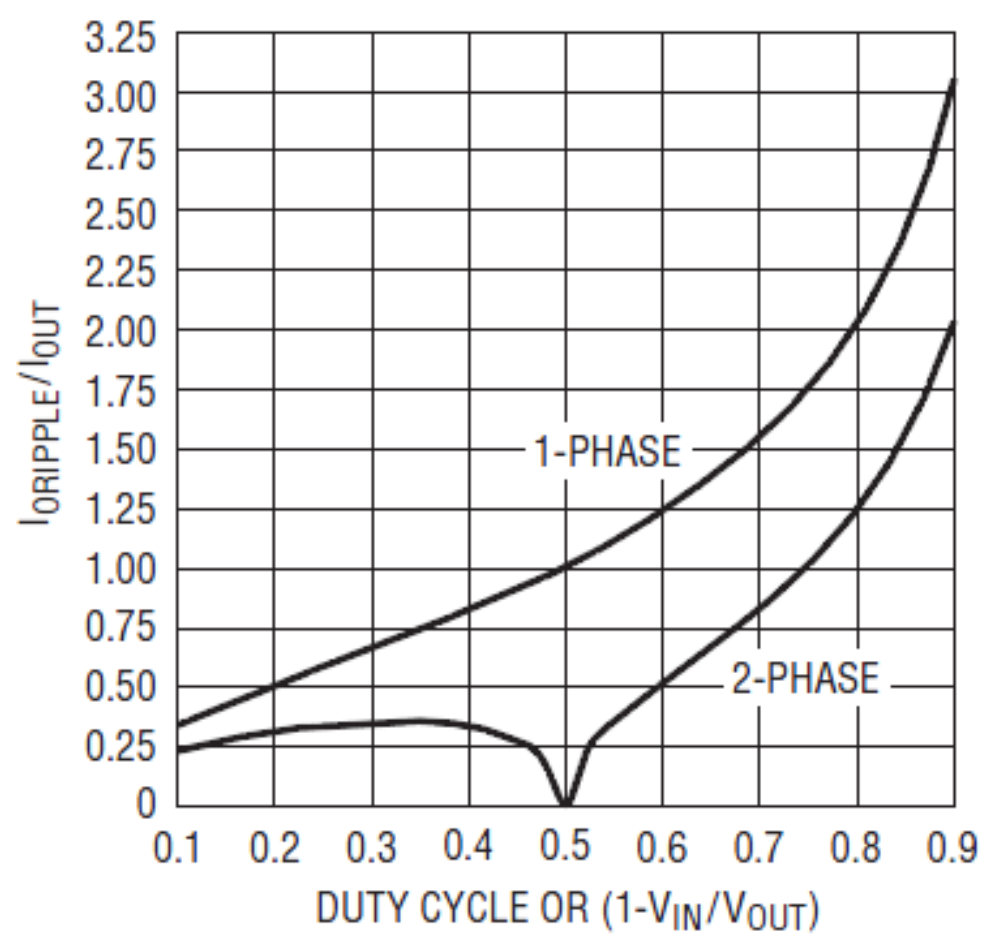

Figure 4-3: RMS Ripple Output Current Rating [7] 


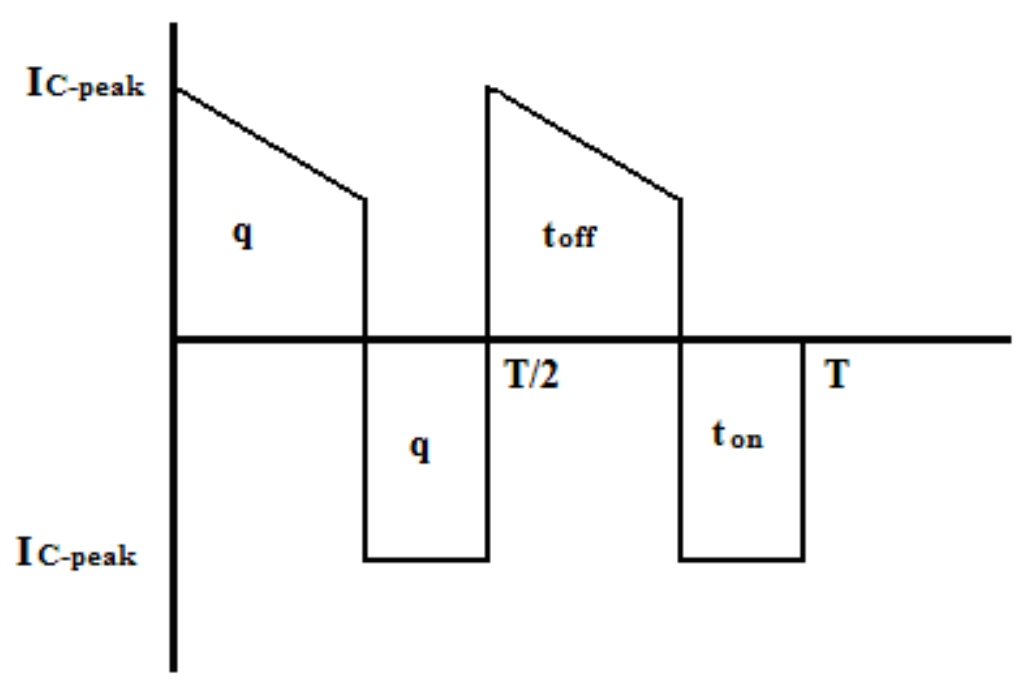

Figure 4-4: Output Capacitor Current

Rounding up the calculated value, the output capacitor is chosen to be low ESR, $2.2 \mu \mathrm{F}$ capacitor. As with the input capacitor, $47 \mu \mathrm{F}$ capacitors are also placed in parallel with these low ESR capacitors. Thus, the larger capacitance will perform as storage elements to helpsupply energy to load and to decrease the output voltage ripple. The low ESR capacitors will reduce the total equivalent resistance of the filter and will serve as a good high frequency filter. The output capacitors will continuously see a peak value of $48 \mathrm{~V}$ plus $1 / 2$ of the $\Delta \mathrm{V}_{\mathrm{o}}$ across them during normal operation. So the chosen capacitors need to be able to handle above $48 \mathrm{~V}$.

\subsection{Power MOSFET}

The power MOSFET is another main component in the boost converter. Several important parameters when choosing a power MOSFET are the drain-to-source breakdown voltage $\left(\mathrm{BV}_{\mathrm{DSS}}\right)$, threshold voltage $\left(\mathrm{V}_{\mathrm{GS}(\mathrm{TH})}\right)$, on resistance $\left(\mathrm{R}_{\mathrm{DS}-\mathrm{ON}}\right)$, gate-to- 
source charge $\left(\mathrm{Q}_{\mathrm{GS}}\right)$, gate-to-drain charges $\left(\mathrm{Q}_{\mathrm{GD}}\right)$, maximum drain current $\left(\mathrm{I}_{\mathrm{D}-\mathrm{Max}}\right)$ and the thermal resistances $\left(\mathrm{R}_{\mathrm{TH}(\mathrm{JC})}\right.$ and $\left.\mathrm{R}_{\mathrm{TH}(\mathrm{JA})}\right)$.

Choosing a MOSFET can be started by calculating the approximate power dissipated by the MOSFET. In a two-phase boost that value can be calculated from the equation given in the LT3782A datasheet below:

$$
P_{F E T}=\frac{\left(\frac{I_{O-M a x}}{2}\right)^{2}}{(1-D)} * R_{D S-O N} * D * \rho_{T}+k * V_{O}{ }^{2} * \frac{\left(\frac{I_{O-M A X}}{2}\right)}{(1-D)} * C_{R S S} * f
$$

The power loss is dependent on $\mathrm{I}_{\mathrm{O}-\mathrm{Max}}$, duty cycle, $\mathrm{R}_{\mathrm{DS}-\mathrm{ON}}, \mathrm{V}_{\mathrm{O}}, \mathrm{C}_{\mathrm{RSS}}$, frequency and $\rho_{\mathrm{T}}$. $\mathrm{C}_{\mathrm{RSS}}$ is the reverse transfer capacitance of the MOSFET and $\rho_{\mathrm{T}}$ is the normalized drain to source on resistance. It can be considered that the on $\mathrm{I}_{\mathrm{O}-\mathrm{Max}}$, duty cycle, $\mathrm{R}_{\mathrm{DS}-\mathrm{ON}}, \mathrm{V}_{\mathrm{O}}$, $\mathrm{C}_{\mathrm{RSS}}$ and frequency are constant for this calculation. So the power loss value will change in accordance to $\rho$ which is the normalized drain-to-source on resistance. The value of $\rho$ is dependent on the temperature of the MOSFET and the relationship between the two can be found in the datasheet unique to each MOSFET.

The main MOSFET will be conducting equal to the duty cycle which is $25 \%$ of the time. With the short conducting time, a MOSFET with small switching loss is preferred. This means that the MOSFET should have low output capacitance. After some research FDD3682 power MOSFET was chosen to be the main MOSFET. It has drain-tosource voltage of $100 \mathrm{VDC}$, continuous drain current of 32Amps and drain-to-source resistance of $36 \mathrm{~m} \Omega$. For this calculation let's assume the MOSFET is warm from continuous operation and has a temperature of $120^{\circ} \mathrm{C}$. Looking at Figure $8,120^{\circ} \mathrm{C}$ corresponds to $\rho$ equals to about 1.75 . 


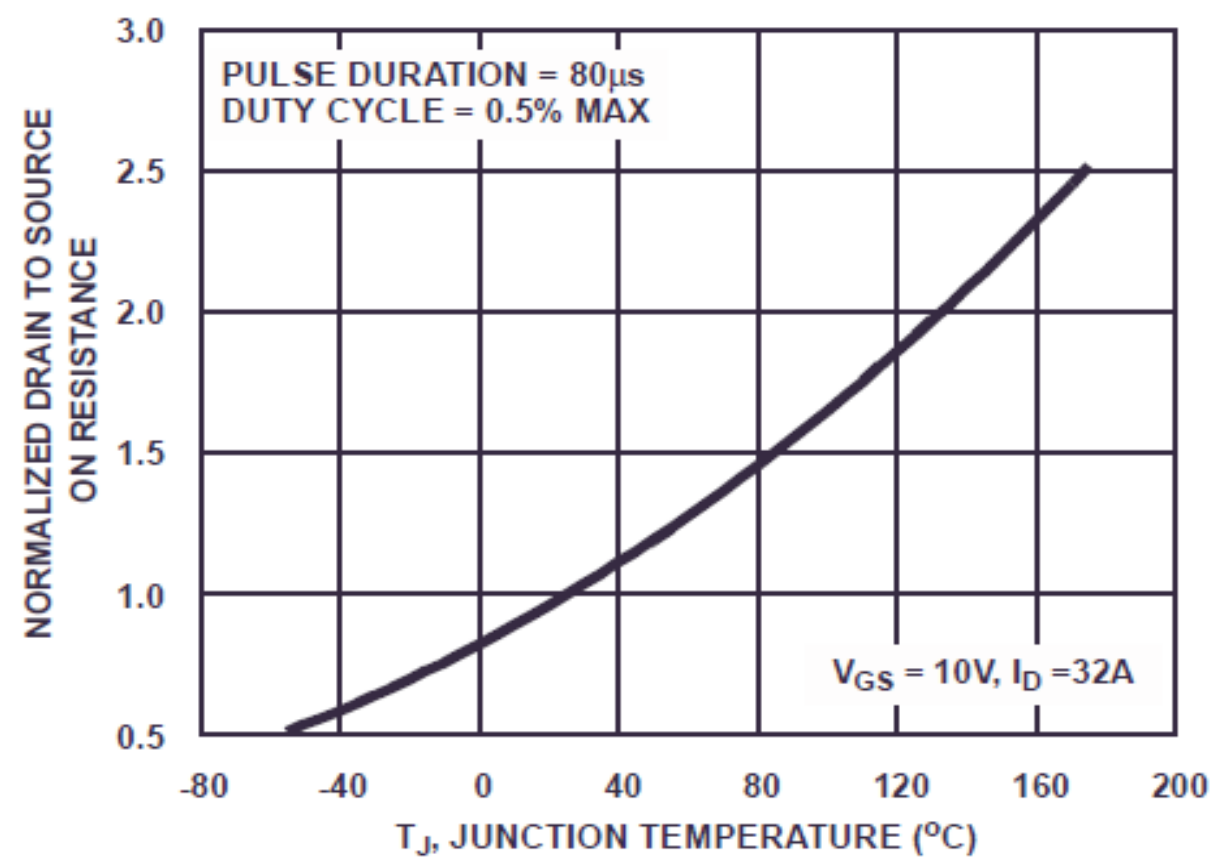

Figure 4-5: $\rho$ vs. Junction Temperature for FDD3682 [4]

Assuming that the variable $\mathrm{k}$ is an empirical constant of 1.7 and $\mathrm{C}_{\mathrm{RSS}}$ given in the datasheet to be $45 \mathrm{pF}$, the power loss from the main MOSFET can then be estimated as:

$$
\begin{aligned}
P_{F E T} & =\frac{\left(\frac{I_{O-M a x}}{2}\right)^{2}}{(1-D)} * R_{D S-O N} * D * \rho_{T}+k * V_{O}^{2} * \frac{\left(\frac{I_{O-M A X}}{2}\right)}{(1-D)} * C_{R S S} * f \\
P_{F E T} & =\frac{\left(\frac{4.167 A}{2}\right)^{2}}{(1-0.25)} * 36 m \Omega * 0.25 * 1.75+1.7 *(48 V)^{2} * \frac{\left(\frac{4.167 A}{2}\right)}{(1-0.25)} * 45 p F * 500 \mathrm{kHz} \\
P_{F E T} & =0.1215+0.2448 \\
P_{F E T} & =0.3663 \text { Watts }
\end{aligned}
$$

With the calculated power dissipation in the MOSFET, the junction temperature can be calculated with:

$$
\begin{aligned}
& T_{J}=T_{A}+P_{F E T} * R_{T H(J A)} \\
& T_{J}=25^{\circ} C+0.3663 \text { Watts }^{\circ} * 52^{\circ} \frac{C}{W} \\
& T_{J}=44.05^{\circ} \mathrm{C}
\end{aligned}
$$


The value of $\mathrm{R}_{\mathrm{TH}(\mathrm{JA})}$ is unique to the MOSFETs and can be found in their respective datasheet.

Notice that the power MOSFET chosen has have drain-to-source voltage and continuous drain current that exceed the required specifications. This was done for safety and reliability reasons. By having an increased threshold voltage and current requirement, it can be guaranteed that the MOSFET will not overload nor be strained beyond its limit during typical operations of the converter.

\subsection{Voltage and Current Sense Resistors}

The pulse width modulator is able to maintain a constant output voltage by adjusting the duty cycle of the converter continuously through the operation. To decide whether it needs to increase or decrease the duty cycle, the pulse width modulator needs feedbacks for both the current and voltage during the operation. This type of controller is called the current mode controller. The monitoring is done through two feedback loops: one from the output voltage and the other from the MOSFET current the main MOSFET.

The voltage sensor is placed in parallel with the load with large resistors by means of a voltage divider. The values of these resistors were chosen so that its midpoint voltage $\mathrm{V}_{\mathrm{x}}$ is the same voltage as the internal reference voltage of the controller, see Figure 4-6. The large resistances $\mathrm{R}_{\text {top }}$ and $\mathrm{R}_{\text {bottom }}$ are needed to prevent significant amount of current being diverted towards the feedback loop. The LT3782A pulse width modulator will try to maintain its reference 2.4 Volts input to the feedback pin. Because the required output for the converter is 48 Volts, it means the voltage divider has to be designed to step down to $\mathrm{V}_{\mathrm{x}}$ to $2.4 \mathrm{~V}$. A voltage divider is the perfect choice for this type of sensing because it 
has $100 \%$ line regulation. This means any fluctuation in the output voltage would be fully reflected to its input hence to the controller.

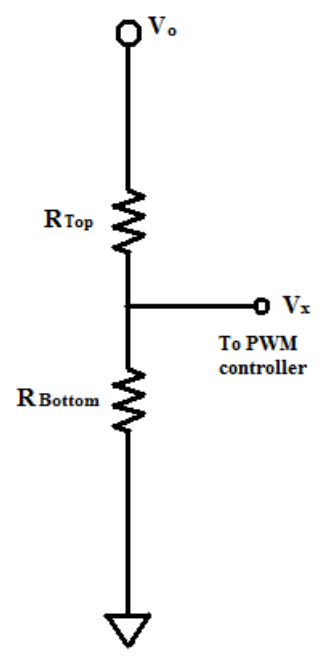

Figure 4-6: Voltage Divider

The ratio of the two resistors for the voltage divider can be calculated as the follows:

$$
\begin{gathered}
V_{O}=2.44 \text { Volts }\left(1+\frac{R_{\text {Top }}}{R_{\text {Bottom }}}\right) \\
\text { 48Volts }=2.44 \text { Volts }\left(1+\frac{R_{\text {Top }}}{R_{\text {Bottom }}}\right) \\
19.672=1+\frac{R_{\text {Top }}}{R_{\text {Bottom }}} \\
18.672=\frac{R_{\text {Top }}}{R_{\text {Bottom }}}
\end{gathered}
$$

For this case $\mathrm{R}_{\text {Top }}$ is chosen to be $2.8 \mathrm{M} \Omega$, which yields.

$$
\begin{aligned}
& 18.672=\frac{2.8 M \Omega}{R_{\text {Bottom }}} \\
& R_{\text {Bottom }}=149.96 \mathrm{k} \Omega
\end{aligned}
$$

$\mathrm{R}_{\mathrm{Bottom}}$ is then rounded to $150 \mathrm{k} \Omega$, both resistors has $1 \%$ tolerance. These are ideal choices because both values are common values for resistors. The combined series resistance for 
them is $2.95 \mathrm{M} \Omega$, which means with 48 Volts it would only draws about $16.3 \mu \mathrm{Amps}$ from 4.167Amps, less than $0.00039 \%$ of the output current.

With increasing concern to minimize energy usage the need to measure the flow of current through an electronic system becomes a common practice. The current feedback loop is taken, as mentioned above, from the current going through the main MOSFET. To do this a resistor, called current sense resistor, is placed between the source pin of MOSFET and the ground. The value of this resistor can be calculated from the equation given in the LT3782A datasheet where $\mathrm{V}_{\text {Sense(Max) }}$ into the controller is $63 \mathrm{mV}$.

$$
\begin{aligned}
& R \leq V_{\text {Sense }(\operatorname{Max})} * \frac{1-D_{\text {Max }}}{1.2 * \frac{I_{O-\operatorname{Max}}}{2}} \\
& R \leq 63 m V * \frac{1-0.25}{1.2 * \frac{4.167 A}{2}} \\
& R \leq 18.89 m \Omega
\end{aligned}
$$

For the Two-phase Boost Converter it uses two $20 \mathrm{~m} \Omega$ resistors in parallel. As recommended by Linear Technology an RC filter is placed in parallel with the resistors before going into the sense pins of the pulse width modulator to clean up the current sense feedback from any noise spikes. The power loss from the sense resistor can be found through the equation given from the LT3782A datasheet:

$$
\begin{aligned}
P_{R(\text { sense })} & =\left(\frac{\frac{I_{O(\text { Max })}}{2}}{1-D_{\text {Max }}}\right)^{2} * R * D_{M a x} \\
P_{R(\text { sense })} & =\left(\frac{\frac{4.167 A}{1-0.25}}{1-2} * 10 m \Omega * 0.25=0.0193\right. \text { Watts }
\end{aligned}
$$


LTSpice, a simulator made by Linear Technology, offers a wide range of Linear Technology chips for simulation, including the LT3782A. The inductors, resistors, diodes and capacitors specifications are based on the previously values and chosen from the list of parts provided by LTSpice. Figure 5-1 below is the screenshot of the LTSpice schematic.

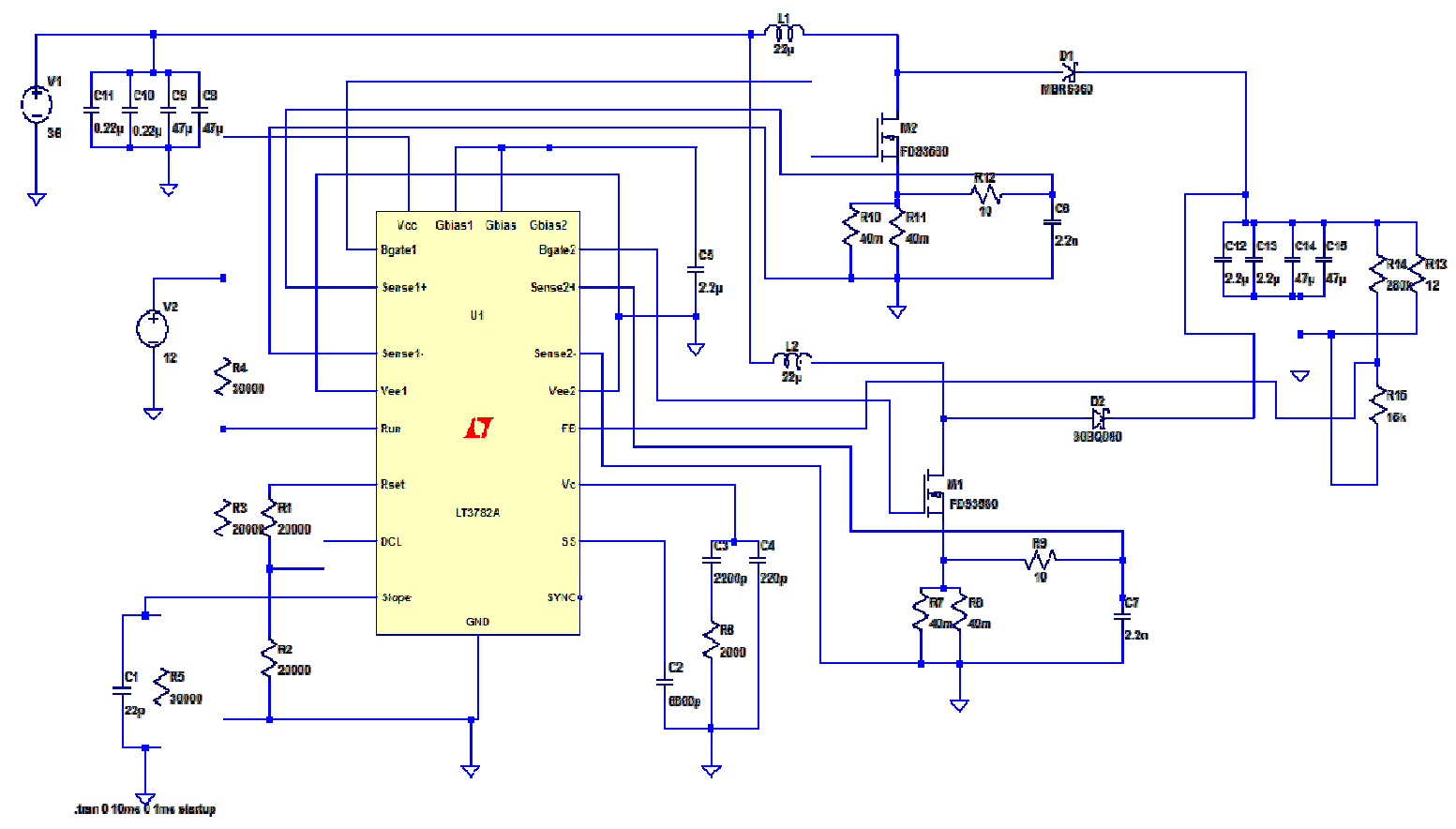

Figure 5-1: Two-Phase Boost Schematic Using LTSpice.

The simulation needs to run until the output voltage and current settle down into steady state before any accurate readings can be taken. Starting the simulation from zero state, that is, the input starts at $0 \mathrm{~V}$ and ramps up to $36 \mathrm{~V}$, takes about $20 \mathrm{~ms}$ to reach steady state. An in depth full load analysis is shown in the sections below, followed by an overview analysis with different level of loads. 


\subsection{Output Voltage}

Figure 5-2 is a snapshot of the output voltage ripple during steady state. It ripples between 48.001 Volts and $47.994 \mathrm{~V}$ with an average value of $47.964 \mathrm{~V}$, approximately $99.9 \%$ of the required value of $48 \mathrm{~V}$. Using the same values, the output voltage ripple is calculated to be $0.007 \mathrm{~V}_{\mathrm{P}-\mathrm{P}}$ or $0.015 \%$ which is well below the required $1 \%$ ripple.

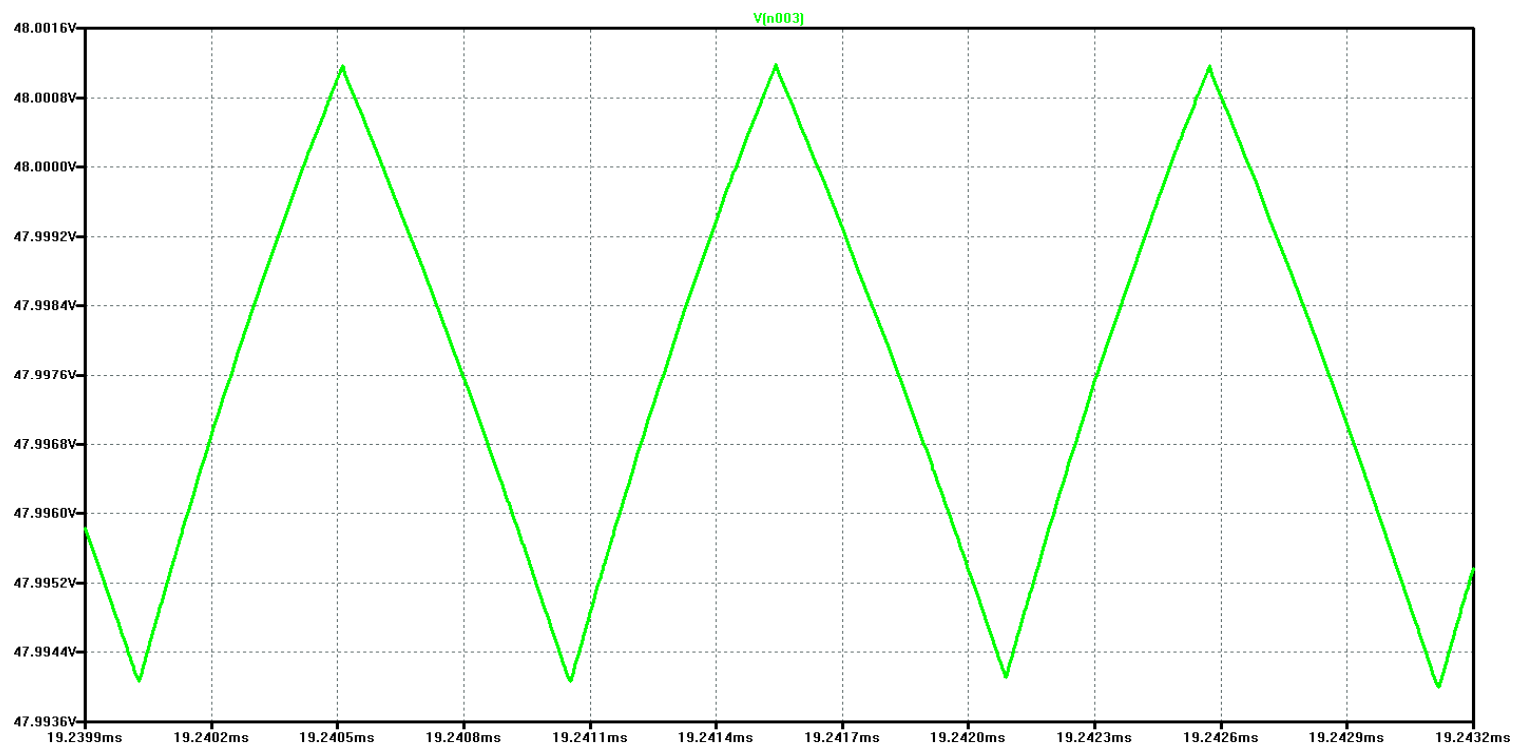

Figure 5-2: Output Voltage Ripple

Secondly it is important to check the output voltage frequency. The required operating frequency of each phase is $500 \mathrm{kHz}$, thus creating an expected output frequency of $1 \mathrm{MHz}$ due to frequency multiplication effect of the Two-Phase topology. Looking at Figure 5-2, a full period happens approximately between 19.242075ms and 19.24105ms.

$$
\text { Freq }_{\text {Output }}=\frac{1}{19.242075 m s-19.241075 m s}=1 M H z
$$

This is the expected $1 \mathrm{MHz}$ output frequency. 


\subsection{Output Current}

The output current for this project can be divided into two different categories, filtered and unfiltered. The unfiltered output currents are recorded by measuring the current through the schottky diodes individually. The resulting plots have distinct characteristics, they are discontinuous and trapezoid shaped as expected, see Figure 5-3. Using the plot below, the frequency of a single phase is calculated out to be:

$$
\text { Freq } q_{\text {Iout-unfittered }}=\frac{1}{19.2225 \mathrm{~ms}-19.2205 \mathrm{~ms}}=500 \mathrm{kHz}
$$

Notice that when the plot from both phases are overlaid, phase 1 (green) and 2 (blue), the phase are shifted by $180^{\circ}$. This is because the main MOSFET switched alternately and evenly between the two phases, creating the phase shift.

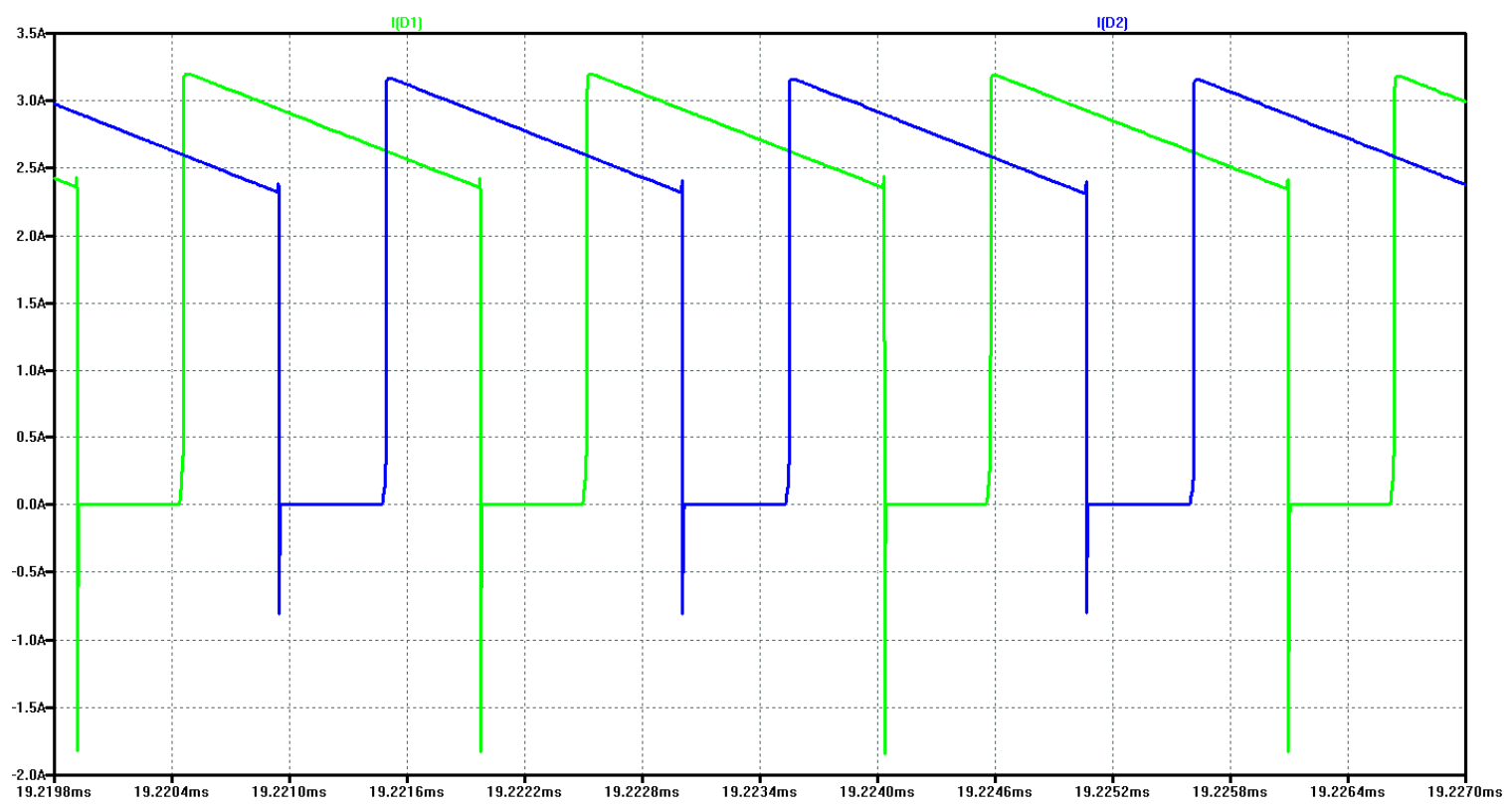

Figure 5-3: Overlaid Unfiltered Output Current of Phase 1 and Phase 2.

Figure 5-4 shows the filtered output current seen during full load. The filtered waveform is once again continuous and possesses both $\mathrm{AC}$ and $\mathrm{DC}$ component, similar to the input current. The required output current level for this converter is specified to be 
4.167A. Taking the average of the output current waveform gives the value of 3.997A or $95.98 \%$ of the expected output current. The output current ripple is $0.59 \mathrm{~mA}$, or $0.014 \%$, well below the required $1 \%$ ripple. As for the operating frequency, just like the output voltage, it can be hypothesized that the output current should operate at a higher frequency. Because both of the phases are connected to the same load it forces the filtered output current to have a frequency of $1 \mathrm{MHz}$. With both phases operating close to $500 \mathrm{kHz}$, the filtered output should operate at a frequency close to $1 \mathrm{MHz}$. Using the period of the graph in Figure 5-4 the frequency comes out to be:

$$
\text { Freq } q_{\text {Iout-Filtered }}=\frac{1}{19.8414 m s-19.8404 m s}=1 \mathrm{MHz}
$$

This is the expected value of $1 \mathrm{MHz}$ and hence proves the frequency multiplication effect of the two-phase boost converter.

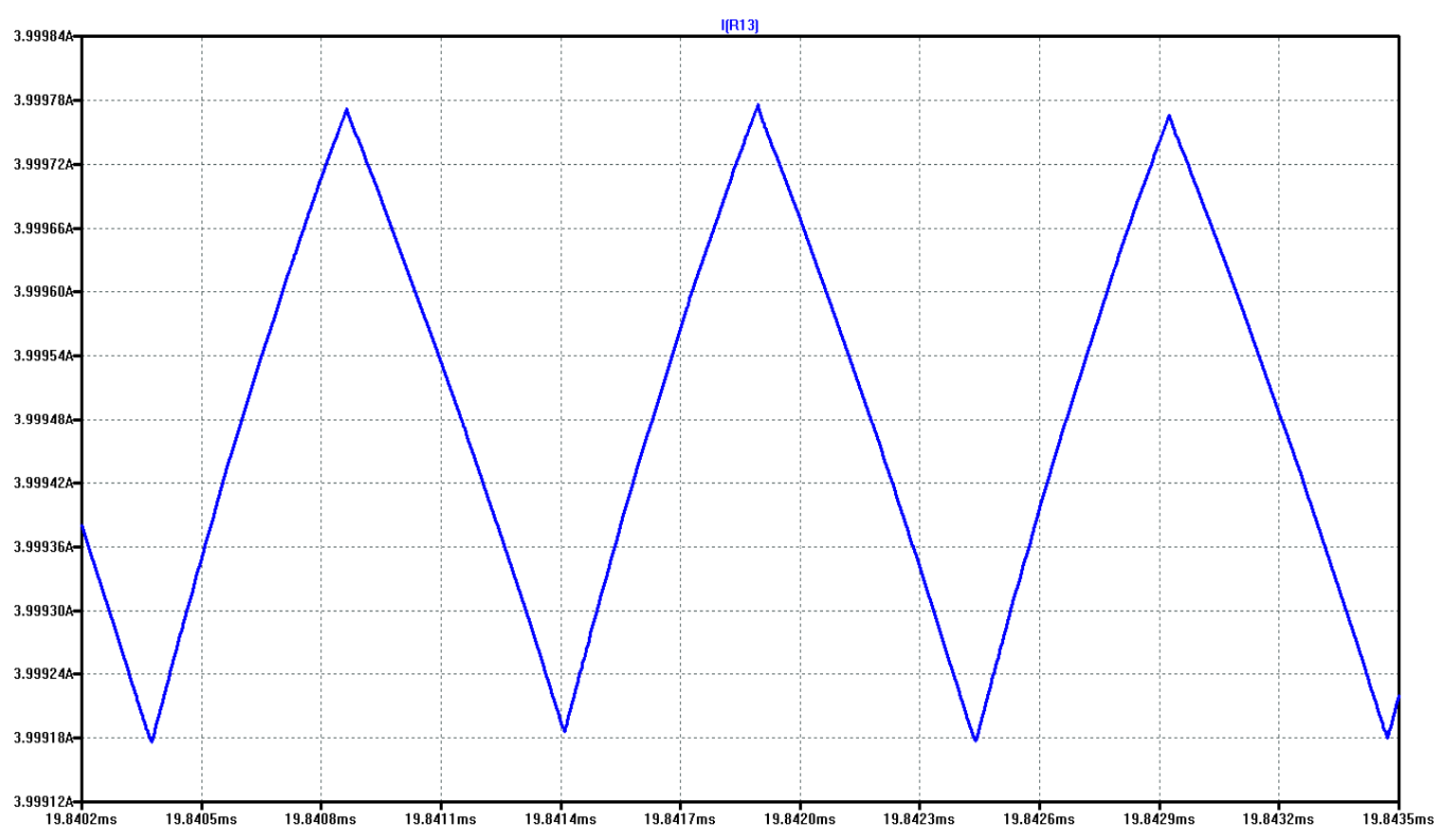

Figure 5-4: Filtered Output Current Ripple 


\subsection{Switching Signals}

Switching signals are the signals sent by the Pulse width modulator to drive the MOSFETs. According to the specification, the pulse width modulator is able to supply $10 \mathrm{~V}$ of gate drive at a maximum operating frequency of $500 \mathrm{kHz}$ per phase. The duty cycle, or the "on time", for this simulation is calculated to be $25 \%$. By analyzing the switching signals in Figure 5-5 we can see that the full cycle happens between $6.5842 \mathrm{~ms}$ and $6.5862 \mathrm{~ms}$ with a period of $2 \mu \mathrm{s}$ and a calculated frequency of:

$$
\text { Freq }_{\text {Dutycycle }}=\frac{1}{6.5862 m s-6.5842 m s}=500 \mathrm{kHz}
$$

The signal has $11 \mathrm{~V}$ gate drive, slightly over the specification, and lasted for $0.6 \mu$ s for a duty cycle of $28.6 \%$. The higher duty cycle than expected value should make sense since the circuit use real model of the components which introduce losses.

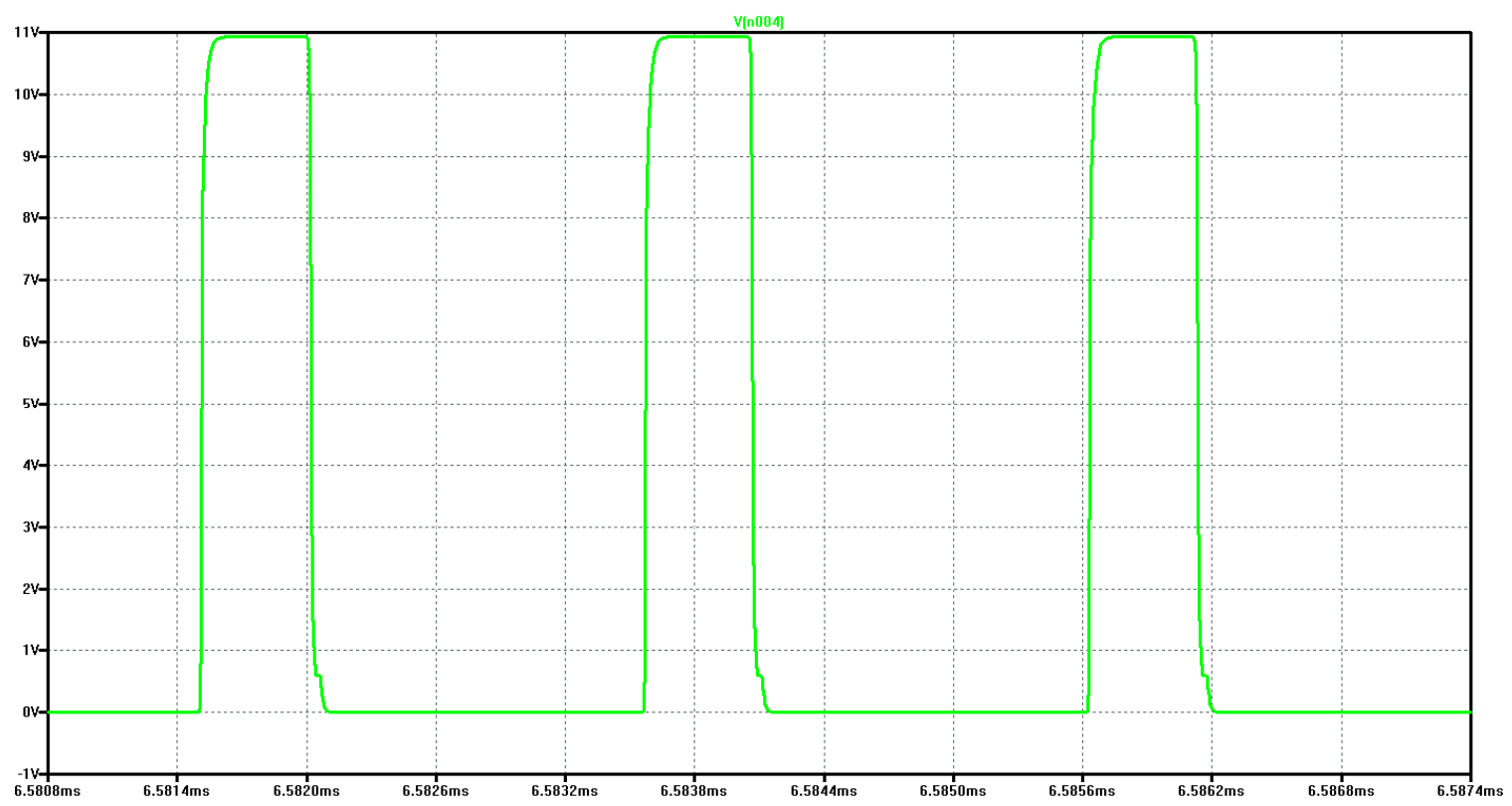

Figure 5-5: Phase 1 Switching Signals

The duty cycle from the second phase is shown in Figure 5-6. A full cycle lasts between $6.0242 \mathrm{~ms}$ and $6.0262 \mathrm{~ms}$ with a period of $2 \mu \mathrm{s}$ and an operating frequency of: 


$$
\text { Freq }_{\text {DutyCyle2 }}=\frac{1}{6.0262 m s-6.0242 m s}=500 \mathrm{kHz}
$$

Similar to the first phase, the gate drive operates at $11 \mathrm{~V}$ and lasts approximately for $0.6 \mu \mathrm{s}$ for a duty cycle of $30 \%$.

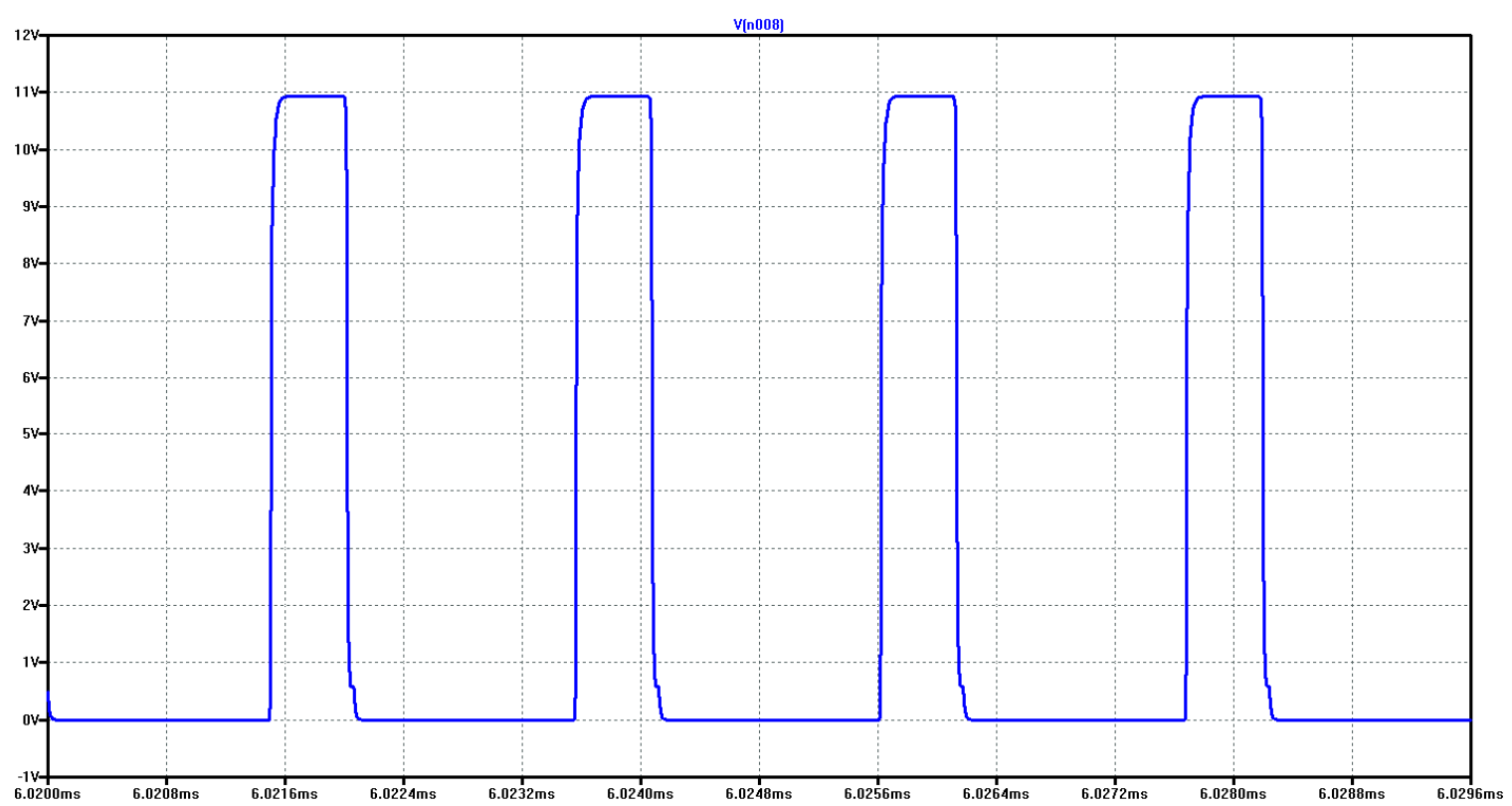

Figure 5-6: Phase 2 Switching Signals

A two phase converter is required to have a staggered switching signal. In other words, in one period there would be two turn on signals, one from each phase, spaced evenly by half of a period as seen in Figure 5-7. The overlaid figure is a great graphical representation of why the output and input frequency is doubled that of the phase operating frequency. Both output and input are connected to phases 1 and 2, so they "see" the overlaid switching signal instead of a single phase signal, causing them to have an operating frequency of $1 \mathrm{MHz}$. This can be proven by finding the period of the wave while superimposed. The new waveform finished a complete cycle between $6.5786 \mathrm{~ms}$ and $6.5796 \mathrm{~ms}$. Calculating the frequency using these values gives: 


$$
\text { Freq }_{\text {NewDutyCycle }}=\frac{1}{6.5796 m s-6.5786 m s}=1 M H z
$$

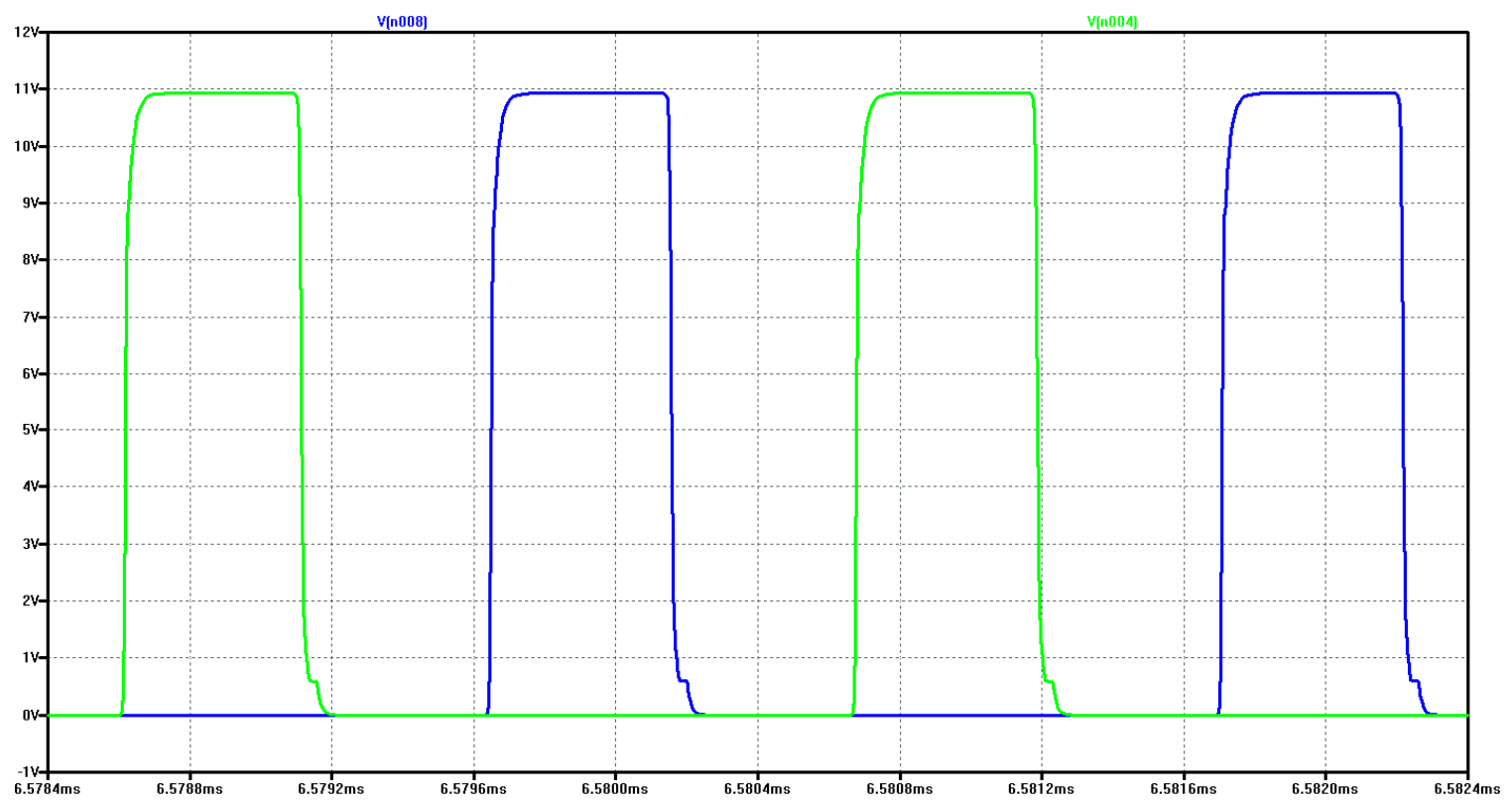

Figure 5-7: Superimposed Duty Cycles

\subsection{Inductor Current}

For a Two-Phase Boost Converter, the inductor current in each phase was expected to be half of its single phase counterpart with $180^{\circ}$ phase shift between the two phases. This hypothesis was drawn from the fact that the two phases are in parallel, dividing the current evenly, and it employs staggered switching between the two phases as discussed in section 5.3. 


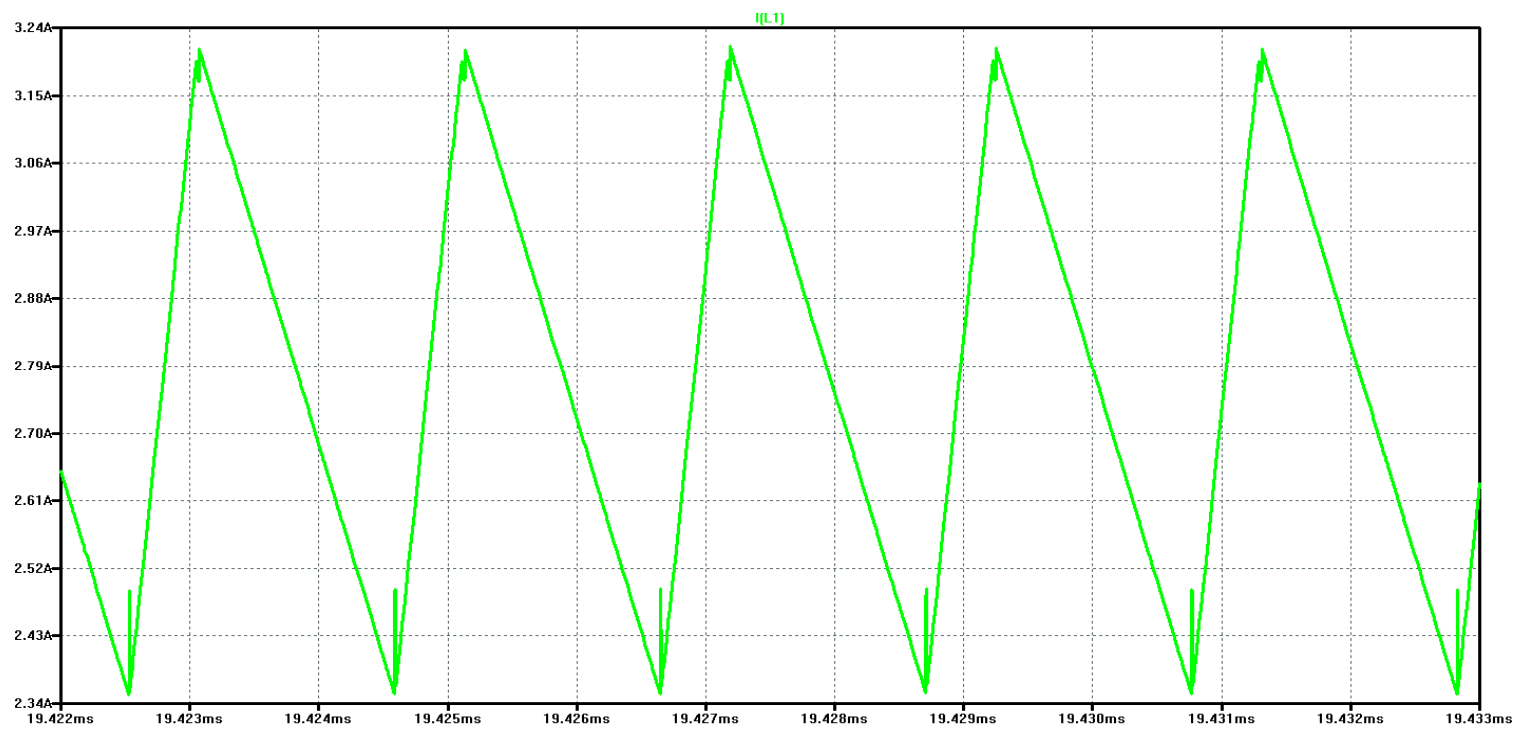

Figure 5-8: Inductor Current at Phase 1

Figure 5-8 shows that the inductor current of phase 1 swings between 3.2As and $2.35 \mathrm{~A}$ or $0.85 \mathrm{~A}_{\mathrm{P}-\mathrm{P}}$. These average out to $2.775 \mathrm{~A}$ which is about half of the input current at $5.56 \mathrm{~A}$ with a ripple of $30.63 \%$ and slightly less than the calculated $1.11 \mathrm{~A}$ or $40 \%$ ripple. The frequency of the signal can be calculated using the time it took to finish one period.

$$
\text { Freq }_{\text {Inductor }}=\frac{1}{19.4265 m s-19.4245 m s}=500 \mathrm{kHz}
$$

For comparison, Figure 5-9 shows the inductor current from the second phase of the converter. The second phase inductor current swings between 3.18Amps and 2.33Amps, which average out to about $2.755 \mathrm{Amps}$, a mere $20 \mathrm{~mA}$ less than the first phase's inductor current. The current ripple is $0.85 A_{\mathrm{P}-\mathrm{P}}$ or $30.85 \%$ which is still less than the expected $40 \%$. The frequency can similarly be found using the period of the plot, for example the full cycle happens between $19.221 \mathrm{~ms}$ and $19.223 \mathrm{~ms}$ gave:

$$
\text { Freq }_{L 2}=\frac{1}{19.223 m s-19.221 \mathrm{~ms}}=500 \mathrm{kHz}
$$




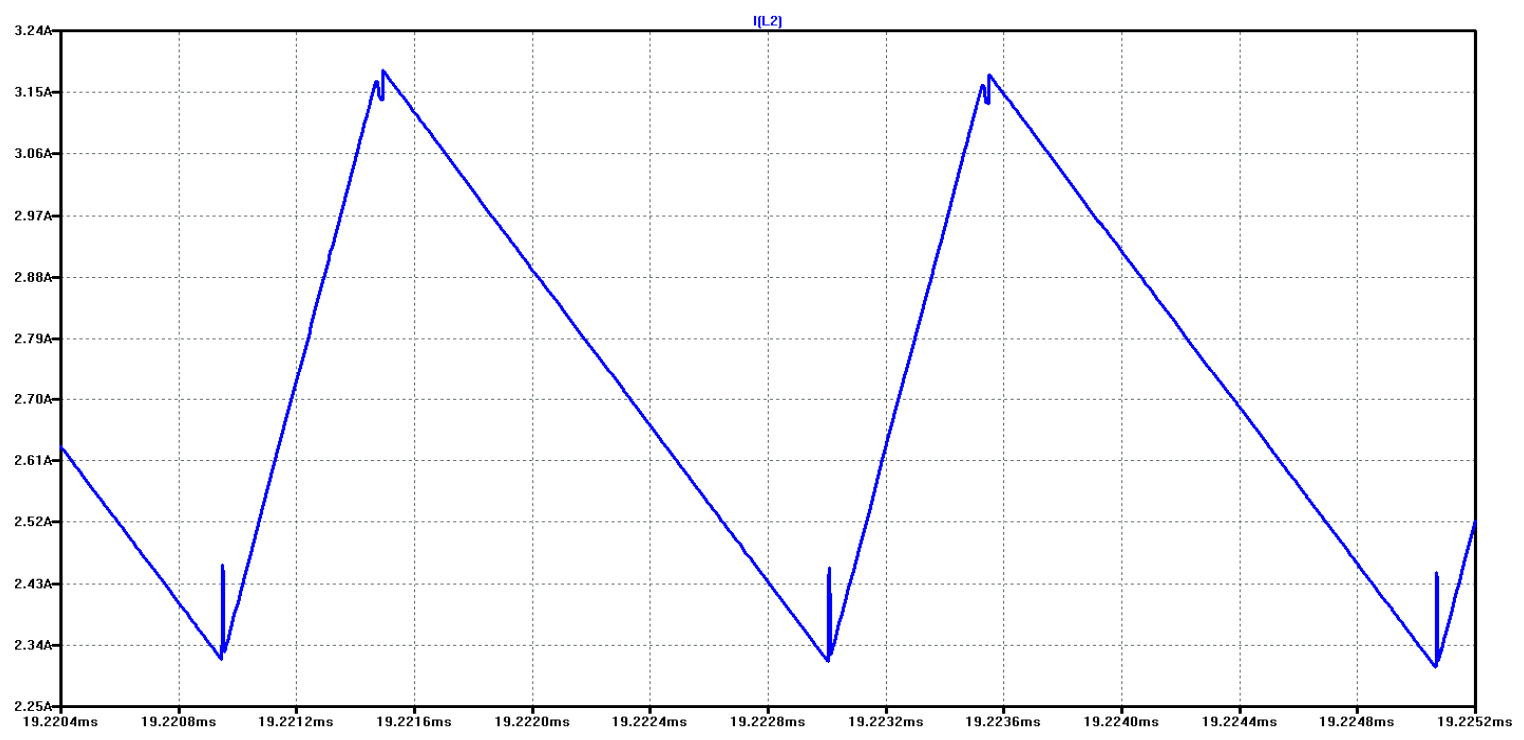

Figure 5-9: Inductor Current at Phase 2.

One of the easiest ways to see the phase shift between the inductor currents is to overlay the output plot on the same axis. Figure 5-10 has both phase 1 (green) and 2 (blue) inductor current and observing the $\mathrm{x}$-axis it can be seen that one of the phase is shifted by about $1 \mathrm{~ms}$. So with a period of $2 \mathrm{~ms}$ the $1 \mathrm{~ms}$ shift, half of a period, introduces the $180^{\circ}$ phase shift.

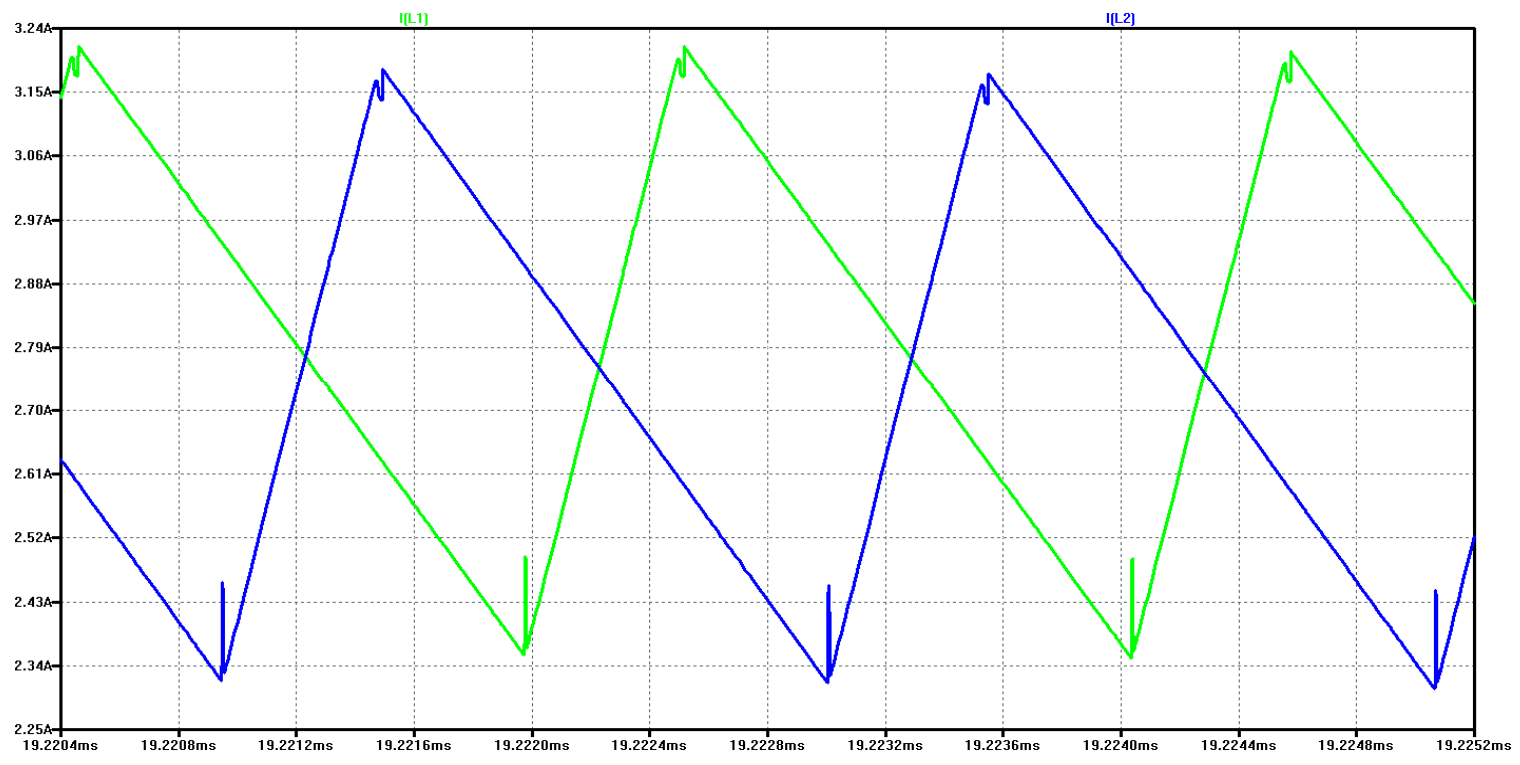

Figure 5-10: Overlay of Phase 1 and Phase 2 Inductor Current 
To be thorough it is important to check that the converter operates in continuous conduction mode through out the load range. The most susceptible condition for discontinuous conduction mode is during low load or 5\% load. At low load there is less current being drawn by the load so the average current through the inductors will drop. With the same current ripple in the inductor, if the average current drops there is a chance that the converter will enter discontinuous conduction mode. Figure 5-11 shows that the converter is actually operating in discontinuous conduction mode because the current barely drops below $0 \mathrm{~A}$. This problem can be solved by increasing the inductance of the design.

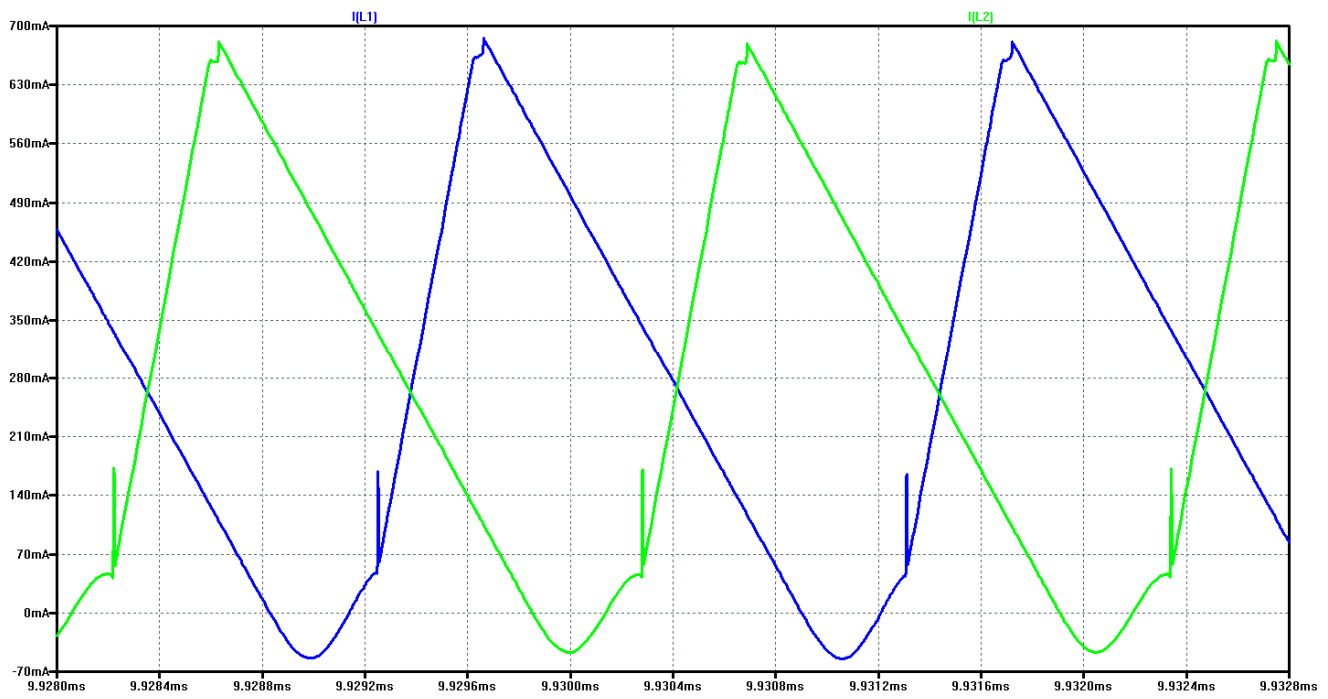

Figure 5-11: Low Load Inductor Currents

\subsection{Converter's Efficiency}

One of the main focuses in power electronics is efficiency. Board layout, temperature and component tolerances all affect the efficiency of a DC - DC converter. In the simulation those losses cannot be simulated. So it is apparent that the power 
efficiency calculations done based on the simulation result will not be accurate, yet it gives a broad sense of the efficiency of the design.

The input power in Figure 5-12 is obtained by multiplying the average input current with the average input voltage. The input power swung between - $209 \mathrm{~W}$ and $190.5 \mathrm{~W}$, the negative indicates that the source was supplying power. According to the simulation the average power supplied by the input is $197.62 \mathrm{~W}$, slightly off from the 200W specified in the requirement table.

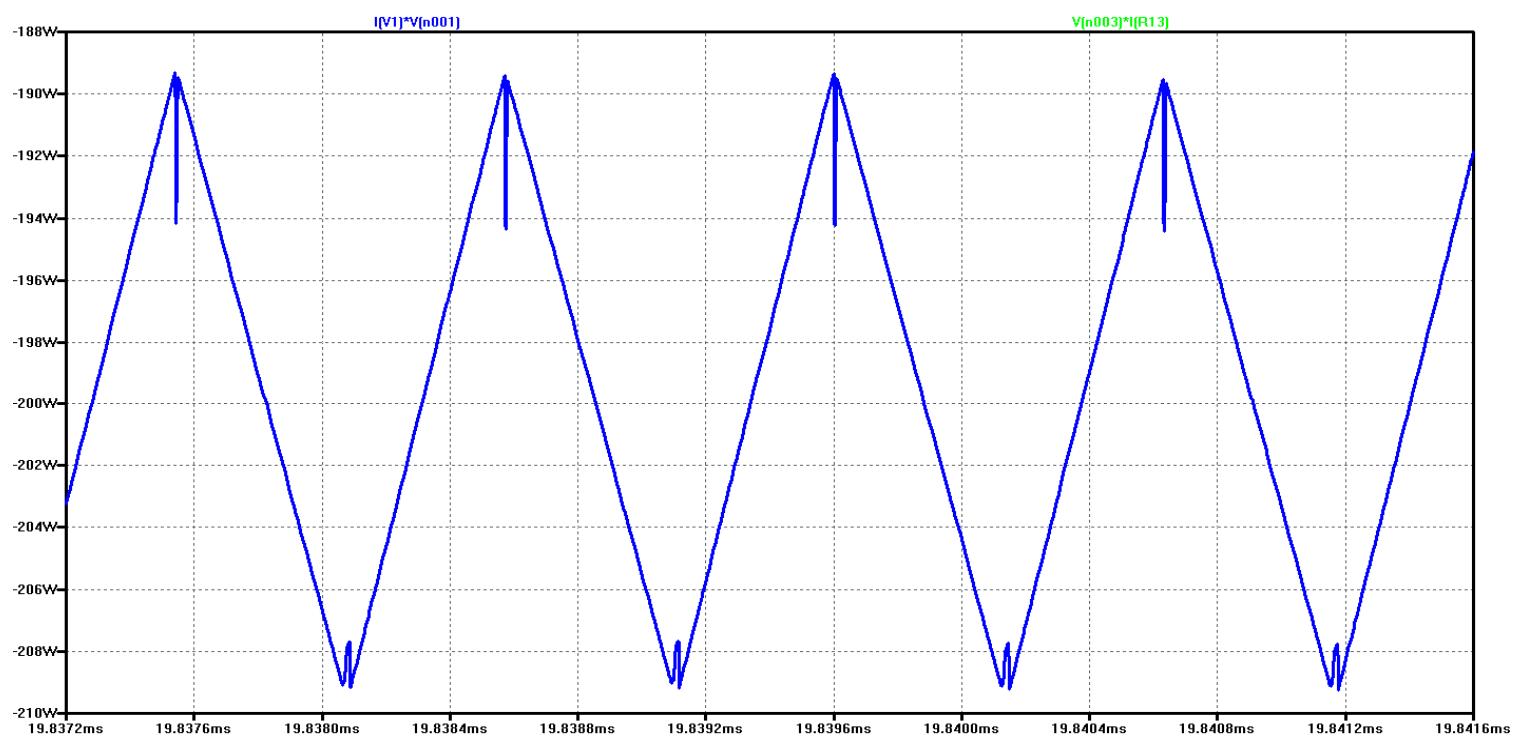

Figure 5-12: Input Power Ripple

To find the output power the same technique was used, multiply the average output current with the average output voltage. Figure 5-13 of the output power ripple shows that the output power rippled between $191.92 \mathrm{~W}$ and $191.975 \mathrm{~W}$. The simulation estimated the average to be around 191.71W. In the case of output power, the graph shows that it existed in the positive Y-axis, meaning that $191.95 \mathrm{~W}$ was being consumed by the load. 


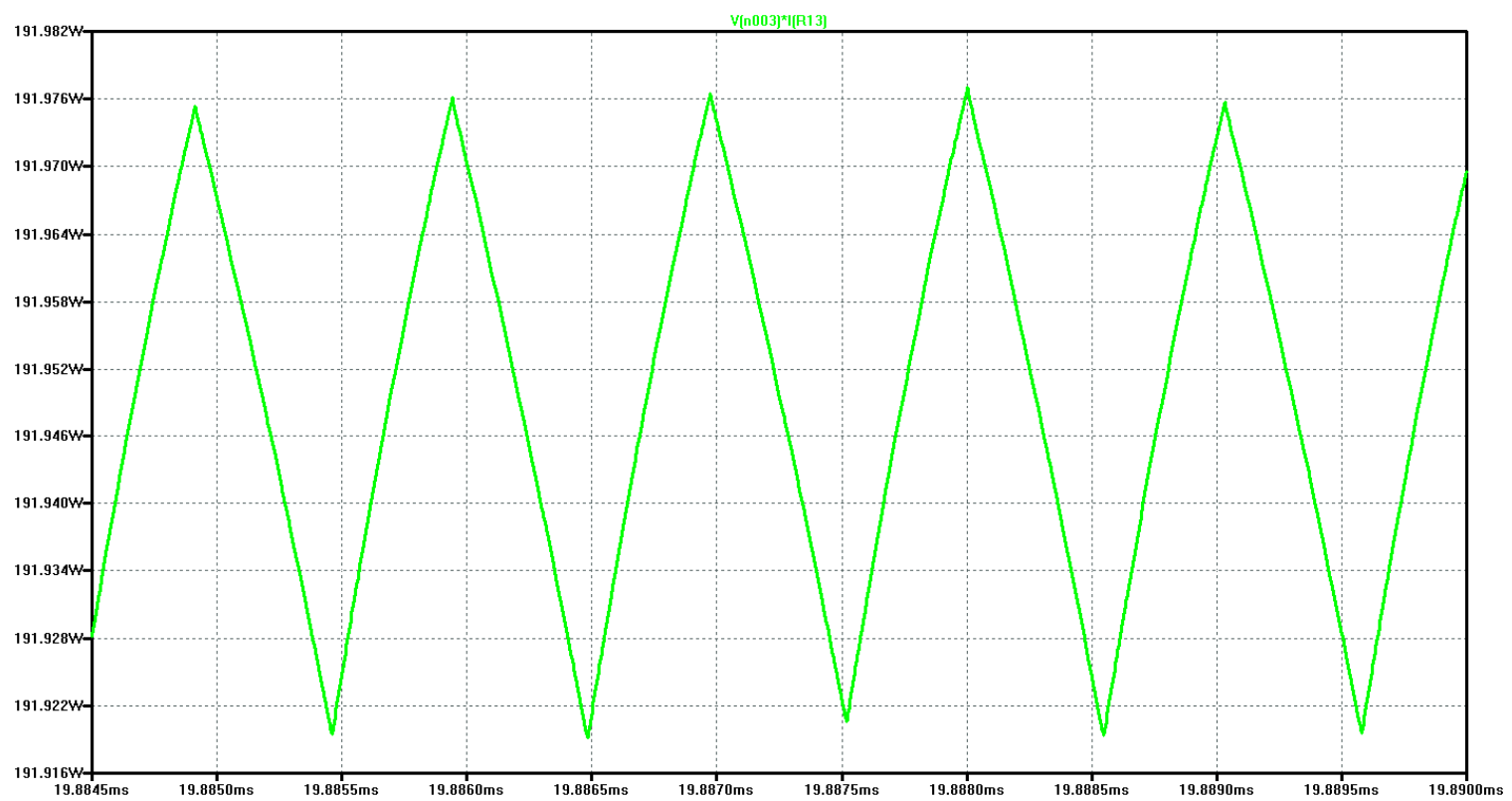

Figure 5-13: Output Power Ripple

Using the average power of both the output and input power, we can now calculate the simulated efficiency of the converter.

$$
\begin{aligned}
& \text { Efficiency }=\frac{P_{\text {out }}}{P_{\text {In }}} * 100 \%=\frac{191.71 \mathrm{~W}}{197.62 \mathrm{~W}} * 100 \% \\
& \text { Efficiency }=97.01 \%
\end{aligned}
$$

This efficiency is comparable to the simulated efficiency done by Linear Technology for a slightly different 200W Two-Phase Boost Converter. Linear Technology's design of two-phase boost with LT3782A states that it can reach $98 \%$ efficiency. However, it is not specified whether the efficiency is calculated during a full load or no load simulation. 
Table 5-1: Simulated Efficiency from 10\% - 100\% Load

\begin{tabular}{|c|c|c|c|c|c|c|c|c|}
\hline $\begin{array}{c}\text { Load } \\
{[\%]}\end{array}$ & $\begin{array}{c}\mathrm{R}_{\text {Load }} \\
{[\Omega]}\end{array}$ & $\begin{array}{l}\text { Vout } \\
\text { [V] }\end{array}$ & $\begin{array}{l}\text { lout } \\
{[A]}\end{array}$ & $\begin{array}{l}\text { Vin } \\
\text { [V] }\end{array}$ & $\operatorname{lin}_{[\mathrm{A}]}$ & $\begin{array}{c}\text { Pout } \\
\text { [W] }\end{array}$ & $\begin{array}{l}\text { Pin } \\
\text { [W] }\end{array}$ & $\begin{array}{c}\text { Efficiency } \\
{[\%]}\end{array}$ \\
\hline $10 \%$ & 120 & 47.985 & 0.399 & 36 & 0.5563 & 19.188 & 21.836 & 95.81 \\
\hline $20 \%$ & 60 & 47.98 & 0.7997 & 36 & 1.1546 & 38.369 & 41.564 & 92.31 \\
\hline $30 \%$ & 40 & 47.98 & 1.1995 & 36 & 1.6908 & 57.551 & 60.87 & 94.55 \\
\hline $40 \%$ & 30 & 47.985 & 1.5995 & 36 & 2.2589 & 76.752 & 81.319 & 94.38 \\
\hline $50 \%$ & 24 & 47.974 & 1.9989 & 36 & 2.7876 & 95.896 & 100.35 & 95.56 \\
\hline $60 \%$ & 20 & 47.976 & 2.3988 & 36 & 3.3185 & 115.09 & 119.47 & 96.33 \\
\hline $70 \%$ & 17.14 & 47.974 & 2.799 & 36 & 3.8704 & 134.28 & 139.33 & 96.38 \\
\hline $80 \%$ & 15 & 47.971 & 3.1981 & 36 & 4.417 & 153.41 & 158.93 & 96.53 \\
\hline $90 \%$ & 13.3 & 47.975 & 3.599 & 36 & 4.9597 & 172.66 & 178.55 & 96.70 \\
\hline $100 \%$ & 12 & 47.964 & 3.997 & 36 & 5.4894 & 191.71 & 197.62 & 97.01 \\
\hline
\end{tabular}

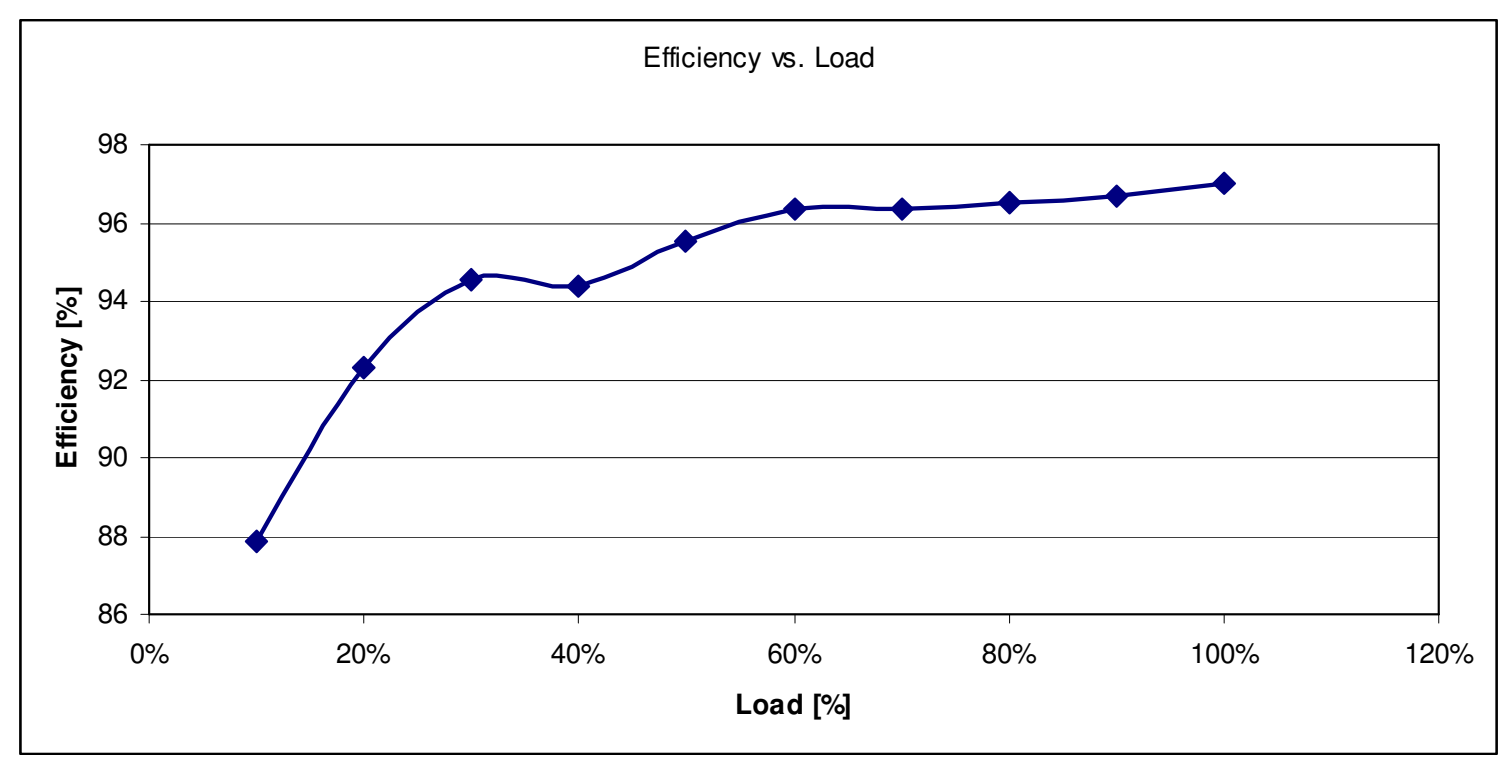

Figure 5-14: Efficiency vs. Load from Simulation 


\subsection{Load Regulation}

Load regulation refers to the ability of the converter to maintain the required output voltage with changing loads. Using Table 5-1 above the load regulation can be calculated using:

$$
\begin{aligned}
& \text { Load Regulation }=\frac{V_{O-\text { Lowload }}-V_{O-\text { Fulload }}}{V_{\text {Lowload }}} * 100 \% \\
& \text { Load Regulation }=\frac{47.985 \mathrm{~V}-47.964 \mathrm{~V}}{47.985 \mathrm{~V}} * 100 \%=0.052 \%
\end{aligned}
$$

Table 5-2: Simulated Load Regulation

\begin{tabular}{|c|c|c|}
\hline $\mathrm{V}_{\text {Lowload }}[\mathrm{V}]$ & $\mathrm{V}_{\text {Fulload }}[\mathrm{V}]$ & Load Regulation [\%] \\
\hline 47.99 & 47.964 & $0.052 \%$ \\
\hline
\end{tabular}

\subsection{Line Regulation}

Line regulation is the converter's ability to maintain the required output voltage when the input voltage fluctuates. The highest input this converter is required to handle is $38 \mathrm{~V}$ and the lowest input required is $34 \mathrm{~V}$. Table $5-3$ holds the data gathered during full load with input voltage of $34 \mathrm{~V}, 36 \mathrm{~V}$ and $38 \mathrm{~V}$. Using these data the line regulation for the simulation can be calculated to be:

$$
\begin{aligned}
& \text { Line Regulation }=\frac{V_{O-\text { highestinput }}-V_{O-\text { lowestinput }}}{V_{O-\mathrm{No} \min a l}} * 100 \% \\
& \text { Line Regulation }=\frac{47.973 \mathrm{~V}-47.965 \mathrm{~V}}{48 \mathrm{~V}} * 100 \%=0.0167 \%
\end{aligned}
$$

Table 5-3: Simulated Line Regulation

\begin{tabular}{|c|c|c|c|}
\hline $\mathrm{V}_{\text {O-Lowestinput }}[\mathrm{V}]$ & $\mathrm{V}_{\text {O-Highestinput }}[\mathrm{V}]$ & $\mathrm{V}_{\text {Nominal }}[\mathrm{V}]$ & \multicolumn{2}{|c|}{ Line Regulation [\%] } \\
\hline 47.965 & 47.973 & 48 & $0.0167 \%$ \\
\hline
\end{tabular}




\section{Hardware Design and Results}

\subsection{Hardware Components}

When creating the first prototype for the design, it was originally thought that it could have been done on a breadboard or protoboard to save money. The protoboard was the first choice because it was the cheaper of the two. After purchasing and designing the circuit for the protoboard, it was then realized that the protoboard could not easily be adapted to the small controllers. Protoboard is also a poor choice to design a high current controller, because it could not safely isolate and carry such large current. This also rules out using breadboard for the prototype for the same two reasons. The first prototype ends up being done on a double sided PCB board. It costs considerably more to prototype with a manufactured PCB, but it is a much safer and reliable choice.

The first prototype design ends up to be a reliable and correct design that only little tweaks were made to create the final board design. Compared to the first board the final design in Figure 6-1 has closer, thicker traces and larger ground plane. The large metal plate in Figure 6-1 is the ground trace for the converter. It is made specifically so that the ground traces only exist on the top of the board and close to the controller to provide good grounding and thermal conductivity. On the bottom layer there is only a few inches of ground trace to connect the remaining parts that does not fit on the top layer. The main focus of the PCB design is to separate the control nodes and switching nodes as far away as possible to reduce noise and ripple. On the top layer is where the pulse width modulator can be found. All of the control nodes are also found to the left and on the top layer of the board. To place the switching nodes as far away as possible it is designed so they are found to the right and on the bottom layer of the board. 


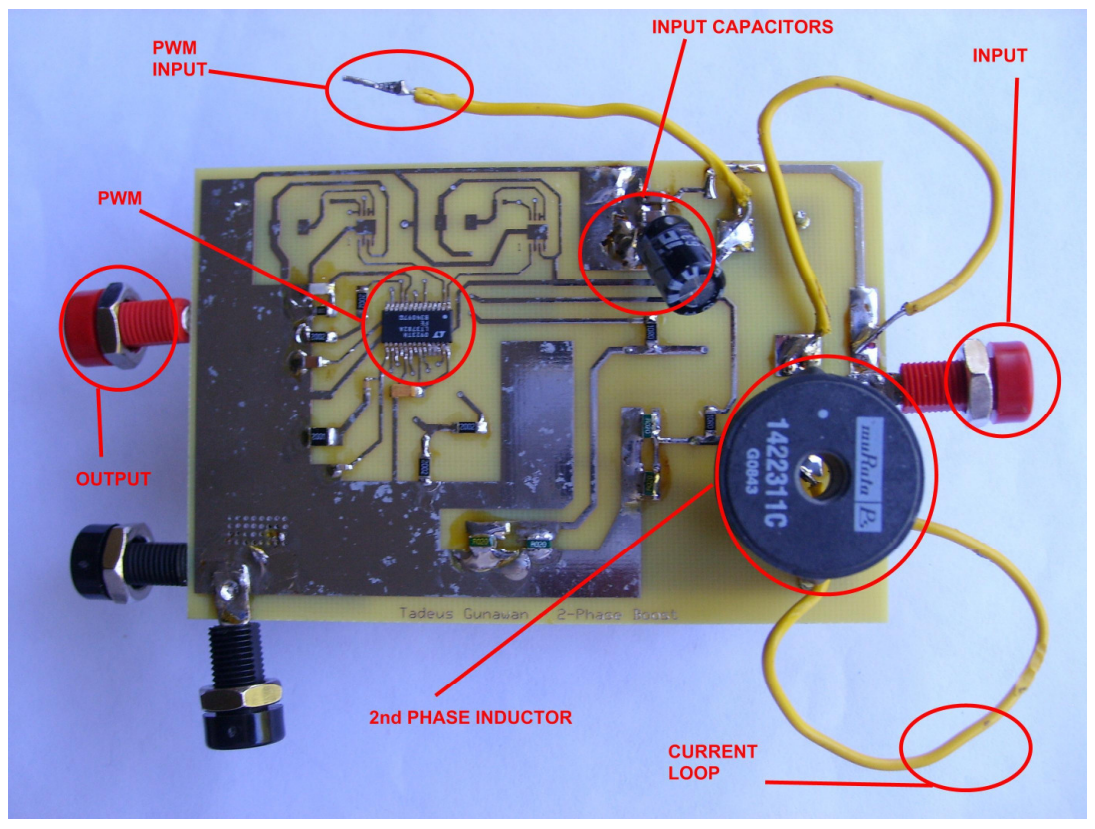

Figure 6-1: Top Layer of the Final PCB Design

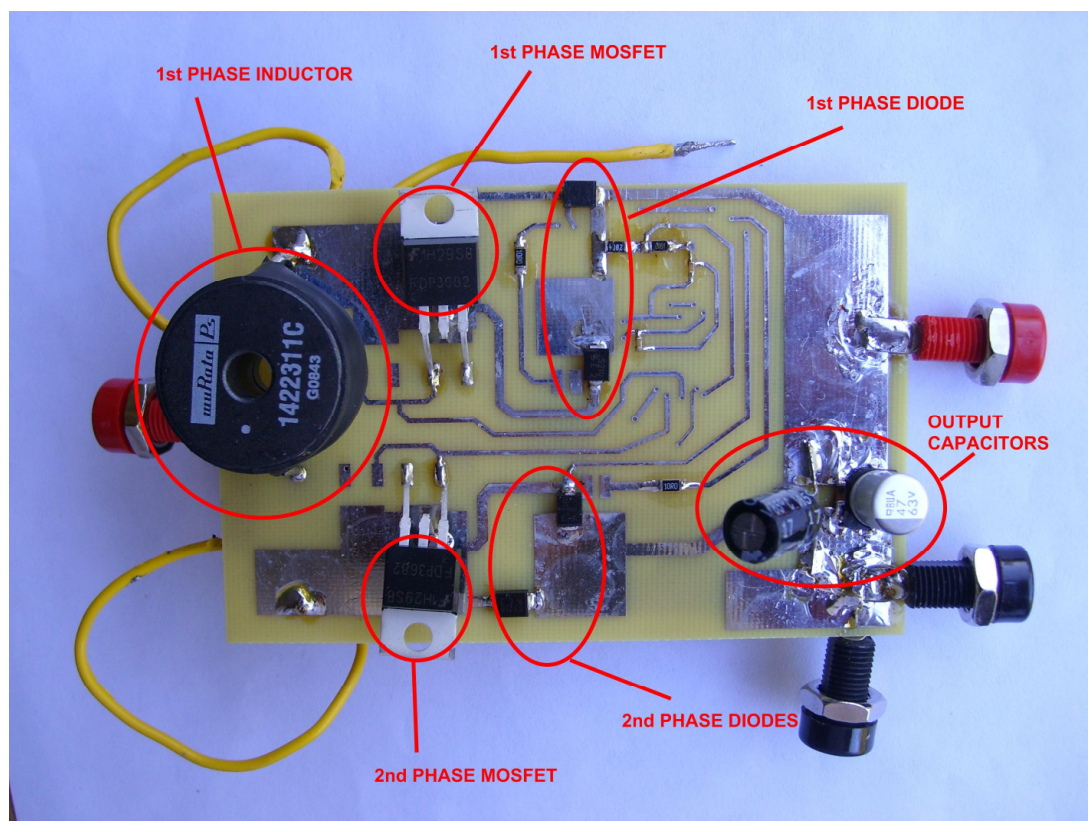

Figure 6-2: Bottom Layer of the Final PCB Design 


\section{$\underline{\text { 6.1.1 Pulse Width Modulator }}$}

A starting point for this design lies in the pulse width modulator controller, also known as PWM. This project will require one PWM controller which should be able to control the main switches with correct timing. Prominent companies such as Texas Instrument, Maxim and Linear Technology have various selections of efficient two phase controllers. After researches, a Linear Technology DC/DC controller chip, LT3782A, is chosen for the two phase boost design. It is an efficient two phase controller that also accommodates two high side drivers for synchronous rectification if need be.

The LT3782A comes in FE 28-leads plastic TSSOP packaging with the $29^{\text {th }}$ pin on the bottom to provide good thermal conduction. LT3782A has an input range between 6 volts to 40 volts which includes the desired input of 36 volts. The range of programmable switching frequency of the controller goes up to $500 \mathrm{kHz}$ which is the required speed. With the 10 volts and high current gate drive this controller could handle most of the industrial MOSFETs, which helps widen the component options for the power MOSFETs. LT3782A has other safety features for the circuit such as under voltage lockout, soft-start, current limit, DCL (Duty Cycle Limit) and slope compensation.

To set limit and program the pulse width modulator, the design merely follows the information given in the datasheet. To set the operating frequency, $40 \mathrm{k} \Omega$ is attached to pin 11 for $\mathrm{R}_{\text {SET. }}$. The value of $40 \mathrm{k} \Omega$ is determined by reading Figure 6-3 which was taken out of LT3782A datasheet. 


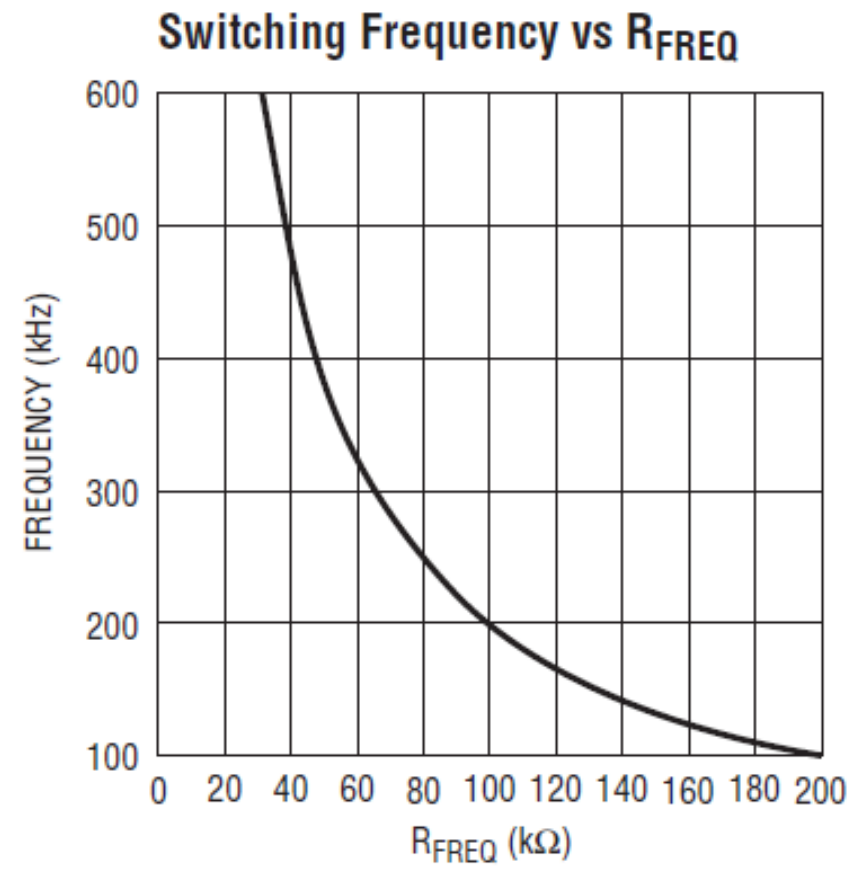

Figure 6-3: LT3782A R $\mathrm{R}_{\text {Freq }}$ vs. Frequency [7]

The soft start capacitance value is calculated from:

$$
t=\frac{C^{*} 2.44 V}{10 \mu A}
$$

Where $t$ is the typical time it takes the output to reach the programmed level. The time is set to $2.5 \mathrm{~ms}$, so the soft start capacitance comes out to be:

$$
\begin{aligned}
& C=\frac{t^{* 10 \mu A}}{2.44 V} \\
& C=\frac{2.5 m s^{*} 10 \mu A}{2.44 V}=10.25 p F
\end{aligned}
$$

The soft start capacitor is chosen to be $10 \mathrm{pF}$ and it is attached to pin 14 . The other resistor values and capacitors are set according to the recommended value stated in the datasheet. 


\section{$\underline{6.1 .2 \text { Inductor }}$}

Using the calculated values above and taking into accounts the inductor requirements, Murata high current $1422311 \mathrm{C}$ inductor is the perfect candidate. It has an inductance of $22 \mu \mathrm{H}$, maximum rms current rating 11 Amps, maximum resistance of 11 $\mu \Omega$ and self-resonance frequency of $9.3 \mathrm{MHz}$. It has larger inductance than the calculated value to provide cushion against inductance drop due to thermal and frequency during normal operation. The power loss through the inductor winding can be calculated by:

$$
\begin{aligned}
& P_{\text {Winding }}=\left(\frac{\frac{I_{O(\operatorname{Max})}}{2}}{1-D_{\text {Max }}}\right)^{2} * R_{W} \\
& P_{\text {Winding }}=\left(\frac{\frac{4.167 A}{2}}{1-0.25}\right)^{2} * 11 \mu \Omega=84.89 \mu \text { Watts }
\end{aligned}
$$

\section{$\underline{\text { 6.1.3 MOSFET }}$}

The MOSFET chosen for the hardware prototype is a power MOSFET by Fairchild Semiconductor FDP3682. The FDP3682 model has exactly the same parameters and rated power dissipation as FDD3682, analyzed in section 4.5. It has maximum $\mathrm{V}_{\mathrm{DS}}$ of $100 \mathrm{~V}$ and maximum forward current rating of $32 \mathrm{~A}$. They merely differ in the packaging; FDP3682 has TO-220 packaging whereas FDD3682 has TO-252 packaging. FDP3682 is chosen for the final hardware because it offers better heat dissipation compared to its surface mount counterpart. TO-220 has an option that allows a heat sink to be attached to the back of the MOSFET. 


\section{$\underline{\text { 6.1.4 Schottky Diode }}$}

To increase efficiency a schottky diode is used for output stage of each phase. With a fast diode more power could be transferred to the output from the converter

during the discharging time of the inductor. SS210 Multicomp schottky diode is an ideal choice with its maximum forward current of $2 \mathrm{~A}$ with maximum reverse voltage of $100 \mathrm{~V}$. The power loss of each diode can be approximated through:

$$
\begin{aligned}
& P_{\text {Diode }}=\frac{I_{O-\max }}{2} * V_{D} \\
& P_{\text {Diode }}=\frac{4.167 \mathrm{~A}}{2} * 0.85 \mathrm{~V}=1.77 \text { Watts }
\end{aligned}
$$

\section{$\underline{6.1 .5 \text { Input and Output Capacitors }}$}

There are two types of capacitors being used in both the input and output filter, ceramic and electrolytic capacitors. Ceramic capacitors are known to have low ESR, so they are ideal for filtering high frequency noises. The electrolytic capacitors, on the other hand, have higher ESR value and capacitance, which are ideal for energy storage. To grain the benefit of both the ceramic and electrolytic capacitors, they are placed in parallel. This increases the total capacitance, granting the filter a higher energy storage capacity to decrease the input and output voltage ripple. At the same time the total ESR of the filter decreases, decreasing total power loss from the filter.

For safety purposes and reliability, the current and voltage ratings on the chosen capacitors are about double of the values found in Section 4.3 and 4.4. The input capacitors have maximum voltage rating of at least $63 \mathrm{~V}$. The output capacitors have maximum voltage rating of at least $100 \mathrm{~V}$. 


\subsection{Final Hardware Design}

In the final hardware design, two SS210 Schottky diodes are used in parallel for each phase. The objectives are two-folds. First at full load each phase carries a maximum current around 2.1A, larger than the rated maximum forward current of the SS210 Schottky diodes. This, by having two diodes in parallel in each phase, the amount of current is now down to $1.05 \mathrm{~A}$ per diode. Secondly, the decrease in current per diode also means reduced power loss, hence increasing the overall efficiency of the converter. The power loss in each of the diode is now half of that calculated in section 6.1.4. The new power lost in each diode would approximately be $0.885 \mathrm{~W}$.

The schematic and layout designs were done using Express PCB Schematic and Express PCB Layout. Both programs are free software developed and distributed by Express PCB. Both the schematic and layout program are linked together to simplify the board design process. First the schematic is drawn according to the specification of the converter. Next, Express PCB Layout allows the users to link the footprints for each part in the schematic to their footprint database. It also has the flexibility to allow the users to create custom footprints for any irregular parts. By linking the schematic to the layout, the programs guide the user during the layout connection process, minimizing the chance of mistake in the final PCB board layout.

To reduce noise and feedback interference the control node and the switching node of the converter needs to be separated. To isolate the switching node from the control node the final design of the board is a double sided PCB as shown in Figure 6-1 and 6-2. The top layer holds the control node and input signals whereas the bottom layer holds the switching node and the output signals. 


\subsection{Hardware Results and Analysis}

During the hardware test, it is decided that the pulse width modulator's input should be separated from the input power. With this, it is possible to monitor if the chip has been damaged during the test. If the chip does burn out, the voltage drawn by the chip will drop and it will instead draw a large current from the power supply. If the power supplies are turned off as soon as any anomalies are observed, it helps prevent any damage from being done to the whole converter. This also works vice versa for the chip, were there any disturbance to the converter's input it helps to protect the costly pulse width modulator. Another benefit from this technique is the ability to monitor the power dissipated from the chip throughout the test.

The plots and calculations analyzed are all done during full load test. During a full load test the converter is operating at its maximum rated current of $4.2 \mathrm{~A}$ and rated input voltage of $36 \mathrm{~V}$. A nearly constant $200 \mathrm{~W}$ of power flows through the board, creating a great condition to analyze the design's capabilities and limits. Through out this section, phase 1 and 2 are merely arbitrary notations to distinguish data gathered from the two phases. For the sake of consistency and accuracy, phase 1 and 2 will always represent the same path through out the analysis.

\section{$\underline{\text { 6.3.1 Output Voltage Ripple }}$}

Figure 6-4 displays the output voltage ripple during a full load test. The ripple height is about 2.5 divisions with $1 \mathrm{~V} /$ division setting, resulting in $2.68 \mathrm{~V}$ peak-to-peak ripple measured using the oscilloscope. With an output voltage rated at $42.545 \mathrm{~V}$ during full load, from Table 6-1, the output voltage ripple could be calculated to be $6.3 \%$ 
Compared to the required $1 \%$ output voltage ripple this converter performs outside the parameter.

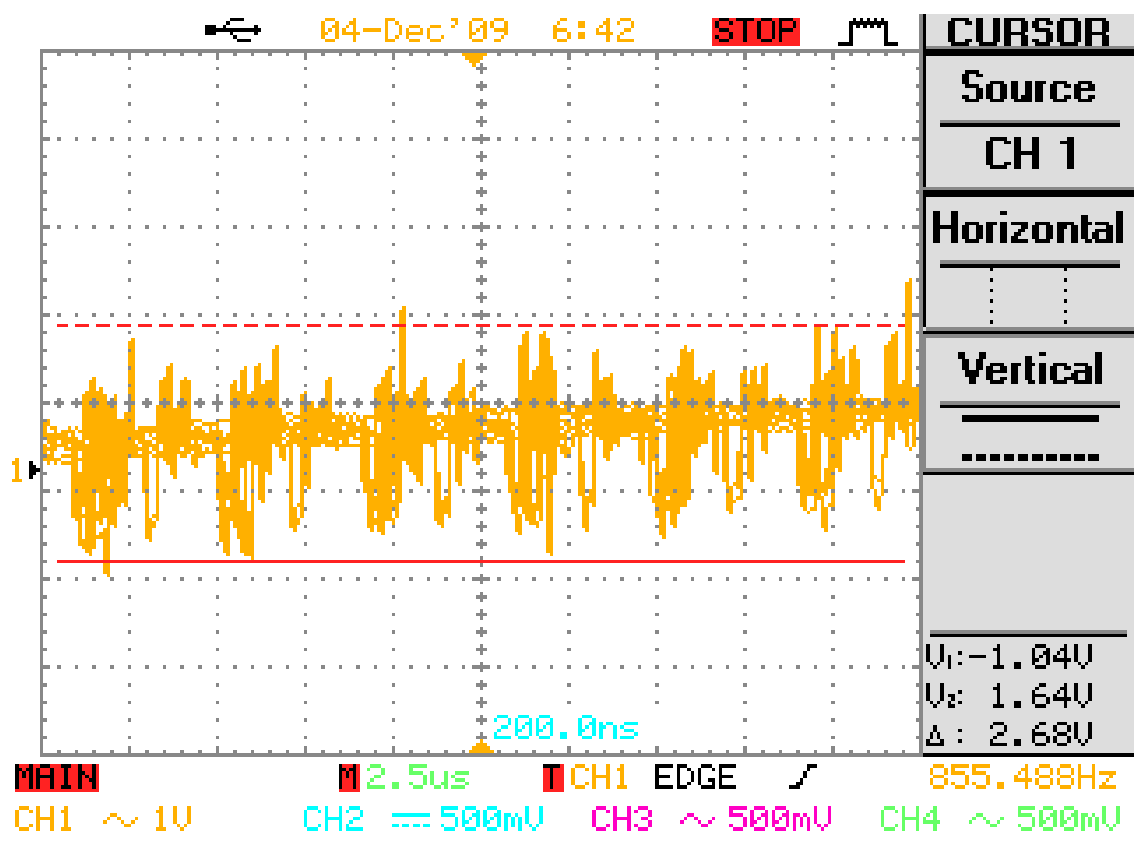

Figure 6-4: Output Voltage Ripple

It is apparent that the output voltage level is well below the required parameter of $48 \mathrm{~V}$.

Discussions and troubleshooting techniques for this issue will be covered in Section 6.4.

\subsubsection{Switching Signal}

To drive the power MOSFETs the pulse width modulator sends out two switching signals, one for each phase. Using the LT3782A datasheet, the switching signal has been programmed to operate at $500 \mathrm{KHz}$ per phase at $25 \%$ duty cycle. The switching signal can be observed by placing the scope probe on pin 20 and 23 of the pulse width modulator [7]. Figure 6-5 is taken from pin 23 which drives the MOSFET in the path that has been considered as "phase 1" in this section. The signals heights in the oscilloscope reading are approximately at 2.5 divisions at $5 \mathrm{~V} /$ division. Multiplying the two values out gives the signal strength to be around $12.5 \mathrm{~V}$, enough to drive the $10 \mathrm{~V}$ gate drive required by 
FDP3682. Horizontally, the graph is rated at 500ns/division with a full cycle of the switching signal being approximately 4.2 divisions, $2.1 \mathrm{~ms}$ in length. The signal itself lasted for 1 division which is $500 \mathrm{~ns}$ long. At $2.1 \mathrm{~ms}$ period the duty cycle of the first phase is calculated to be $25 \%$ and measured to be $23.81 \%$ by the oscilloscope. The operating frequency of the first phase can then be calculated as the following:

$$
\begin{aligned}
& \text { Freq }_{\text {phase } 1}=\frac{1}{\text { Period }_{\text {Phase } 1}} \\
& \text { Freq }_{\text {phase } 1}=\frac{1}{2.1 \mathrm{~ms}}=476.2 \mathrm{kHz}
\end{aligned}
$$

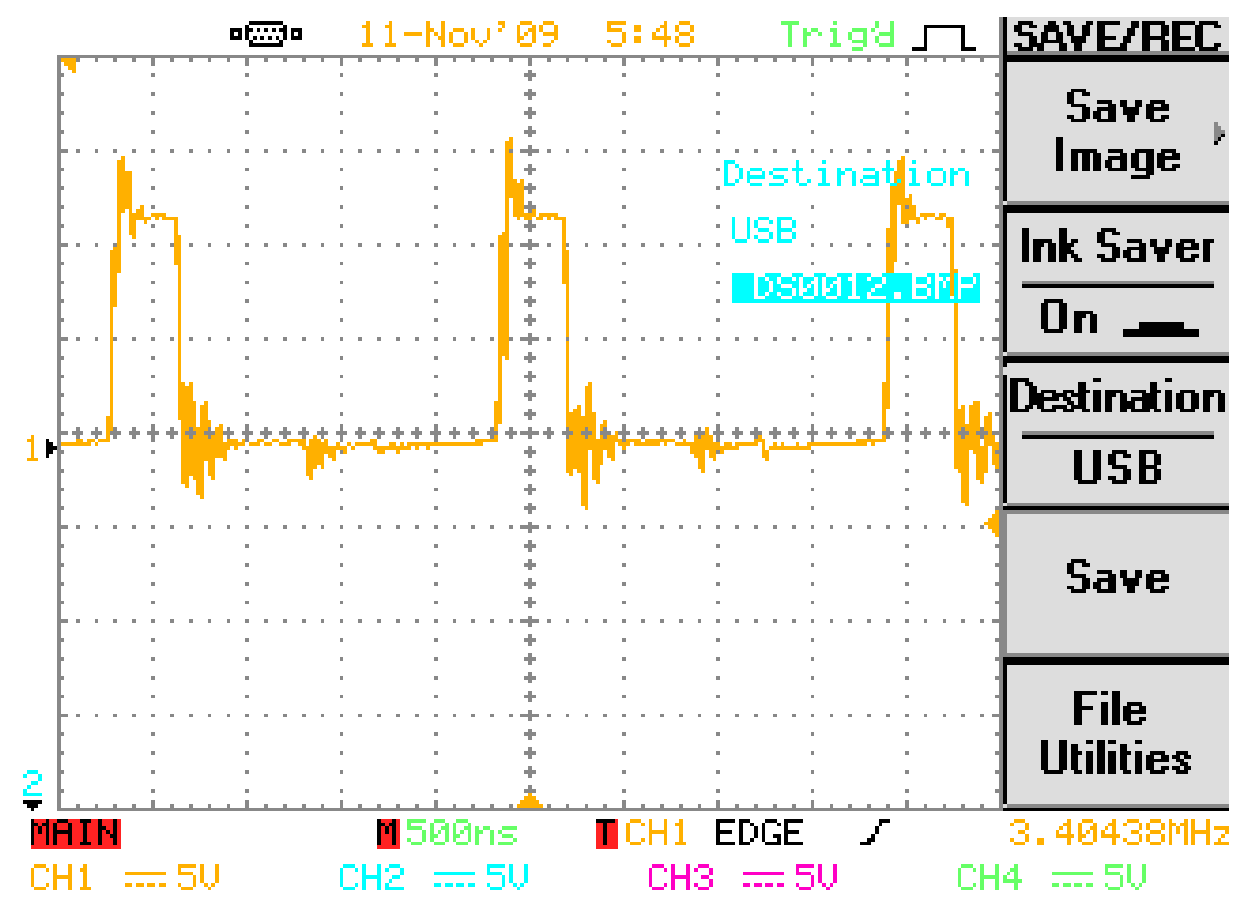

Figure 6-5: Phase 1 Duty Cycle

Switching the scope probe to pin 23 of the pulse width modulator allows the oscilloscope to capture Figure 6-6. Approximating with the noise the signal strength is about 2.25 divisions. The vertical scale of this graph is still at $5 \mathrm{~V} /$ division resulting in signal strength of $11.25 \mathrm{~V}$ which is still enough to drive the FDP3682 power MOSFET. 
For the signal to complete a full cycle it takes 4 divisions at 500ns/division. Multiplying the two values gives the period of the signal which is $2 \mathrm{~ms}$. The signal itself lasts for about 0.75 divisions or $375 \mathrm{~ns}$; the duty cycle is calculated to be about $25 \%$ and measured to be $18.75 \%$ by the oscilloscope. The calculated and measure duty cycle for the second phase differs extremely due to noise in the switching signals. Figure 6-6 and 6-7 show that the duty cycle of the second phase does last for approximately a quarter of each period, but notice that the peak of the signals has a lot of noise. The noise reduces the switching signals height to below $10 \mathrm{~V}$ which is less than the gate turn on voltage. This will reduce the duty cycle and disturb the output voltage level. The operating frequency of the second phase is calculated to be:

$$
\begin{aligned}
& \text { Freq }_{\text {Phase } 2}=\frac{1}{\text { Period }_{\text {Phase } 2}} \\
& \text { Freq }_{\text {Phase } 2}=\frac{1}{2 m s}=500 \mathrm{kHz}
\end{aligned}
$$

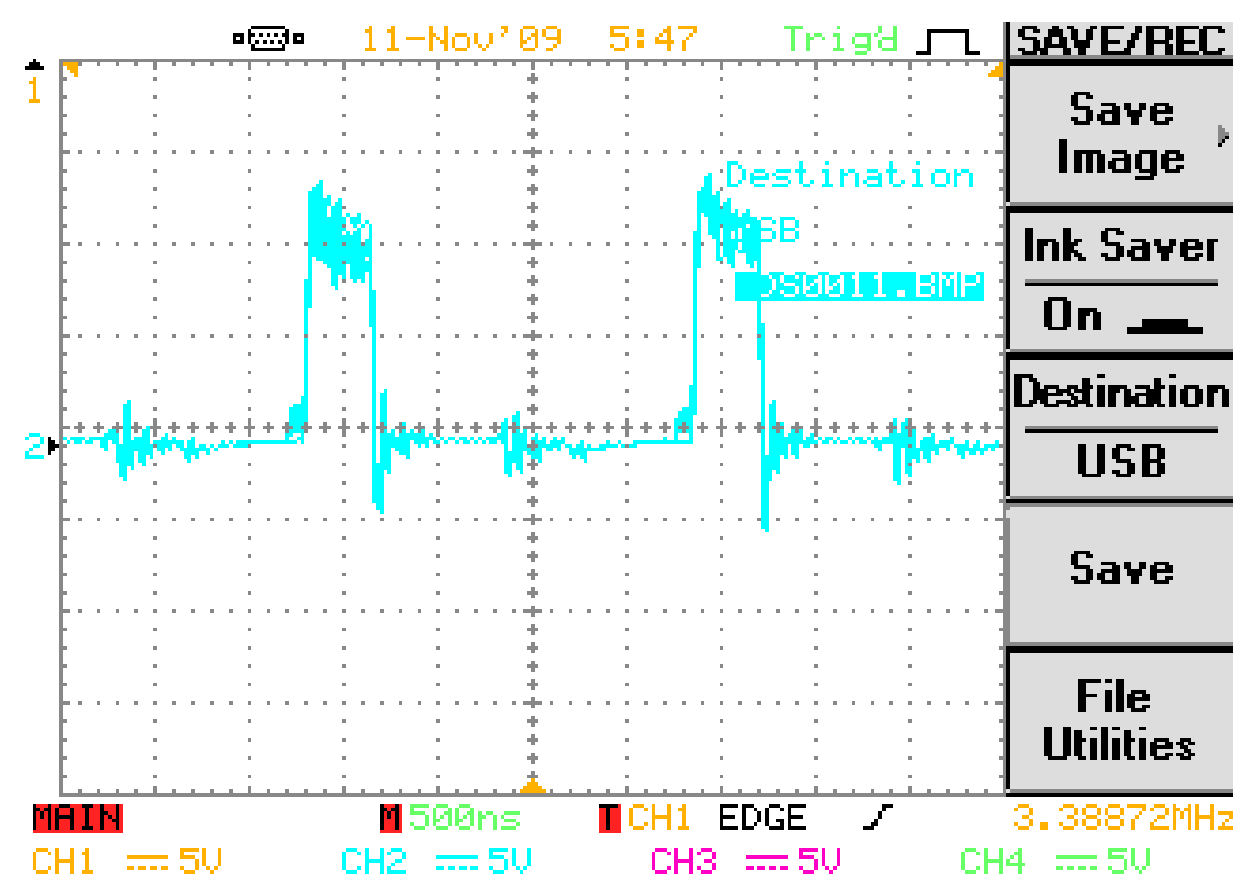

Figure 6-6: Phase 2 Duty Cycle 
To increase efficiency, a two-phase pulse width modulator phase shifts one of its signal by $180^{\circ}$. To prove the two switching signals turns on alternately, start by superimposing Figure 6-5 and Figure 6-6 resulting in Figure 6-7. Phase 2 switching is shifted by about 2 divisions from phase 1 and vice versa. This creates $1 \mathrm{~ms}$, or half a period shift, which can be translated to be $180^{\circ}$ phase shift. The period of the new waveform is about 2.1 divisions at 500ns/division, about $1.05 \mathrm{~ms}$. The overlaid signal frequency is the operating frequency seen by the input and output of the converter. The new frequency can be calculated using the new period through the following equation:

$$
\begin{aligned}
& \text { Freq }_{\text {new }}=\frac{1}{\text { Period }_{\text {new }}} \\
& \text { Freq }_{\text {new }}=\frac{1}{1.05 \mathrm{~ms}}=952.4 \mathrm{kHz}
\end{aligned}
$$

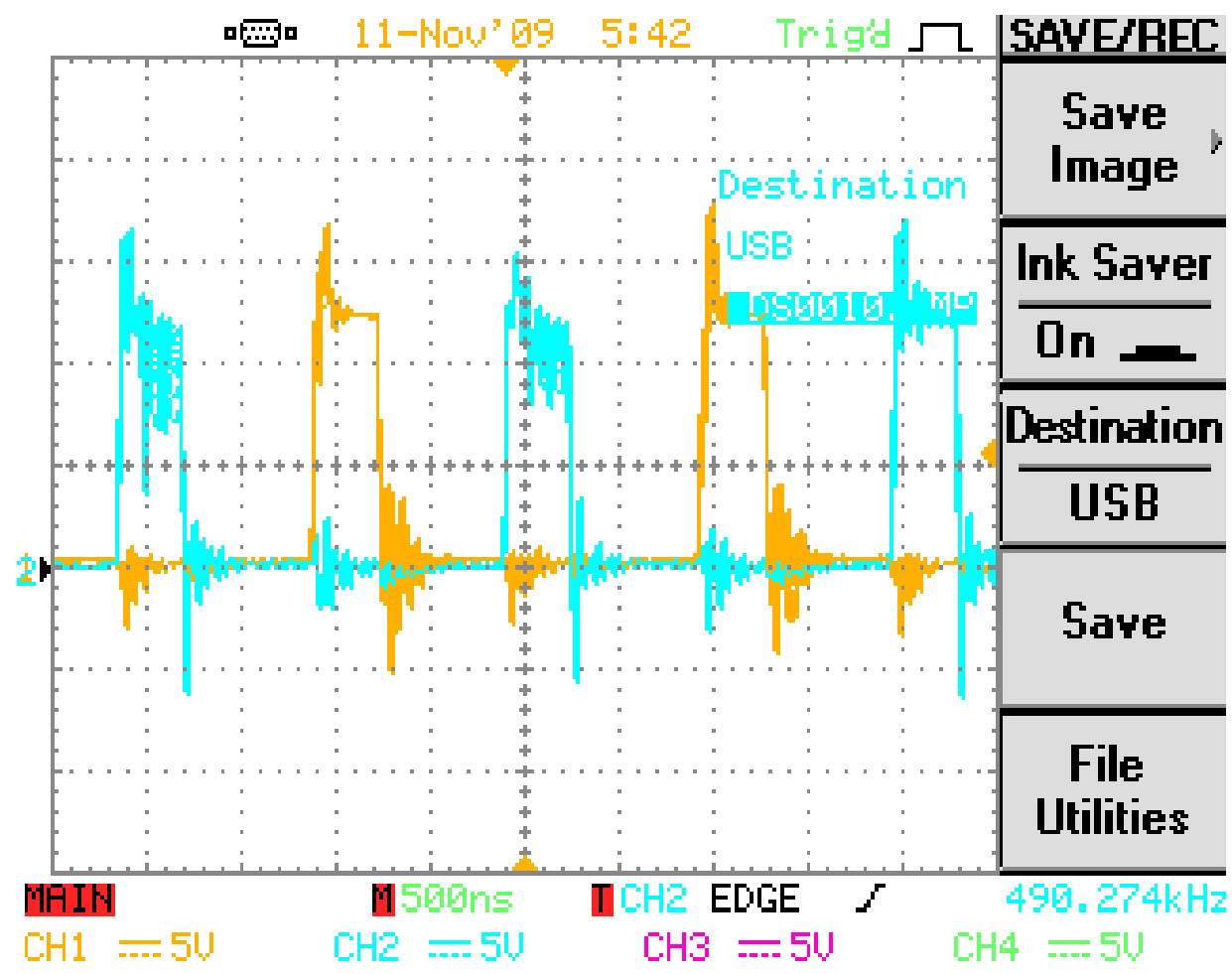

Figure 6-7: Overlaid Duty Cycle 


\subsubsection{Inductor Current Ripple}

One of the requirements for the two-phase boost is that both phases need to operate in continuous conduction mode. To determine the mode of operation for both inductors a current loop is placed between the input plane and each of the inductors. Figure 6-8 is the captured inductor current waveform from the first phase using the current probe. The peak-to-peak ripple of the first phase current is approximately 2 divisions. With the setting of $50 \mathrm{mV} /$ divison on the oscilloscope and $0.1 \mathrm{~A} / 10 \mathrm{mV}$ on the current probe, the first phase inductor current has a ripple of 1A. Figure 6-8 also shows that the first phase is operating in continuous conduction mode during full load. The period of a full cycle in phase 1 takes an approximate 2 division lengths at $1 \mu$ s/division which is $2 \mathrm{~ms}$. Using the period, the frequency of the first phase comes out to be:

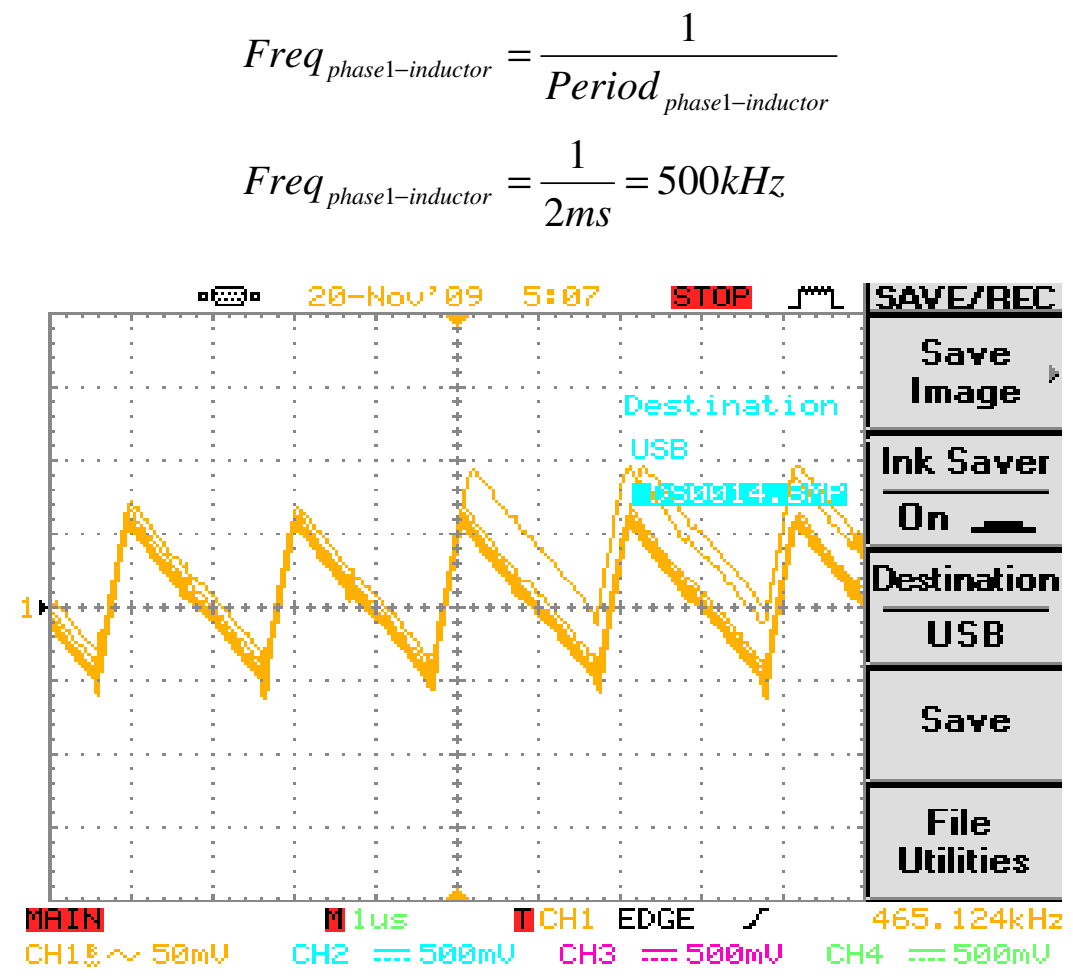

Figure 6-8: First Phase Inductor Current 
Figure 6-9 is the captured waveform of the inductor current in the second phase. The peak-to-peak ripple of this current is noticeable smaller, around 0.5 divisions. This measurement is taken using the same vertical axis settings as the first phase. Thus, using the same conversion rates the ripples come out to be $0.05 \mathrm{~A}$. The difference in the current ripple can be traced to the noise found in the switching signal in phase 2 (see Section 6.3.2.) Notice in section 6.3 .2 that the duty cycle of the second phase is about $18.75 \%$ whereas the ideal duty cycle is $25 \%$. A shorter effective duty cycle, as mentioned in section 2.1, decreases the amount of time the inductor is allowed to store up energy from the input. With a constant voltage drop across the inductor, the shorter duty cycle will drop the amount of current being charged in the inductor. Hence, the smaller inductor current ripples seen in Figure 6-9.

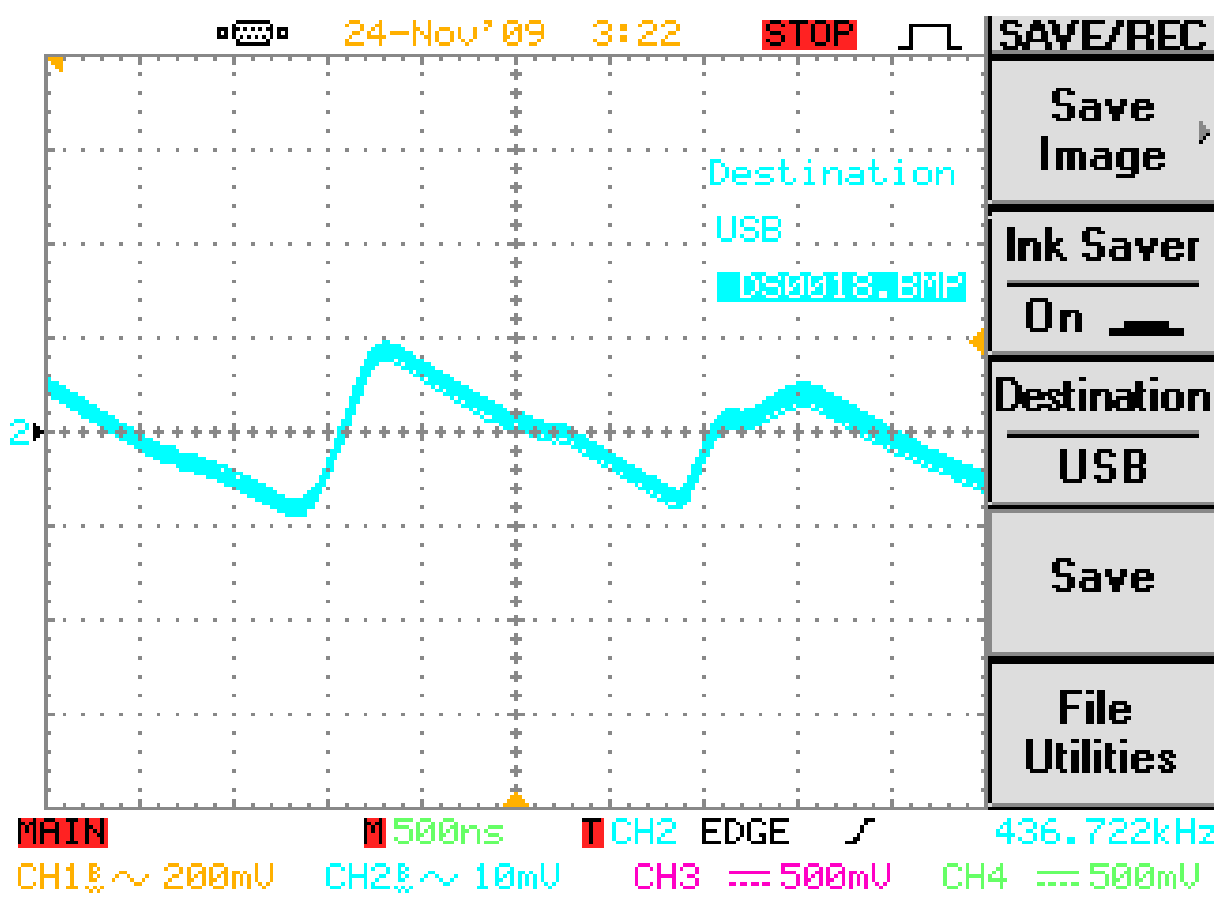

Figure 6-9: Second Phase Inductor Current 
The period of the second phase inductor current is slightly larger than phase 1 at 4.2 divisions, $500 \mathrm{~ns}$ /division scale. With $2.2 \mathrm{~ms}$ period, the frequency of the second phase inductor current is:

$$
\begin{aligned}
& \text { Freq }_{\text {Phase 2-Inductor }}=\frac{1}{\text { Period }_{\text {Phase 2-Inuductor }}} \\
& \text { Freq }_{\text {Phase 2-Inductor }}=\frac{1}{2.2 \mathrm{~ms}}=454.5 \mathrm{kHz}
\end{aligned}
$$

Like the switching signals, section 6.3.2, when the inductor currents are superimposed it will show the frequency and phase shift seen by the input. It was predicted that because of the staggered switching signals of the pulse width modulator the input and output of the converter will see an operating frequency of $1 \mathrm{MHz}$. Finding the new period in Figure 6-10 gives a period of about 1.05ms, 2.1 divisions at 500ns/division.

$$
\begin{aligned}
& \text { Freq }_{\text {new }}=\frac{1}{\text { Period }_{\text {new }}} \\
& \text { Freq }_{\text {new }}=\frac{1}{1.05 \mathrm{~ms}}=952.4 \mathrm{kHz}
\end{aligned}
$$

The doubling in frequency also means that the new waveform is a combination of two waveforms where they are shifted by $180^{\circ}$ from each other. The requirement also stated that the converter must operate in the continuous conduction mode. In continuous conduction mode the lowest peak of the inductor current ripple is larger than 0A. Figure 6-10 shows that both phases are indeed operating in continuous conduction mode from the triangular shape of the current. Notice that the currents are able to hit the bottom peak without being clipped at $0 \mathrm{~A}$, just like the example graph in Figure 2-7. 


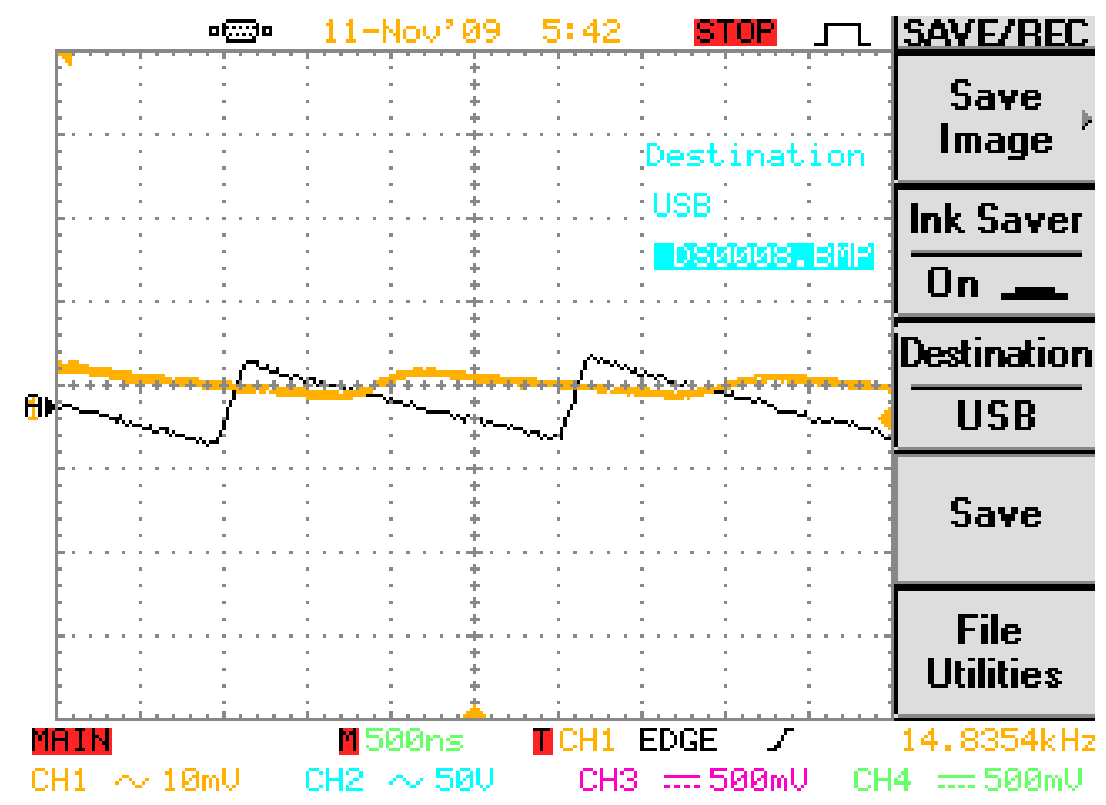

Figure 6-10: Overlaid Inductor Current

\subsubsection{Current Sense}

Each phase has current sense resistors connected to an RC filter as a current mode control. This control is connected to the source pin of the power MOSFET to allow the pulse width modulator to monitor the current going through the MOSFET during operation. In this design the two $20 \mathrm{~m} \Omega$ resistors in parallel act as the current sense resistor. Figure 6-11 shows the voltage across the current sense resistors. With $500 \mathrm{mv} /$ division scale, the current through the resistors in the first phase starts to swing from about $750 \mathrm{mV}$ and $-1 \mathrm{~V}$ and settles around $500 \mathrm{mV}$. The same figure can seen on the second phase's current sense resistors as seen is Figure 6-12. For the second phase, the voltage through the resistors swings between $500 \mathrm{mV}$ and $-500 \mathrm{mV}$. 


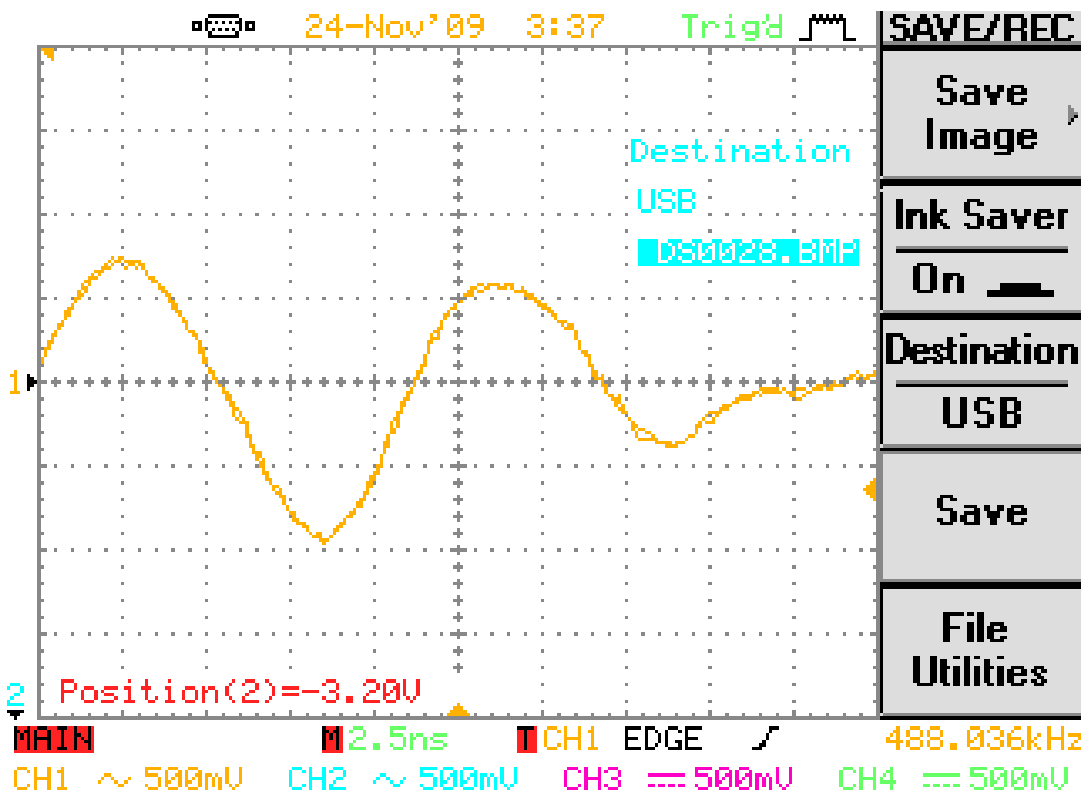

Figure 6-11: Phase 1 Current Sense Waveform

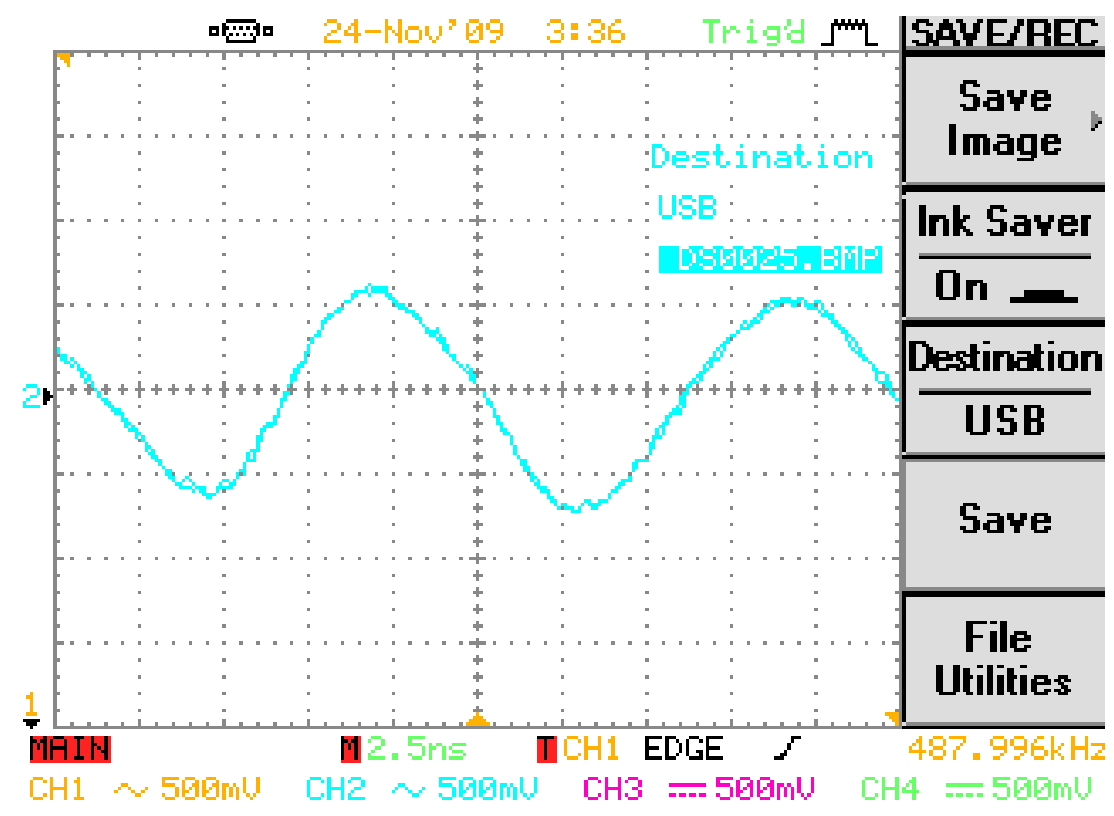

Figure 6-12: Phase 2 Current Sense Waveform 


\section{$\underline{\text { 6.3.5 Load Test Results }}$}

The first test done on the converter is a no load test. During no load test the output pins are left open with only a multimeter connected to them. No load test exerts the least amount of stress on the converter because it pulls a miniscule amount of current. Hence, during no load test the output current and input current are read as $0 \mathrm{~A}$ by the multimeter. The output voltage during no load test comes out to be $47.985 \mathrm{~V}$. With the unreliable current readings it is impossible to calculate the efficiency of the converter during no load condition.

The load data covers from $10 \%$ to full load with $10 \%$ steps. Due to the large power rating of the converter, resistor box cannot be used as the load. Instead, electronic load is used to simulate load at the output end of the converter. Table 6-1 shows a compilation of the signals measured and calculated during the load tests. The values of $\mathrm{V}_{\text {Out }}, \mathrm{I}_{\text {Out }}, \mathrm{V}_{\text {In }}$ and $\mathrm{I}_{\text {in }}$ are measured through the multimeters. Both input and output powers are calculated by multiplying the voltage and current measured through respective ports. The output powers are determined from $\mathrm{V}_{\text {Out }}$ and $\mathrm{I}_{\text {Out }}$ from each load steps. To calculate the total input powers, the total sum of the input power to the board and the input power to the chip is considered. The powers supplied to the board are calculated using $\mathrm{V}_{\text {In }}$ and $\mathrm{I}_{\text {in }}$ from each load steps. The values of $\mathrm{P}_{\text {Chip }}$ are calculated by multiplying voltage and current supplied to the pulse width modulator. During no load test the chip pulls $11.9 \mathrm{~V}$ and a miniscule amount of current which is interpreted as $0 \mathrm{~A}$ by the multimeter, resulting in an incalculable $\mathrm{P}_{\text {Chip. }}$ Starting from $10 \%$ to full load the pulse width modulator pulls a constant $0.05 \mathrm{~A}$ and $11.9 \mathrm{~V}$. Calculating $\mathrm{P}_{\text {Chip }}$ for all the load steps gives a constant value of $0.595 \mathrm{~W}$ being supplied to the pulse width modulator. 
Table 6-1: Hardware Efficiency from 10\%-100\% Load

\begin{tabular}{|c|c|c|c|c|c|c|c|c|c|}
\hline $\begin{array}{c}\text { Load } \\
{[\%]}\end{array}$ & $\begin{array}{l}\text { Vout } \\
\text { [V] }\end{array}$ & $\begin{array}{l}\text { lout } \\
{[A]}\end{array}$ & $\begin{array}{l}\text { Vin } \\
\text { [V] }\end{array}$ & $\begin{array}{l}\operatorname{lin} \\
{[\mathrm{A}]}\end{array}$ & $\begin{array}{l}\text { Pout } \\
\text { [W] }\end{array}$ & $\begin{array}{l}\text { Pchip } \\
\text { [W] }\end{array}$ & $\begin{array}{c}\text { Pboard } \\
\text { [W] }\end{array}$ & $\begin{array}{l}\text { Pin } \\
{[W]}\end{array}$ & $\begin{array}{c}\text { Efficiency } \\
{[\%]}\end{array}$ \\
\hline $5 \%$ & 43.46 & 0.2 & 36 & 0.249 & 8.692 & 0.595 & 8.97 & 9.56 & 90.93 \\
\hline $10 \%$ & 43.03 & 0.412 & 35.95 & 0.524 & 17.73 & 0.595 & 18.84 & 19.43 & 91.23 \\
\hline $20 \%$ & 43.05 & 0.76 & 35.98 & 0.934 & 32.72 & 0.595 & 33.61 & 34.20 & 95.67 \\
\hline $30 \%$ & 43.119 & 1.17 & 36.09 & 1.421 & 50.45 & 0.595 & 51.28 & 51.88 & 97.24 \\
\hline $40 \%$ & 42.707 & 1.627 & 35.95 & 1.975 & 69.48 & 0.595 & 70.99 & 71.59 & 97.06 \\
\hline $50 \%$ & 42.665 & 2.065 & 36.01 & 2.511 & 88.10 & 0.595 & 90.42 & 91.02 & 96.80 \\
\hline $60 \%$ & 42.592 & 2.36 & 35.99 & 2.852 & 100.52 & 0.595 & 102.66 & 103.26 & 97.35 \\
\hline $70 \%$ & 42.612 & 2.76 & 36.00 & 3.341 & 117.61 & 0.595 & 120.28 & 120.88 & 97.30 \\
\hline $80 \%$ & 42.622 & 3.16 & 36.01 & 3.822 & 134.69 & 0.595 & 137.63 & 138.23 & 97.44 \\
\hline $90 \%$ & 42.63 & 3.56 & 36.01 & 4.312 & 151.76 & 0.595 & 155.28 & 155.87 & 97.36 \\
\hline $100 \%$ & 42.545 & 4.16 & 36.01 & 5.053 & 176.99 & 0.595 & 181.96 & 182.55 & 96.95 \\
\hline
\end{tabular}

The efficiencies listed in Table 6-1 are calculated using the equation shown in the sample calculation below:

$$
\begin{aligned}
& \text { Efficiency }_{\text {Fulload }}=\frac{P_{\text {out }}}{P_{\text {In }}} * 100 \% \\
& \text { Efficiency }_{\text {Fullload }}=\frac{181.96}{182.55} * 100 \%=96.95 \%
\end{aligned}
$$

Compared to the simulated full load efficiency, the values are almost identical. The hardware efficiency is $0.06 \%$ lower than the simulated efficiency, but it is above the required $90 \%$ or better efficiency. Compared with those available in the market, single phase boost converter boasts around 95\%-97\% efficiency. To compare against other twophase boost, this design is comparable to the Linear Technology's two-phase boost design with $98 \%$ efficiency. This design can probably match or be more efficient than the Linear Technology design with synchronous rectification and/or other modification. It is difficult to accurately compare against single and multi phase converters that are designed for lower or much different specification. Figure 6-13 shows that as the load 
increases the efficiency of the converter increases along until about $30 \%$ load. With a load at $30 \%$ or higher the efficiency of the converter maintains an average of $97 \%$.

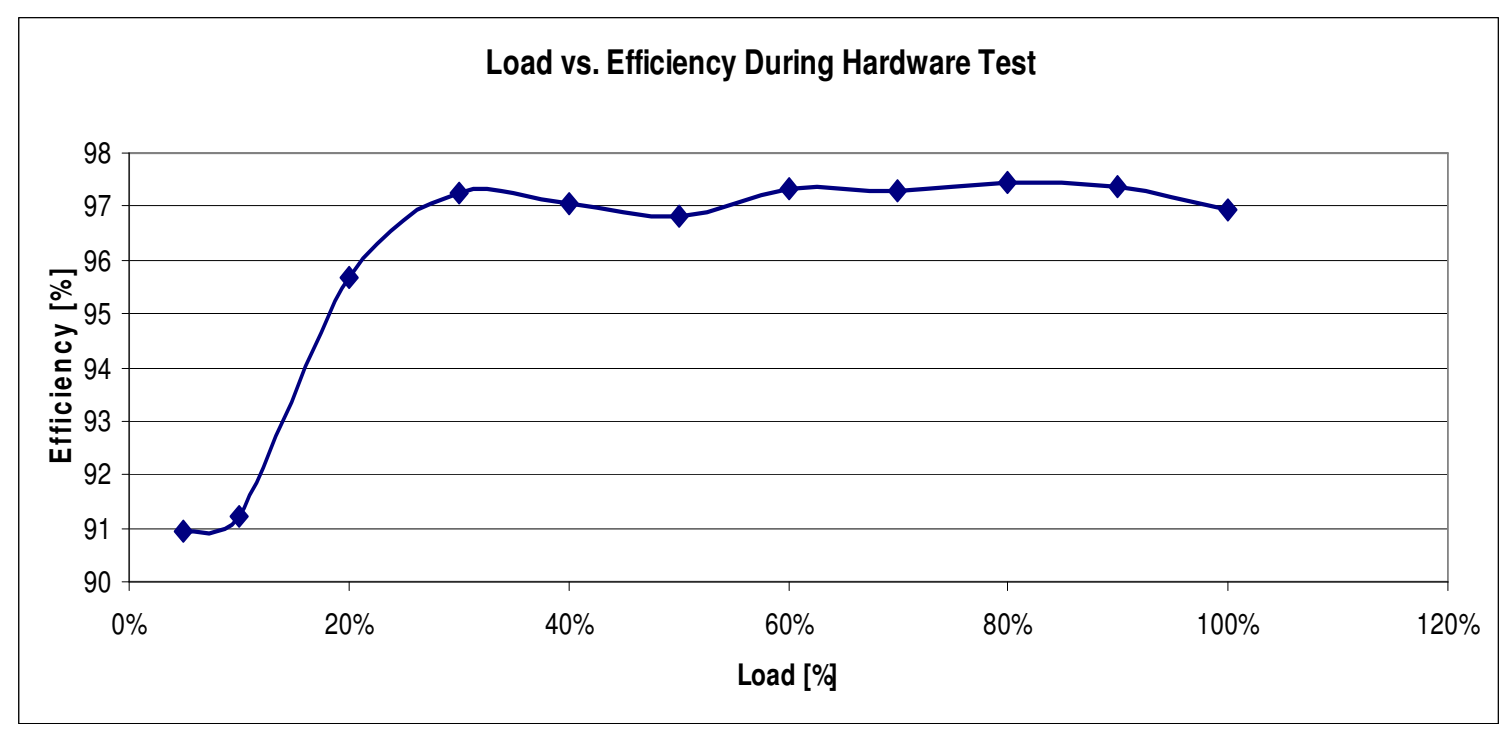

Figure 6-13: Load vs. Efficiency for Hardware Test

\subsubsection{Load Regulation}

To calculate the load regulation the value of $\mathrm{V}_{\text {O-LowLoad, }}, \mathrm{V}_{\text {O-HighLoad }}$ and $\mathrm{V}_{\text {O-nominal }}$ are required. The nominal output voltage is determined to be the voltage at full load and the other two values can be found from Table 6-1. Low load voltage is referring to the output voltage during 5\% load. The high load voltage, on the other hand, refers to the full load output voltage which is now equal to the nominal output voltage. Using these three values the load regulation can then be calculated through:

$$
\begin{aligned}
& \text { Load Regulation }=\frac{V_{O-\text { Lowload }}-V_{O-\text { Fulload }}}{V_{O-\text { Lowload }}} * 100 \% \\
& \text { Load Regulation }=\frac{43.46 \mathrm{~V}-42.545 \mathrm{~V}}{43.46 \mathrm{~V}} * 100 \%=2.11 \%
\end{aligned}
$$


Table 6-2: Hardware Load Regulation

\begin{tabular}{|c|c|c|}
\hline $\mathrm{V}_{\text {Lowload }}[\mathrm{V}]$ & $\mathrm{V}_{\text {Fulload }}[\mathrm{V}]$ & Load Regulation [\%] \\
\hline 43.03 & 42.545 & $2.15 \%$ \\
\hline
\end{tabular}

The load regulation is double higher than the required $1 \%$ value, but still within an acceptable range.

\subsubsection{Line Regulation}

To calculate the line regulation the equation requires two extra output voltages, from the lowest input voltage and the highest input voltage. The lowest input to calculate the line regulation for this design in $34 \mathrm{~V}$ and the highest input is at $38 \mathrm{~V}$. With $34 \mathrm{~V}$ input it yields $40.073 \mathrm{~V}$ and with $38 \mathrm{~V}$ input it yields $43.76 \mathrm{~V}$. To maintain consistency in the data and calculations, both readings were done with full load.

$$
\begin{aligned}
& \text { Line Regulation }=\frac{V_{O-\text { highestinput }}-V_{O-\text { lowestinput }}}{V_{O-N o \min a l}} * 100 \% \\
& \text { Line Regulation }=\frac{43.76 \mathrm{~V}-40.073 \mathrm{~V}}{42.545 \mathrm{~V}} * 100 \%=8.67 \%
\end{aligned}
$$

Table 6-3: Hardware Line Regulation

\begin{tabular}{|c|c|c|c|}
\hline $\begin{array}{c}\mathrm{V}_{\text {O-Lowestlnput }} \\
{[\mathrm{V}]}\end{array}$ & $\begin{array}{c}\mathrm{V}_{\text {O-Highestlnput }} \\
{[\mathrm{V}]}\end{array}$ & $\begin{array}{c}\mathrm{V}_{\text {nominal }} \\
{[\mathrm{V}]}\end{array}$ & $\begin{array}{c}\text { Line Regulation } \\
{[\%]}\end{array}$ \\
\hline 40.073 & 43.76 & 48 & $8.67 \%$ \\
\hline
\end{tabular}

The line regulation for the hardware test falls far from the required $1 \%$ regulation. Attempts were made to improve the line regulation and they are discussed in the next section 6.4 . 


\subsubsection{Transient Response}

Transient response test check the ability of they proposed converter to handle abrupt and large change in the load. With AC coupling and single trigger setting on the oscilloscope it is able to capture the overshoot and ripple time. Two tests were done to check the transient response of the converter. The first test changes the load from full load to $10 \%$ load. Figure 6-14 is the captured waveform of the transient response of the converter. The vertical overshoot is about $6 \mathrm{~V}$ and it takes 3 division length at $50 \mathrm{~ms} /$ division or $150 \mathrm{~ms}$ for the signal to settle. The positive overshoot is caused by the large and sudden current drop in the load.

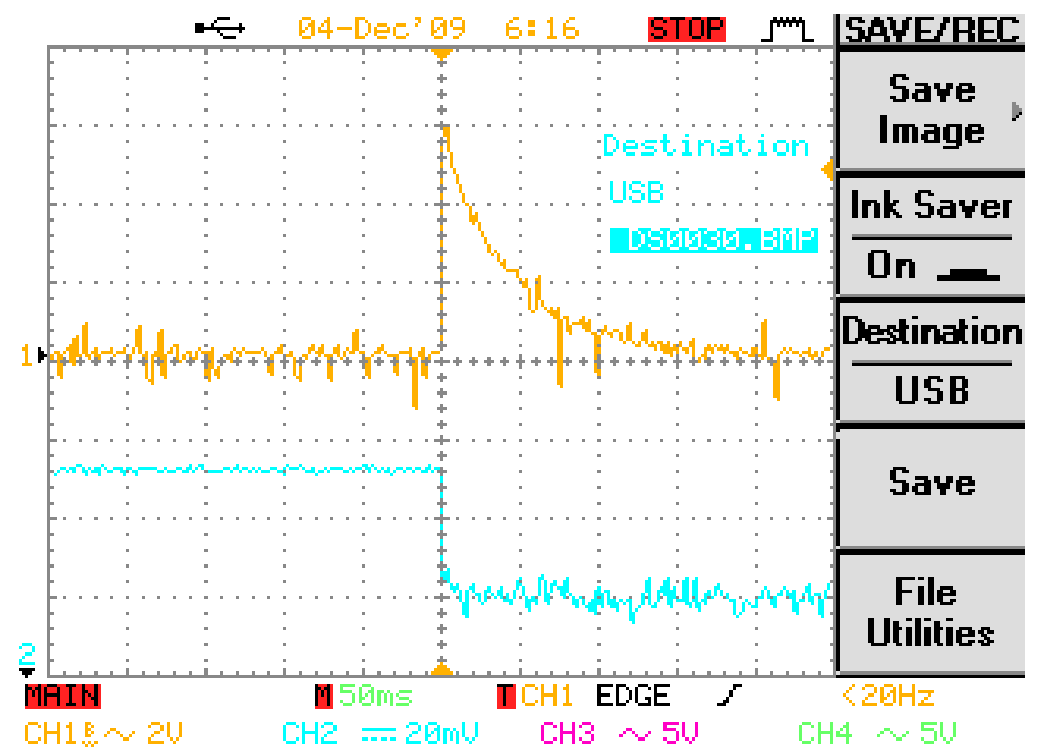

Figure 6-14: Output Voltage Overshoot from Full Load to Low Load

The second test changes the load from 10\% load to full load. Notice that Figure 6-15 has a negative overshoot instead due to the large current being drawn suddenly by the load. It has an overshoot of about $7 \mathrm{~V}$ and lasts for $125 \mathrm{~ms}$ before settling into a steady state. 


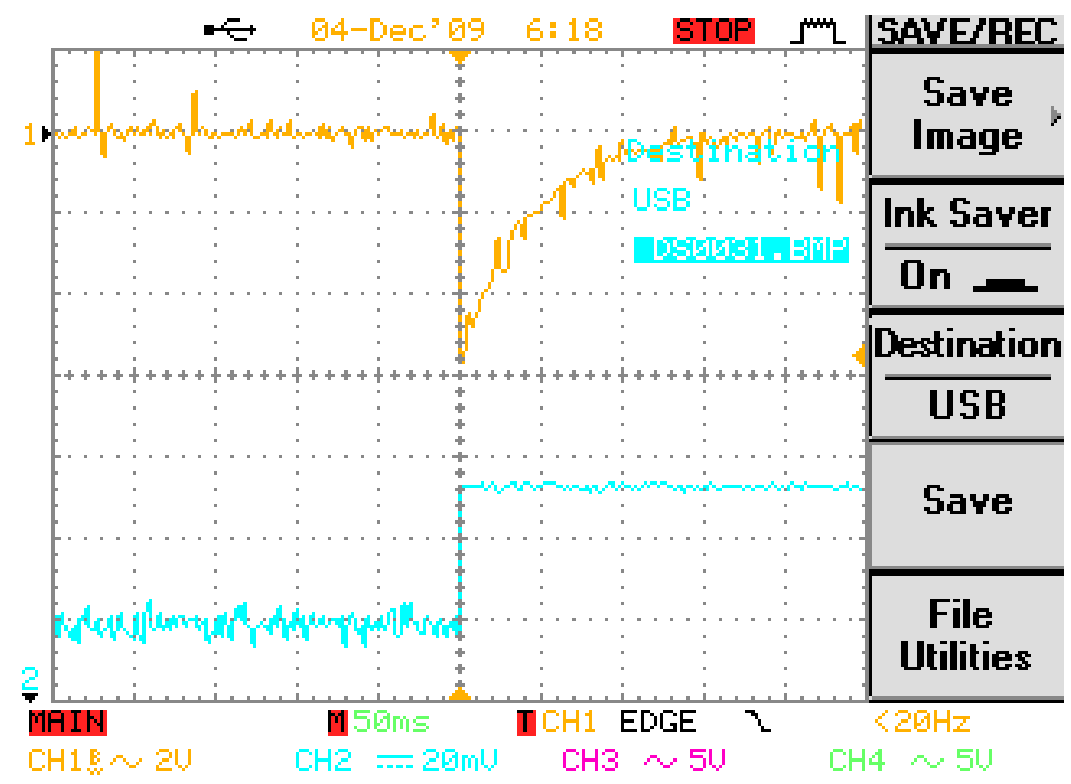

Figure 6-15: Output Voltage Overshoot from Low Load to Full Load

\subsection{Hardware Troubleshooting}

\subsubsection{Output Voltage}

Comparing Table 6-1 with Table 5-1 it is obvious that the hardware's output voltages are well below the required level. There were three theories of why this might have happened. One of the theories hypothesized that by decreasing the voltage feedback level it increase the output voltage level. This hypothesis is based by the ability of the pulse width modulator to increase the output voltage when the feedback signal drops below $2.44 \mathrm{~V}$. To test this theory, the value of the output voltage divider was dropped to $30 \mathrm{k} \Omega$ and $700 \mathrm{k} \Omega$. During testing it is observed that the no load output voltage increased to $53.12 \mathrm{~V}$ and the loaded output to an average of $44 \mathrm{~V}$. This proves that dropping the voltage feedback ratio does indeed increase the output voltage level, but it does not solve 
the large voltage drop between the no load and loaded test. All of the resistors used have a $1 \%$ tolerance.

The second theory is that the converter is not operating in continuous conduction mode when loaded. To check validity of this theory a current probe is used to obtain the inductor current through the current test loops. The two crucial points in the load test are the two extreme ends of the load test, $5 \%$, and full load. During full load it was already discussed that the converter is indeed operating in the continuous conduction mode. In the $5 \%$ load test the converter is most susceptible to being in discontinuous conduction mode. At this point a small amount of current is being pulled by the load so the average inductor current also drops. If the average inductor current drop low enough, the lowest peak of the inductor current ripple can dip below zero. To check if at 5\% load the converter operate in continuous conduction mode a current waveform is taken from each of the current loop. Figure 6-13 shows the first phase inductor current during low load test and Figure 6-16 shows the second phase. Both figures have full triangular ripples without having the bottom peak dipping below $0 \mathrm{~A}$ meaning phase 1 and 2 are in continuous conduction mode. These two graphs prove that the drop in output voltage is not due to the converter operating in discontinuous or boundary conduction mode. 


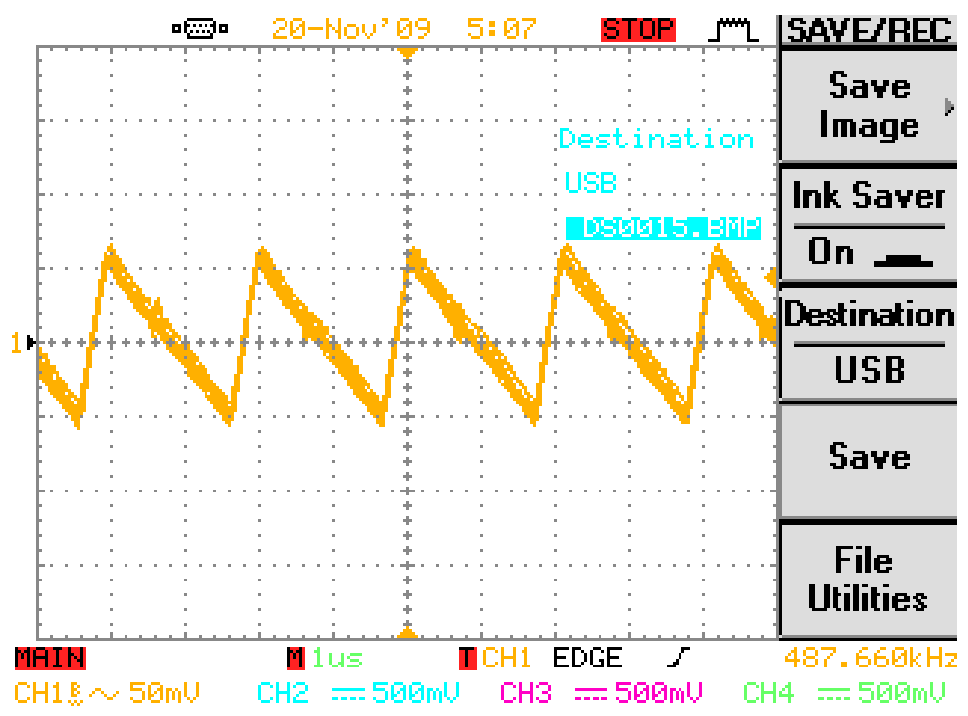

Figure 6-16: Phase 1 Inductor Current during Low Load

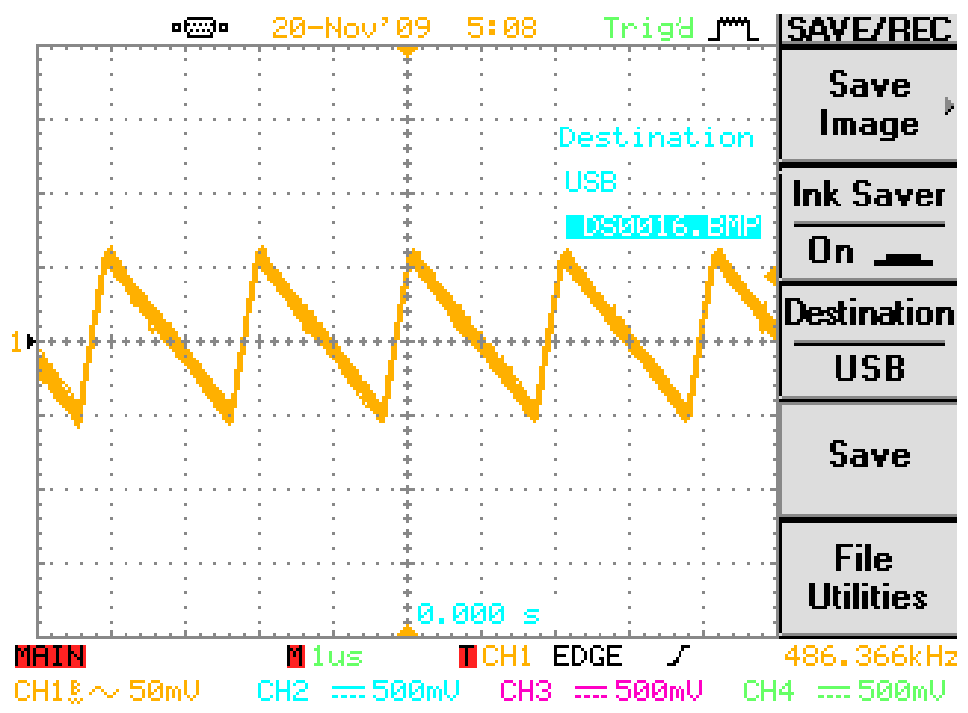

Figure 6-17: Phase 2 Inductor Current during Low Load

Third, the issue might have come from the noisy switching signals. As mentioned before, the noise at the peak of the switching signal drops the signals value below $10 \mathrm{~V}$. When this happen the MOSFETs gates are receiving below the required gate turn on voltage. This could cause the second phase MOSFET to not conduct as long as the 
controller signaled it to be, reducing the output voltage. However, because this theory has not yet been thoroughly tested no results could be reported regarding this hypothesis.

\section{$\underline{6.4 .2}$ Line Regulation}

The first idea is to change the current sense resistor size from $20 \mathrm{~m} \Omega$ to $10 \mathrm{~m} \Omega$. By lowering the current sense resistor it would make the converter more sensitive to any change in the voltage. This modification increased the $\mathrm{V}_{\mathrm{O} \text {-LowestInput }}$ by a few $\mathrm{mV}$, a barely noticeable change. The second idea is to increase the output capacitance. The idea is that by increasing the amount of stored energy it might help to bump the input power, creating an overall higher output voltage. With the extra capacitance the line regulation still has the same general value. So, this idea does not effect the converter in the way it was planned either. 


\section{Conclusion}

Efficient, cheap and fast switching converters are in high demand in the high-tech world. With varying needs and specifications, engineers are expected to design unique and reliable solutions. The size, cost and safety of each design is also top priority in today's industrialist economy. The two-phase boost converter discussed in this report was designed and built under the same pretense of the real world expectancy. The converter is designed to be safe, efficient, low cost, and small.

After gathering and comparing the different results from the simulation and hardware, the values from both tests are consistent in general. In both cases, the converter successfully completes the full load tests while operating in continuous conduction mode. The voltage ripple and load regulation from both results are also below or equal to the required $1 \%$. It is also impressive to observe that the hardware efficiency reaches $96.95 \%$, merely $0.06 \%$ less than the simulated efficiency. This efficiency can be improved, by following some of the recommended improvements suggested above. The largest difference is found in the line regulation where in simulation it is $0.0167 \%$, but the hardware data reads $7.68 \%$.

Fixing the output voltage so it reaches the designed $48 \mathrm{~V}$ is a crucial fix that this design needs. More tests, trials and calculations need to be done to find the root of the problem. Some of the things that could be done are resizing some of the energy storage components, e.g. the inductors and capacitors or change in the pulse width modulator settings and sensing components.

The efficiency of this design can be improved further by adding synchronous rectification into the design. In the current design two parallel schottky diodes are 
controlling the high side switching in each phase. Synchronous rectification will replace those diodes with MOSFETs. By placing MOSFETs with low $\mathrm{R}_{\mathrm{DS} \text {-on }}$ it will decrease the amount of loss through the high side switch especially at low duty cycle. Controlled MOSFETs will also decrease the dead time between switching to a more efficient length. LT3782A has two outputs that will accommodate synchronous rectification for the high side switching; it just needs to be implemented. A total redesign or some tweaks can be done to the current high side driver design to allow it to interface better with the converter.

Paralleling MOSFETs will also increase the efficiency of the converter. Each MOSFETs has a certain value of $\mathrm{R}_{\mathrm{DS}-\mathrm{on}}$, and hence by paralleling them it will decrease the total resistance across the switches.

Even with the satisfactory results, the final hardware project does not output the required $48 \mathrm{~V}$ with $<1 \%$ line regulation. Many troubleshooting ideas were tested although none solved the problems at hand. Despite this issue, the project successfully proves that a two-phase boost concept can actually be implemented. The challenges this design presented has taught me that design is not all in the numbers and papers. Component placements and board design also play out a major part in creating electrical equipments. This project has also taught me invaluable troubleshooting and design skills that will continue to improve and grow with experience. 


\section{BIBLIOGRAPHY}

[1] Alou, Pedro, Jose Cobos, Oscar Garcia, Roberto Prieto, and Javier Uceda. "A New Driving Scheme for Synchronous Rectifiers: Single Winding Self-Driven Synchronous Rectification." IEEE Transactions on Power Electronics, 16.6 (2001): 803-811.

[2] Axelrod, B, Y Berkovich, S Tapuchi, and A Ioinovici. "Single-Stage SingleSwitch Switched-Capacitor Buck/Buck-Boost-Type Converter." IEEE

Transactions on Aerospace \& Electronic Systems, 45.2 (2009): 419-430.

[3] Du, Xiong, Luowei Zhou, and Heng-Ming Tai. "Double-Frequency Buck Converter." IEEE Transactions on Industrial Electronics, 56.5 (2009): 16901698 .

[4] Fairchild Semiconductor. FDD3682 datasheet. http://www.fairchildsemi.com/ds/FD/FDD3682.pdf

[5] Florian, Paul. "Buck Converter Powers 5-V Circuits from 12-V Solar-Cell Array." Electronic Design, 57.19 (2009): 45-46.

[6] Garcia, Oscar, Pablo Zumel, Angel de Castro, Pedro Alou, and Jose Cobos. "Current Self-Balance Mechanism in Multiphase Buck Converter." IEEE Transactions on Power Electronics, 24.6 (2009): 1600-1606.

[7] Linear Technology. LT3782A datasheet. http://cds.linear.com/docs/Datasheet/3782af.pdf

[8] Miura, Hidekazu, Shinsuke Arai, Fumihiro Sato, Hidetoshi Matsuki, and Tadakuni Sato. "A Synchronous Rectification Using a Digital PLL Technique for Contactless Power Supplies." IEEE Transactions on Magnetics, 41.10 (2005): 3997-3999.

[9] Rashid, M. H. Power electronics circuits, devices, and applications. Upper Saddle River, N.J: Pearson/Prentice Hall, 2004.

[10] Selders, Robert. "Synchronous Rectification in High-Performance Power Converter Design." EDN, 51.12 (2006): 1-7.

[11] Taufik, “Introduction to Power Electronics,” Lecture Notes, 6th revision 2008.

[12] Taufik, “Advance Power Electronics,” Lecture Notes, 3rd revision 2009. 